SRNL-STI-2013-00020

Rev. 0

\title{
STATUS REPORT -CANE FIBERBOARD PROPERTIES AND DEGRADATION RATES FOR STORAGE OF THE 9975 SHIPPING PACKAGE IN KAMS
}

\author{
W. L. Daugherty
}

Savannah River National Laboratory

Materials Science \& Technology

Publication Date: January 2013

Savannah River Nuclear Solutions

Savannah River Site

Aiken, SC 29808

This document was prepared in conjunction with work accomplished under

Contract No. DE-AC09-08SR22470 with the U.S. Department of Energy. 
SRNL-STI-2013-00020

Rev. 0

\section{DISCLAIMER}

This work was prepared under an agreement with and funded by the U.S. Government. Neither the U. S. Government or its employees, nor any of its contractors, subcontractors or their employees, makes any express or implied: 1 . warranty or assumes any legal liability for the accuracy, completeness, or for the use or results of such use of any information, product, or process disclosed; or 2. representation that such use or results of such use would not infringe privately owned rights; or 3. endorsement or recommendation of any specifically identified commercial product, process, or service. Any views and opinions of authors expressed in this work do not necessarily state or reflect those of the United States Government, or its contractors, or subcontractors. 


\section{STATUS REPORT - CANE FIBERBOARD PROPERTIES AND DEGRADATION RATES FOR STORAGE OF THE 9975 SHIPPING PACKAGE IN KAMS}

\section{APPROVALS:}

W. L. Daugherty

Date

Author, Materials Science and Technology

T. E. Skidmore

Date

Technical Review, Materials Science and Technology

K. A. Dunn

Date

Pu Surveillance Program Lead, Materials Science and Technology

G. T. Chandler

Manager, Materials App \& Process Tech

Date

E. R. Hackney

Date

NMM Engineering

\section{REVIEWS:}

D. R. Leduc

Date

Savannah River Packaging Technology 
Rev. 0

\section{Revision Log}

Document No. SRNL-STI-2013-00020 Rev. No. 0

Document Title Status Report - Cane Fiberboard Properties and Degradation Rates for Storage of the 9975 Shipping Package in KAMS

Rev. \# Page \# Description of Revision Date

0 all Original document 1/31/2013 
Rev. 0

\section{$\underline{\text { Summary }}$}

Thermal, mechanical and physical properties have been measured on cane fiberboard samples following accelerated aging for up to approximately 7 years. The aging environments have included elevated temperature $\leq 250{ }^{\circ} \mathrm{F}$ (the maximum allowed service temperature for fiberboard in 9975 packages) and elevated humidity. The results from this testing have been analyzed, and aging models fit to the data. Correlations relating several properties (thermal conductivity, energy absorption, weight loss and height decrease) to their rate of change in potential storage environments have been developed. Combined with an estimate of the actual conditions the fiberboard experiences in KAMS, these models allow development of service life predictions.

Some of the predicted degradation rates presented in this report are relatively extreme. However, these relate to environments that do not exist within KAMS, or would be postulated only as upset conditions that would not likely persist for an extended period. For a typical package with $\sim 10$ watts internal heat load or less, and ambient temperatures below $90{ }^{\circ} \mathrm{F}$, the fiberboard experiences storage conditions less severe than any of the aging environments. Little or no degradation of the fiberboard is expected for typical storage conditions. It should be noted that the ultimate service life will be determined by the cumulative effect of degradation from all the conditions these packages might encounter. The assumptions and inputs behind the models in this report should be well understood before attempting to identify an actual service life in KAMS. Additional data continue to be collected to permit future refinements to the models and assumptions.

For developing service life predictions, the ambient conditions within KAMS can be reasonably identified, and the temperature profiles within the various packages (with a range of heat loads and at varying locations within an array of packages) can be calculated. However, the humidity within the package is not as well characterized. While the outer drum does not provide an air-tight seal, it does greatly restrict the gain or loss of moisture in the fiberboard. Preliminary efforts have identified a relationship between the moisture content of fiberboard samples and the relative humidity of the surrounding air, but further work is needed in this area. Improvement in understanding this relationship might be realized with a change in the way humidity data are collected during field surveillances. It is recommended that the humidity be measured through a caplug hole before the package is removed from its storage location. The package would remain in thermal equilibrium, and anomalous humidity changes could be avoided.

Further work should be performed to better define KAMS storage conditions and the environment within the 9975 shipping packages, and to identify appropriate limits for each property. This should be a joint effort by SRNL and NMM personnel.

The results and model predictions presented in this report are applicable to 9975 packages with cane fiberboard overpack assemblies. A separate effort is underway to identify whether softwood fiberboard would behave similarly. In addition, the degradation models do not address the effects of non-conforming conditions such as the presence of excess moisture and mold, or beetle infestations. 
Rev. 0

\section{Background}

Celotex ${ }^{\circledR}$ fiberboard material is used in the 9975 shipping package between the outer 304L stainless steel drum and the lead shielding, and provides three safety functions: thermal insulation to limit internal temperature during a fire, criticality control and resistance to package crushing [1]. A bounding estimate of the range of environments which fiberboard in KAMS can experience is illustrated in Figure 1. Also shown in this figure is the range of fiberboard environments under loss of ventilation (including natural convection) conditions.

The fiberboard material must retain its dimensions and density within certain ranges to provide the required impact resistance, criticality control and fire resistance. Several properties of interest to demonstrate acceptable long-term performance of the material include dimensional stability, moisture absorption/retention, density, compressive strength, thermal conductivity and specific heat capacity. In some cases, limits on property ranges have not been identified. In other cases, sensitivity analyses may not have been performed to evaluate the impact of out-of-range values.

Samples are conditioned in support of several specific tests [2]. Thermal tests are performed to measure thermal conductivity and specific heat capacity. The thermal conductivity is measured on two sample orientations; the axial orientation measures the conductivity of heat perpendicular to the fiberboard layers (axial heat flow within the package), and the radial orientation measures the conductivity of heat parallel to the fiberboard layers (radial heat flow within the package). Compression test samples are tested in either of two orientations, with the applied load either parallel or perpendicular to the fiberboard layers. Physical measurements are made for small samples ( 2 inch cubes) in each conditioning environment as well as for full sized upper fiberboard assemblies. The upper assemblies are maintained in an ambient environment and track seasonal variation in physical properties.

Samples have been taken from several different packages, with a range of package histories. Duplicate samples from multiple package sources have been conditioned to identify the range of variability. The package sources are as follows:

- LD1, LD2 - undamaged portions of 2 lower fiberboard assemblies from drop tested packages, which were in storage for $\sim 10$ years prior to this effort.

- MSC - undamaged portions of several fiberboard assemblies from drop tested packages, which were in storage for $\sim 10$ years prior to this effort. Traceability to specific assemblies was not maintained for these samples.

- $\quad \mathrm{KT} 2$ - lower assembly from an unused package following several years in storage.

- 2234, 826 - lower assemblies removed from packages following several years service in KAMS and subsequent surveillance activities.

- 826U, 600U - upper assemblies removed from packages following several years service in KAMS and subsequent surveillance activities.

- New - remnant portions of a new assembly (upper and lower) purchased in 2005 for a separate effort. 
Rev. 0

Table 1 summarizes the maximum conditioning times for each environment through September 2012. Due to different start times, the duration may vary for different samples in a given environment. Environments which include humidity control typically have shorter durations since only a single environmental chamber was available through 2010, and samples were conditioned sequentially. Since 2010, three environmental chambers have been available for conditioning samples.

Baseline and long-term testing of mechanical and thermal properties through fiscal year 2010 has been reported previously [3, 4]. Additional data have since been collected, and the cumulative data set through September 2012 has been analyzed for the development of an aging model. All the data considered herein have been collected on cane fiberboard samples. Recently, the use of softwood fiberboard in 9975 packages has been approved. A separate effort is in progress to demonstrate the degree to which the two materials are comparable in regards to aging behavior. At this point, the conclusions of this report are applicable only to cane fiberboard.

\section{$\underline{\text { Test Data }}$}

\section{Compression Tests}

Unlike the thermal and physical tests, compression testing is destructive - each sample can be tested only once. Therefore, these samples become increasingly important after extended conditioning periods as fewer conditioned samples remain for future testing. Compression testing has been performed following aging for as long as 4 years in some environments.

Typical compression stress-strain curves are shown in Figures 2-3 for samples conditioned in two of the aging environments $-185^{\circ} \mathrm{F}$ dry and $250^{\circ} \mathrm{F}$ dry. These show a noticeable drop in compression strength over time at $250{ }^{\circ} \mathrm{F}$, but not at $185{ }^{\circ} \mathrm{F}$. Compression testing of conditioned material has been performed on samples from five of the source packages (LD1, LD2, MSC, New and KT2).

A range of behaviors has been observed during compression testing (varying shape of the stress-strain curve). Because of this variation, two metrics have been used for quantifying and comparing the performance of different samples. For samples loaded parallel to the fiberboard layers, the stress at which the layers buckle is an indication of the load sustained before the accumulation of significant damage. For all samples (tested either parallel or perpendicular to the fiberboard layers), the integrated area under the stress-strain curve up to a strain of $40 \%$ provides a relative measure of the energy absorption capability of the sample. The $40 \%$ strain level is arbitrary, but provides a consistent point of comparison. These two metrics are summarized in Tables 2-4 for all compression tests to date, and representative groupings of these data are presented in Figures 4-6.

Several trends in the compression test data can be summarized as follows:

- The buckling strength (for parallel orientation) and the area under the curve to $40 \%$ strain (for both orientations) decrease with increasing exposure time at $250^{\circ} \mathrm{F}$. A similar trend might exist at $215^{\circ} \mathrm{F}$, but is weaker and less consistent. No significant change over time is observed at lower temperature dry environments. 
Rev. 0

- The buckling strength (for parallel orientation) and the area under the curve to $40 \%$ strain (for both orientations) is significantly lower after conditioning at $100 \%$ relative humidity (RH) (regardless of the temperature) compared to samples conditioned at lower humidity levels. To a lesser extent, the buckling strength and area under the curve to $40 \%$ strain (for parallel orientation samples) are lower at $70 \% \mathrm{RH}$ than for lower humidity levels, and tend to decrease over time. There are insufficient data for perpendicular orientation samples to identify whether such a trend exists for them as well.

- Mechanical properties vary from one package to another. For example, samples from the New package tend to have the highest buckling strength and the highest area under the curve to $40 \%$ strain for each conditioning environment in which they were tested. Samples from the LD2 package tend to have the lowest buckling strength for each conditioning environment in which they were tested.

\section{Thermal Tests}

Thermal conductivity data for each environment are summarized in Figure 7 . For ease of comparison, the thermal conductivity data for each sample are normalized to the first measurement taken after conditioning began. These first conditioned values are listed in Table 5 to show the range of sample-to-sample variation that might be expected, and the degree to which thermal conductivity varies with each environment. Several trends are summarized as follows:

- In the 250, 215 and $185{ }^{\circ} \mathrm{F}$ dry environments, the thermal conductivity decreases with increasing conditioning time. The rate of change increases with temperature. No significant change over time is observed in a $125^{\circ} \mathrm{F}$ dry environment.

- At $185^{\circ} \mathrm{F}$, the thermal conductivity decreases faster as the humidity level increases. The rate of decrease at $185{ }^{\circ} \mathrm{F} 70 \% \mathrm{RH}$ is greater than in a $250{ }^{\circ} \mathrm{F}$ dry environment. This effect of humidity is not seen at $125^{\circ} \mathrm{F}$ comparing a dry oven with $70 \% \mathrm{RH}$.

- A similar rate of decrease in thermal conductivity is seen in the $160{ }^{\circ} \mathrm{F} 50 \% \mathrm{RH}, 185{ }^{\circ} \mathrm{F}$ $30 \% \mathrm{RH}$ and $215^{\circ} \mathrm{F}$ dry environments.

The thermal conductivity samples conditioned at $250{ }^{\circ} \mathrm{F}$ were moved from one oven to another after 56 weeks. It was subsequently noted that a temperature gradient within the first oven caused each thermal conductivity sample to have been at a different temperature. The actual temperatures were subsequently estimated to range from 242 to $279^{\circ} \mathrm{F}$ [5].

The specific heat capacity data can show a significant degree of scatter from one trial to the next. Accordingly, the results are averaged over all samples and trials for a given conditioning interval and test temperature. A summary of these averaged data is shown in Figure 8. In general, an increase in humidity (and in sample moisture content) results in an increase in specific heat capacity.

The measured specific heat capacity has decreased by about $24 \%$ while conditioning at 250 ${ }^{\circ} \mathrm{F}$ over $\sim 5$ years. This may reflect an actual property change, or it may be an artifact resulting from sample shrinkage, which has been significant over this period. A smaller sample produces a loose fit in the brass capsule that is used to measure specific heat capacity, and may impede the conduction of heat from the sample. This in turn may reduce the 
Rev. 0

measured specific heat capacity. Testing of samples that were progressively reduced in size (without conditioning) was inconclusive in demonstrating the extent of this effect.

The nominal decrease in specific heat capacity is shown under Figure 8 by the coefficient in each equation that was fit to the data for each environment. The highest rate of decrease is seen for $160{ }^{\circ} \mathrm{F} 50 \% \mathrm{RH}$ and $250{ }^{\circ} \mathrm{F}$ dry environments. The high rate for $160{ }^{\circ} \mathrm{F} 50 \% \mathrm{RH}$ likely reflects the very limited data (4 points) and the degree of scatter in the data, and is expected to decrease with the accumulation of additional data.

\section{Physical Tests}

The weight and density of samples in each environment have been tracked. In addition to the elevated temperature environments mentioned above, these physical property samples have also been conditioned at temperatures of 50 and $15{ }^{\circ} \mathrm{F}$, at ambient humidity and in a desiccated environment. For these low temperature environments, the ambient humidity is approximately $10 \%$ at $50{ }^{\circ} \mathrm{F}$ and $60 \%$ at $15^{\circ} \mathrm{F}$.

In order to better compare samples and highlight changes among samples with different initial property values, the properties (weight, density, height and length / width) of each sample are normalized to their initial conditioned value. The normalized values of these samples are summarized in Figures 9-12. Samples from multiple material sources are conditioned in each of the elevated temperature environments. Initially, data were collected on a single sample source (MSC) only. Samples from additional package sources were added subsequently.

For samples conditioned at temperatures of $\geq 160{ }^{\circ} \mathrm{F}$, a continuous weight loss (beyond an initial change due to moisture loss / gain) is observed. The rate of weight loss is greater with higher temperatures and with increased humidity. In the $125^{\circ} \mathrm{F}$ dry environment, a slight decrease in weight is observed, superimposed on a stronger seasonal variation. No significant change in weight was observed at low temperatures $\left(50,15^{\circ} \mathrm{F}\right)$. Samples from the different material sources behave similarly, with about the same rate of weight loss in a given environment.

In Figure 9 (a), the MSC sample shows a change in weight loss rate after approximately 330 days at $250{ }^{\circ} \mathrm{F}$. This was attributed to temperature gradients within the oven initially used to condition those samples [5]. Analysis of the available data suggests that these physical property samples were at a location within the oven with an actual temperature of approximately $236{ }^{\circ} \mathrm{F}$. The samples were subsequently moved to a different oven with a more consistent temperature profile, and the weight loss rate has since been consistent with that for the other samples subsequently added at this temperature. This same effect is also seen in the density (Figure 10(a)) and height (Figure 11(a)) data.

Density data for the physical property samples are shown in Figure 10. For samples conditioned in dry ovens at 215 and $250{ }^{\circ} \mathrm{F}$, a continuous decrease in density is observed. Within each of the humid environments at 160 and $185^{\circ} \mathrm{F}$, a continuous density decrease is observed. At $125^{\circ} \mathrm{F} 70 \% \mathrm{RH}$, there is no significant change in density over time. Above $125^{\circ} \mathrm{F}$, the rate of density loss is greater for higher temperatures and higher humidity levels. Comparable rates of density loss are observed for the various material sources within each 
Rev. 0

environment. Qualitatively, dimensional changes in each environment follow those described for density. The change in height tends to be significantly greater than the change in length or width for a given environment.

Three fiberboard upper subassemblies have been weighed and measured periodically (see Figure 13). Following the accumulation of greater than 12 months data, and establishing the seasonal variation in these measurements, several incremental changes were made in the exposure of these assemblies, as follows.

- Each upper subassembly was initially exposed to ambient environment, in a room that experiences some degree of temperature and humidity fluctuation.

- One upper subassembly was placed back inside its drum in October 2005 (Figure 13, point 1) and removed only for weekly (initially) or monthly measurement. The lid was loosely placed on the drum. This provides a lower bound estimate of the degree of isolation provided by the drum.

- A second upper subassembly was placed back inside its drum in June 2006 (Figure 13, point 2) and removed for measurement at intervals of several months duration. The lid was loosely placed on the drum. By varying the opening frequency for these two drums, but observing the same weight changes, it was shown that opening the drums to weigh the subassemblies did not influence the weight change.

- $\quad$ The lid for the second upper subassembly in its drum was bolted tight in August 2007 (Figure 13, point 3). This provides a more realistic estimate of the degree of isolation provided by the drum in service.

Comparing the range of seasonal weight change for subassemblies in and out of a drum shows a significant degree of isolation is provided by the drum, even with the lid only loosely placed. Over the 1 year period from 8/07 to 8/08, the open subassembly experienced a total weight variation of $178 \mathrm{~g}$ (or $1.5 \%$ of its total weight). During the same period, the subassembly in a drum with the lid loosely placed experienced a weight variation of $21 \mathrm{~g}$ (0.18 wt\%), and the subassembly in a drum with the lid bolted in place experienced a weight variation of $4 \mathrm{~g}(0.034 \mathrm{wt} \%)$.

\section{Termination of $250^{\circ} \mathrm{F}$ Aging Environment Samples}

All of the original cane fiberboard samples aging at $250{ }^{\circ} \mathrm{F}$ have been terminated, as described below. Samples conditioning in other environments will also be considered for termination as similar circumstances arise.

\section{Compression Test Samples}

The area under the stress-strain curve up to a strain of $40 \%$ has been adopted as a metric for relative comparison of compressive behavior between different samples. Finite element analysis has been performed to demonstrate that the 9975 package in KAMS will survive a forklift impact scenario even if the nominal fiberboard compression strength is reduced by $80 \%$. [6] The main contribution of the fiberboard to this scenario is energy absorption, which is proportional to the area under the compression test stress-strain curve. The Reference 6 calculation uses a fiberboard stress-strain curve for sample “16pkg”, reported in Reference 7. This sample was conditioned at ambient temperature and $40 \% \mathrm{RH}$ prior to testing in the perpendicular orientation. 
Rev. 0

As such, it represents a typical undegraded fiberboard condition. Using the data from this sample, the area under the engineering stress-strain curve up to a strain of $40 \%$ is 55 psi. Reducing this value by $80 \%$ produces 11 psi, which is used as the minimum acceptance value for fiberboard mechanical properties.

Since the forklift impact scenario loads the fiberboard primarily from the side, the compression test metric (area under the stress-strain curve up to 40\% strain) for samples tested with the load applied in the parallel orientation will be considered. At $250^{\circ} \mathrm{F}$, this metric had dropped to 11 psi or less within 64 weeks of conditioning, and remained under this limit (see Figure 14). For package source NEW, no compression test data is available beyond 32 weeks conditioning, but the available data extrapolate to a similar conclusion - that the metric would be less than 11 psi after 64 weeks conditioning at $250{ }^{\circ} \mathrm{F}$. In January 2009, the few remaining compression samples conditioning at $250{ }^{\circ} \mathrm{F}$ were tested, with a total conditioning time of 193 weeks. All data from samples conditioned beyond 64 weeks support the conclusion that the fiberboard will not perform its energy absorption function after 64 weeks at $250{ }^{\circ} \mathrm{F}$.

Compression samples that are tested in the lab are done so without lateral constraint, allowing the sample to shift or bow sideways under load. With this arrangement, the area under the stressstrain curve tends to be reduced relative to that for a constrained sample, and the degradation indicated by the metric will conservatively under-predict the energy absorption capacity of the fiberboard. This conservatism is greater in the drier (hotter) environments, since the dry samples have a greater tendency to slip sideways under load. In contrast, the fiberboard in a 9975 package experiences some degree of lateral constraint, with side motion limited after the air gaps around the fiberboard assembly have been filled by shifting fiberboard. In this configuration, the degree of strain experienced by most regions of the fiberboard assembly is limited as the material starts to compress locally and the stress re-distributes to adjacent less-compressed fiberboard regions. As the fiberboard shifts within the drum, the peak fiberboard strains are limited. By considering the energy absorbed by the fiberboard only up to $40 \%$ strain, the increased energy absorption capacity at higher strains (see for example, the significant increase in compression strength above 60\% strain in Figure 2), is conservatively excluded.

\section{Physical Property Samples}

The physical property samples were removed from conditioning at $250{ }^{\circ} \mathrm{F}$ in January 2011 , following up to 275 weeks in that environment. All samples had experienced greater than 50\% decrease in weight. They were also significantly darkened and fragile (Figure 15) and prone to breakage during handling. The relative change in the physical properties at the time testing was discontinued is summarized in Table 6.

Reference 8 recommends limits on fiberboard density and dimensions based on the values assumed in the nuclear criticality safety evaluation. This evaluation assumed a 2.5 inch radial and 4.0 inch axial fiberboard dimensional loss, and density of $0.20 \mathrm{~g} / \mathrm{cc}$. Response limits were recommended that are conservative to these assumed values -0.5 inch dimensional loss (in either direction) and $0.21 \mathrm{~g} / \mathrm{cc}$ density. At the time of removal, the physical property samples had experienced the following:

- height loss of $\sim 20-30 \%$, corresponding to 7 - 10 inches loss in a full fiberboard assembly. This greatly exceeds the assumed loss and the response limit. 
Rev. 0

- length / width loss of $\sim 8-14 \%$, corresponding to $\sim 0.4-0.7$ inches radial loss in a fiberboard assembly. This equals or exceeds the response limit for most samples.

- density loss of 23-32\%. Fiberboard assembly density measured on destructive examination (DE) packages ranges from 0.24 to $0.30 \mathrm{~g} / \mathrm{cc}$. For an average density of $0.27 \mathrm{~g} / \mathrm{cc}$, the observed losses correspond to final densities of 0.18 to $0.20 \mathrm{~g} / \mathrm{cc}$, which is equal to or less than the value used in the nuclear criticality safety analysis.

\section{Thermal Samples}

Most of the thermal conductivity sample and all of the specific heat capacity samples were removed from the $250{ }^{\circ} \mathrm{F}$ dry environment in September 2010. The thermal conductivity samples had been aging for up to 272 weeks, and had last been tested following a maximum 255 weeks exposure. The specific heat capacity samples had been aging for 268 weeks, and had last been tested following 258 weeks exposure. The two remaining thermal conductivity samples began conditioning later than the rest, and were removed in August 2012 following 180 weeks aging.

These samples showed extreme degradation, discoloration and darkening, and fragility at the time of removal (Figure 16). Breakage during handling was occurring with increasing frequency. (One exception is that two low density thermal conductivity samples remained in the oven since they began conditioning significantly later than the other samples.) Specific acceptance criteria for thermal properties to define an end-of-life condition have not yet been identified.

\section{$\underline{\text { Analysis }}$}

No significant degradation has been observed in fiberboard assemblies from conforming packages (i.e. packages without excessive moisture and/or mold) examined following up to 7 years storage in KAMS. The typical package stored in KAMS contains a modest amount of moisture within the fiberboard assembly, and has an internal heat load significantly less than the 19 watt rating of the package.

The ambient temperature within KAMS can vary seasonally, or due to changes in HVAC status. The normal ambient temperature in KAMS is less than $90^{\circ} \mathrm{F}$, even in the summer. However, with loss of ventilation, the maximum ambient temperature increases to $137^{\circ} \mathrm{F}$ [10], and the corresponding shield temperature is $196^{\circ} \mathrm{F}$ [11] with 19 watts internal heat load. The maximum fiberboard temperature is assumed to be similar to this shield temperature. With normal ventilation conditions, the fiberboard temperature should generally remain below $\sim 150{ }^{\circ} \mathrm{F}$ for all packages. For a typical ambient temperature of $\sim 85^{\circ} \mathrm{F}$ and an internal heat load of 10 watts or less, the maximum fiberboard temperature is expected to be about $115^{\circ} \mathrm{F}$.

To date, all the packages removed from storage for destructive examination have contained cane fiberboard overpacks. They had been held in storage for periods ranging from $\sim 5$ months to 7 years. The consistent trend indicates the storage environment is sufficiently mild to preclude significant degradation over this time period, although baseline data from these specific cane fiberboard assemblies are not available for comparison. In contrast, the environments used for accelerated aging of the test samples described in this report are more severe than typical KAMS 
Rev. 0

storage conditions. This difference is necessary in order to observe degradation and develop models for predicting service life in advance of unacceptable degradation occurring in KAMS.

The 9975 SARP notes that the package does not provide an air- or water-tight seal. However, upper fiberboard subassembly testing described above has demonstrated that a properly closed drum does provide a significant degree of isolation of the fiberboard from the ambient environment. Accordingly, any moisture originally in the fiberboard assembly will likely remain in the package for a long time. The range of moisture content measured in the upper fiberboard subassemblies exposed to the ambient environment is $\sim 6-14 \% \mathrm{WME}$ (wood moisture equivalent) or $\sim 7-12 \mathrm{wt} \%$. This moisture content will define the relative humidity within a package, which needs to be identified to correlate the laboratory test data to degradation under storage conditions.

The fiberboard within a heated package will develop temperature and moisture gradients. Moisture will tend to migrate to the cooler regions of the fiberboard, while the total moisture content will change very slowly (if at all). Packages that have been destructively examined have had a fiberboard moisture content ranging from 6 to $20 \% \mathrm{WME}$. Lower values $(<\sim 13$ \%WME) occurred along the ID surface, while values along the OD surface tended to be higher ( $>\sim 10 \% \mathrm{WME}$ ). These measurements were typically taken $\sim 2-4$ months after the package was unloaded during field surveillance, indicating the degree of persistence of a moisture gradient after the heat load is removed.

An indication of the moisture gradient that can exist in service is seen in an instrumented test package that has been conditioning at elevated temperature (LE1). It contained an internal heat source of 12 watts (creating a temperature gradient in the fiberboard), and was held in a chamber at $142{ }^{\circ} \mathrm{F}$. Before conditioning, the fiberboard moisture content in this package ranged from $13-15 \% \mathrm{WME}$ along the ID, and $16-18 \% \mathrm{WME}$ along the OD. After conditioning for 57 weeks, the fiberboard moisture content was a maximum of $6.4 \% \mathrm{WME}$ along the ID, and ranged from $12-22 \% W M E$ along the OD. Some regions of the bottom of the lower fiberboard assembly had significantly higher moisture content. Thus, a significant amount of the moisture within this package had migrated from the inner (hotter) regions near the shield to the outside and bottom.

Data have been collected comparing the moisture content of fiberboard samples with the equilibrium relative humidity of the surrounding air [9]. These data suggest that moisture content between 8 and $18 \% \mathrm{WME}$ (a typical range for many packages) corresponds to an equilibrium relative humidity between approximately 40 and $75 \%$ at room temperature. At a moisture content of $22 \% \mathrm{WME}$, these data suggest the equilibrium relative humidity would be $>80 \%$. Additional effort is required to demonstrate how this information scales up to a 9975 package with an internal heat source. For example, the Reference 9 data indicate that the relative humidity in air surrounding the fiberboard increases at elevated temperature (up to $\sim 160{ }^{\circ} \mathrm{F}$ ) for the same fiberboard moisture content, indicating a decrease in the fiberboard moisture content with elevated temperature. These data indicate that the humidity within packages in storage could be significant, especially around the OD and bottom.

A variety of temperature / humidity combinations should be considered in conjunction with understanding the range of conditions within KAMS to adequately identify a limiting service 
Rev. 0

life. For instance, for an ambient temperature of $90^{\circ} \mathrm{F}$, the maximum fiberboard temperature of $\sim 150{ }^{\circ} \mathrm{F}$ will occur along the ID surface, in conjunction with relatively low moisture content. The higher moisture concentrations (corresponding to a relative humidity of $\sim 75 \%$ or greater) will tend to occur along the OD surfaces which are close in temperature to the ambient value of $\sim 90{ }^{\circ} \mathrm{F}$ or less. Other intermediate temperature / moisture combinations should also be considered, including the milder temperatures that would accompany heat loads less than 19 watts.

In the laboratory testing, there are two contributions to property changes - immediate, reversible changes due to change in moisture content, and irreversible changes due to degradation. When a sample is placed in an environment, there may be a change in moisture content as the sample comes to equilibrium with the environment (typically within $\sim 1$ day for smaller samples, or after many weeks for a full assembly). The following summarizes the type of reversible changes likely to occur due to moisture change.

- Thermal conductivity will decrease as moisture content decreases. This effect is reported in the literature [12] for wood products (and by extension is applicable to fiberboard) and is observed in the laboratory data.

- $\quad$ The layer buckling strength will increase as moisture content decreases.

- Specific heat capacity will decrease as moisture content decreases. This effect is reported in the literature [12] for wood products (and by extension is applicable to fiberboard) and is observed in the laboratory data.

- Physical properties (weight, density, dimensions) all decrease as moisture content decreases.

Table 7 summarizes short-term (initial) physical property changes observed in the various environments. The weight changes are generally consistent with an initial moisture content of up to $10 \mathrm{wt} \%$. These data also indicate several temperature - humidity combinations which do not produce a significant weight change (i.e. a moisture content close to $10 \mathrm{wt} \%$ is the equilibrium condition for these environments. These environments include $185{ }^{\circ} \mathrm{F}$ $70 \% \mathrm{RH}, 160{ }^{\circ} \mathrm{F}$ 50\%RH and $15{ }^{\circ} \mathrm{F}$ 60\%RH. These same environments have somewhat varying effects on the other physical properties.

In addition to short-term moisture effects, longer term changes may occur as a result of degradation. The literature identifies that slow pyrolysis occurs at modest temperatures [13]. In addition to water vapor, compounds from pyrolysis are evolved at temperatures as low as $95{ }^{\circ} \mathrm{C}\left(203{ }^{\circ} \mathrm{F}\right)$. This is strongly evidenced by samples conditioned at $250{ }^{\circ} \mathrm{F}$, with an immediate weight loss of 8-10\% (moisture loss), followed by an additional 15 - 20\%/year weight loss. At the higher temperature and humidity levels, the samples also change visually. The samples darken, and the coarse fibrous appearance changes to a finer particulate texture.

The aging models that are discussed below deal with degradation rates. They do not include the effect of initial moisture change. Given the tendency for the 9975 drum to provide a high degree of isolation, much of this initial moisture-related change might not occur in service, except as driven locally within the drum by a temperature gradient. 
Rev. 0

Several physical property samples have been maintained at ambient laboratory conditions, and measured periodically. These control samples serve to show if there is an overall bias in the data over time. The weight and density data for two of these control samples are shown in Figure 17. In addition, the overall rate of change in weight and density is indicated. Both of these samples show a slight decrease in weight over time $(\sim 0.1-0.2 \% /$ year $)$, with a small increase in density. Modest changes in fiberboard physical properties are occurring constantly, especially as a result of seasonal variation in moisture level. Overall, these data suggest there is no significant permanent change in properties occurring at ambient conditions.

There may be sources of degradation to the fiberboard that are not captured in the above testing. For example, a limited number of 9975 packages have been removed from service and found to contain mold or were infested with drugstore beetles. The identified scope of beetle infestation to date is 3 packages. However, the possibility of additional / future infestations exists. On the other hand, mold spores are ubiquitous, and mold growth can be expected whenever the environmental conditions are favorable. Laboratory testing has observed mold growth at high humidity (approximately 100\% RH) with temperatures of approximately 50 and $77^{\circ} \mathrm{F}$. Mold was not observed on samples at approximately $100 \% \mathrm{RH}$ and $125{ }^{\circ} \mathrm{F}$, indicating a modest temperature increase beyond ambient may be sufficient to limit or prevent the growth of mold.

Mold has been observed in 89975 packages in service in K Area. In one case (9975-01903), small patches of mold were observed near the bottom of the lower fiberboard assembly. The fiberboard moisture content was 11 - $18 \%$ WME, with readings around $17 \%$ WME near the mold [14]. An extreme example of mold was observed in another package (9975-01819). Moisture levels were elevated throughout the fiberboard (16\%WME on the ID, $20-26$ $\%$ WME on the OD, the bottom 2 inches were saturated) [15]. The specific impact of mold on fiberboard properties or package service life has not been examined, and is not addressed in this report.

\section{Degradation Models}

Aging models have been constructed based on the observed changes in several fiberboard properties. These include weight, height, thermal conductivity (axial and radial) and energy absorption (area under the stress-strain curve to 40\% strain). Most of the models are based on the average behavior of all samples, and do not reflect any variation among packages or samples. The following approach was used to model the change in fiberboard weight, height, and thermal conductivity (axial and radial orientations). Specific steps are illustrated for the change in weight

1. The data are normalized, to show the relative decrease in each property over time (see Figure 9 for normalized weight change).

2. It is observed that very similar rates of change occur for $215^{\circ} \mathrm{F}$ dry, $185^{\circ} \mathrm{F} 30 \% \mathrm{RH}$ and $160{ }^{\circ} \mathrm{F} 50 \% \mathrm{RH}$ environments, and that these 3 environments fall close to a common straight line in humidity - temperature space. This same line includes the environment of $138{ }^{\circ} \mathrm{F}$ $70 \% \mathrm{RH}$. It is assumed that the average of the rates for these 3 environments (3.6\%/year 
Rev. 0

decrease in weight) is also valid for an environment of $138^{\circ} \mathrm{F} 70 \% \mathrm{RH}$.

3. A curve is fit to rate of change vs temperature for 3 environments $-125^{\circ} \mathrm{F}$ $70 \% \mathrm{RH}, 138{ }^{\circ} \mathrm{F} 70 \% \mathrm{RH}$ and $185^{\circ} \mathrm{F} 70 \% \mathrm{RH}$. A binomial provides the best fit, and represents the variation with temperature at a constant relative humidity of $70 \%$.

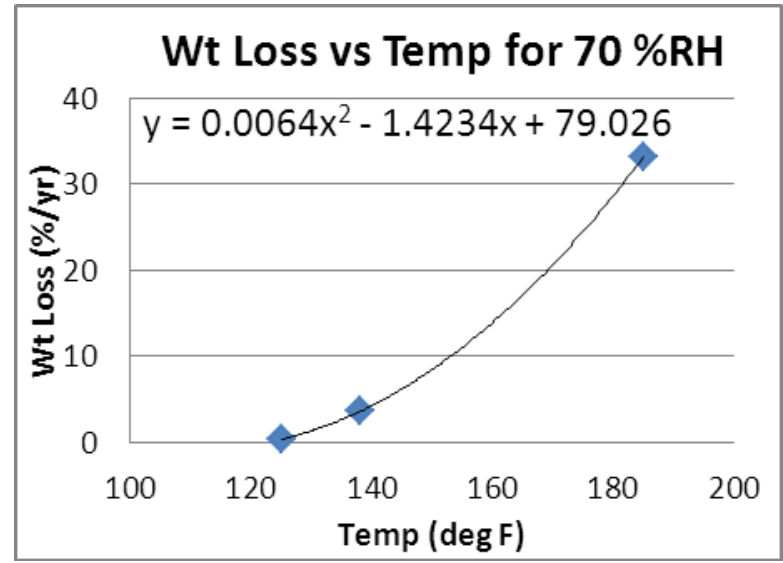

4. A curve is fit to rate of change vs temperature for 4 dry environments $-125^{\circ} \mathrm{F}$ dry, $185^{\circ} \mathrm{F}$ dry, $215^{\circ} \mathrm{F}$ dry and $250^{\circ} \mathrm{F}$ dry. An exponential relationship provides the best fit, and represents the variation with temperature at a low value of relative humidity $(\sim 1-10 \%)$.

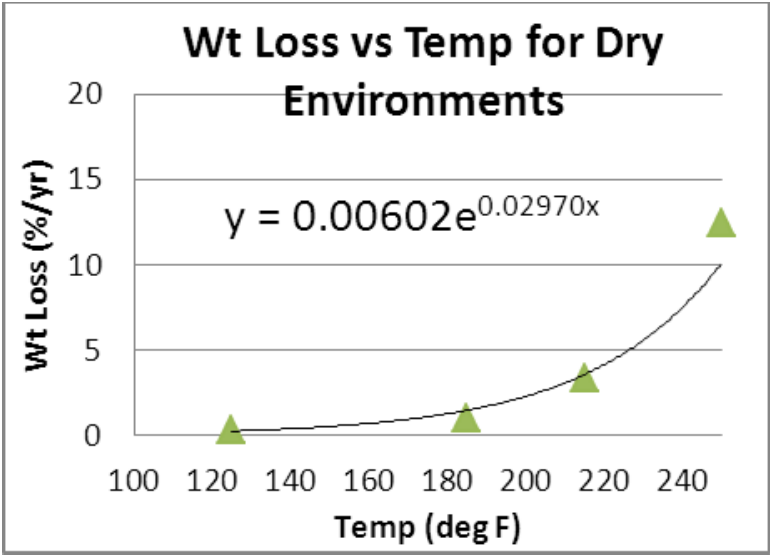

5. The two curve fits developed for the two relative humidity extremes are used to predict the temperatures at which specific rates of change will occur (e.g. a 1\% rate of weight loss is predicted at $172.5^{\circ} \mathrm{F}$ for low relative humidity, and at $128.4^{\circ} \mathrm{F}$ for $70 \% \mathrm{RH}$ ).

6. For the two temperatures identified in the above step, linear interpolation is used to identify combinations of intermediate temperature and relative humidity values that should provide the same rate of change. This provides lines of constant rate change that are plotted on a graph of relative humidity vs temperature. Based on the very low rates of weight loss at $125{ }^{\circ} \mathrm{F}$ dry and $125{ }^{\circ} \mathrm{F} 70$

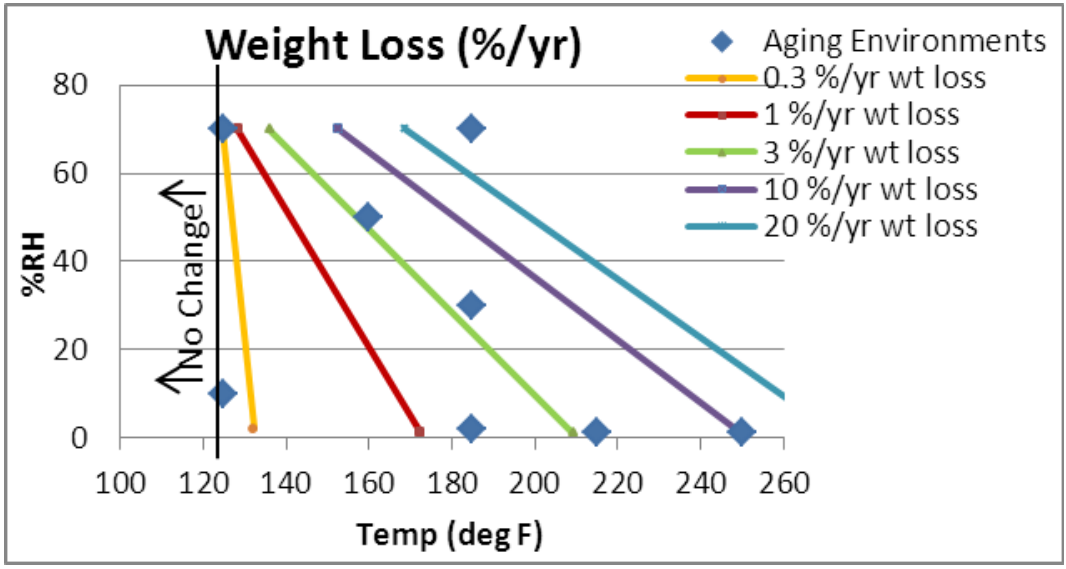
$\% \mathrm{RH}$, it is assumed that there is no change in weight at lower temperature environments. 
Rev. 0

7. The validity of linear interpolation for intermediate relative humidity values is seen by considering the rates of change for $185{ }^{\circ} \mathrm{F}$ at the 3 relative humidity levels ( 2\%, 30\% and 70\%). An exponential curve is fit to the rates of change from these 3 environments, and that curve used to calculate the relative humidity for which specific rates of change are expected. From this

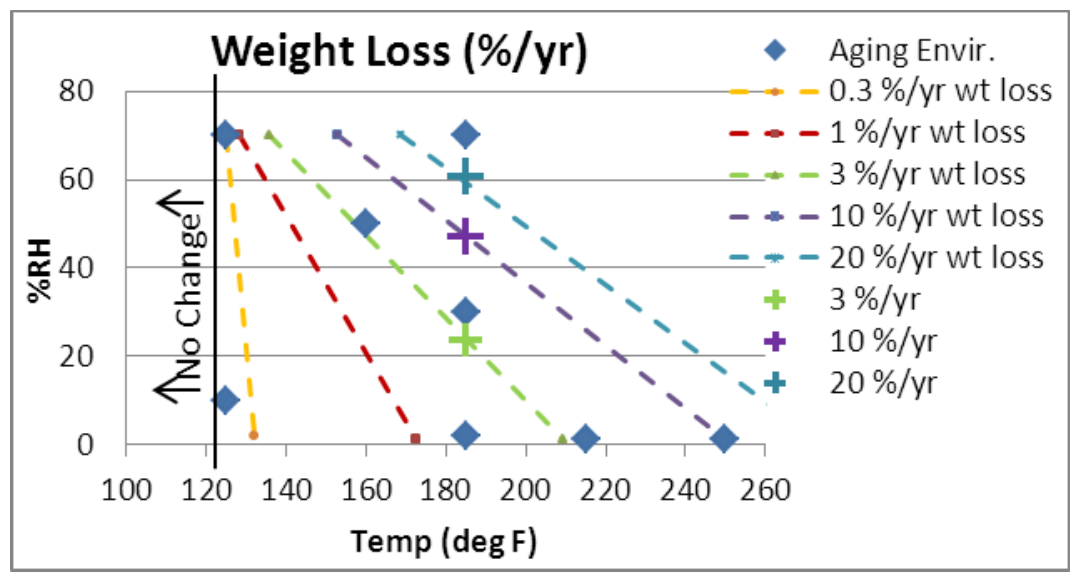
relationship, the relative humidity values that correspond to specific rates of change are calculated. These values are plotted on the graph of relative humidity vs temperature (“+” symbols), and show good agreement with the lines of constant rate change.

8. For a given combination of temperature and relative humidity within the envelope provided by the data, the graphs provide an estimate of the rate of change for the properties considered.

The aging models are shown graphically in Figures 18 - 21 for weight, height, and thermal conductivity (axial and radial orientations). Each of these models was developed through the same process described above for weight.

A further check on the model predictions for weight comes from the thermal conductivity samples. The weight of these samples was measured periodically, but was not used in developing the physical property models. They therefore present a set of independent data for comparison. Trends for the change in weight of thermal conductivity samples are shown in Figure 22 and Table 8.

A slightly different approach was taken in modeling the change in energy absorption, as measured by the area under the compression test stress-strain curve up to $40 \%$ strain. This different approach was necessary for several reasons, including:

- There is significant scatter in the data from sample to sample, and from one material package source to another (Table 3).

- Since compression testing is destructive, each datum represents a different sample.

- For those samples that were tested after aging, their comparable baseline (unaged) condition is unknown, although tests on other unaged samples from the same source package provide an estimate of that condition. Due to sample-to-sample scatter, data cannot reliably be normalized to an initial value. 
Rev. 0

As described above, a strength criterion limiting the area under the stress-strain curve to at least $20 \%$ of that for the nominal stress-strain curve (i.e. 11 psi) is adopted for this analysis. Since the forklift impact scenario primarily loads the fiberboard in a parallel orientation, test data from that orientation are used in model development.

Decreases over time in the area under the stress-strain curve up to $40 \%$ strain are significantly non-linear for the more severe environments. It was observed that an exponential equation provides a good fit to the data for all environments, including the milder environments in which the limited degradation could also be approximated by a linear relationship. Therefore, an exponential fit was adopted to provide a parameter for modeling purposes. This fit takes the form

$$
\text { Area under Curve }=\mathrm{a} * \exp (-\mathrm{b} * \text { time })
$$

In this equation, the exponential factor " $\mathrm{b}$ " describes the rate of decrease of the area under the stress-strain curve.

It is observed from Table 3, that baseline values for area under the stress-strain curve up to $40 \%$ strain vary significantly, but tend to average close to 55 psi (0.055 ksi), consistent with the data used in the forklift impact calculation. However, given the variation observed between source packages, combining (or averaging) the data from multiple packages may be non-conservative. Rather, the exponential fit is applied separately to data from each source package in each environment, and the time for the energy absorption of that source package to decrease to 11 psi is calculated from the curve fit. For each environment, the source package with the shortest time to decrease to 11 psi is conservatively used, with two exceptions:

- In the $160 \mathrm{~F} 50 \% \mathrm{RH}$ environment, samples from 4 of the 5 source packages were aged and tested through 8 weeks only, and scatter in these limited data lead to a positive increase in energy absorption over time. Only New package material shows a decrease with time.

- In the 125F 70\%RH environment, samples from 2 of the 4 source packages show a positive increase in energy absorption over time. Since these two source packages (LD1 and New) also experienced the longer aging times (16 and 64 weeks, respectively), it is judged on average that there is no net degradation in this environment.

With these minimum "failure" times for each environment, the following approach was used to extrapolate these data to other environments. 
Rev. 0

1. The initial data are characterized in terms of the minimum time for the area under the stress-strain curve to a strain of $40 \%$ to decrease to 11 psi. No significant change in energy absorption is observed for $125^{\circ} \mathrm{F}$ dry and $125^{\circ} \mathrm{F} 70$ \%RH environments.

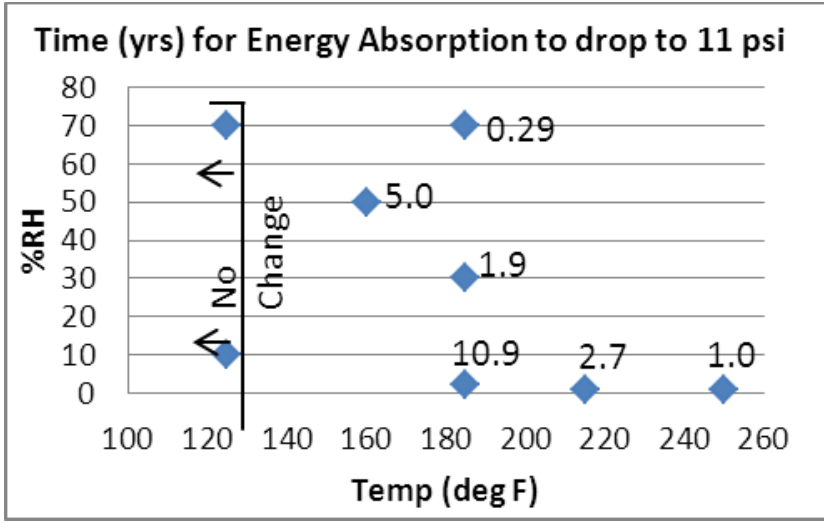

2. Fit an exponential curve to low humidity environments (185, 215 and $250{ }^{\circ} \mathrm{F}$ ), and extrapolate to additional temperatures of interest.

Prediction for $160{ }^{\circ} \mathrm{F}$ (dry) $=24$ yrs Prediction for $125{ }^{\circ} \mathrm{F}$ (dry) = 87 yrs (consistent with observation of very little change at $125^{\circ} \mathrm{F}$ )

Prediction for $173^{\circ} \mathrm{F}$ (dry) $=15$ yrs

Prediction for $204^{\circ} \mathrm{F}$ (dry) $=4.9$ yrs

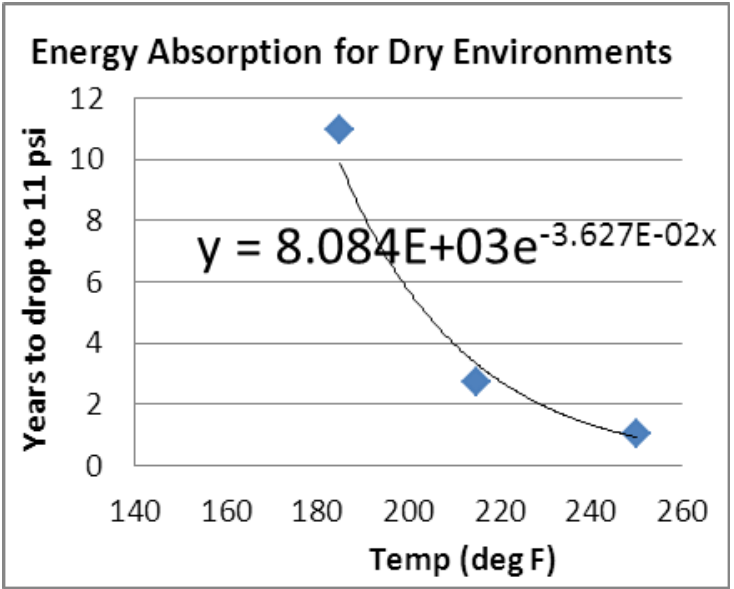

3. Assume $125^{\circ} \mathrm{F} 70 \% \mathrm{RH}$ environment will decrease to 11 psi in half the time as $125{ }^{\circ} \mathrm{F}$ dry, e.g. 43.5 yrs.

4. Fit an exponential curve to $185^{\circ} \mathrm{F}$ environments (dry, 30 and $70 \% \mathrm{RH}$ ), and interpolate to additional humidity values of interest.

Prediction for $15 \% \mathrm{RH}=5 \mathrm{yrs}$

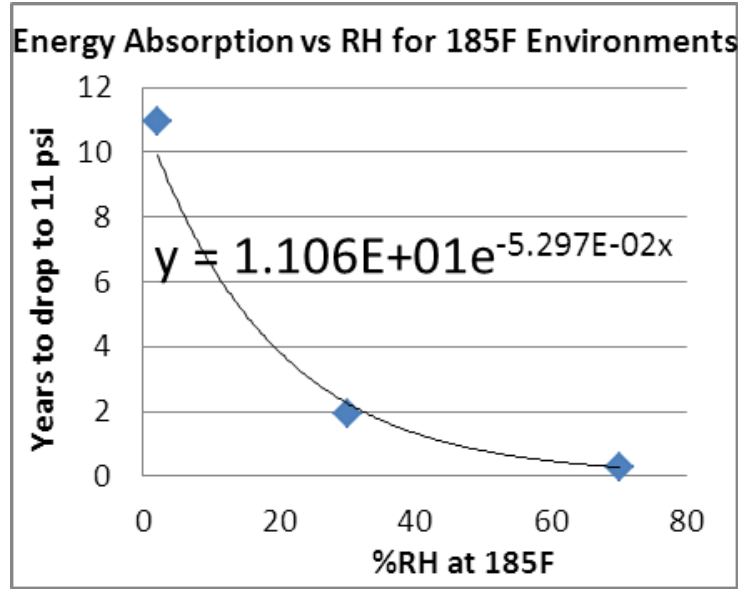


Rev. 0

5. There are now 3 environments with an estimated decrease in energy absorption to 11 psi in $\sim 5$ yrs $-204^{\circ} \mathrm{F}$ dry, $160^{\circ} \mathrm{F} 50 \% \mathrm{RH}$, and $185{ }^{\circ} \mathrm{F} 15 \%$ RH. Fit a binomial curve to these data to describe all environments which will produce a similar drop in energy absorption in $\sim 5$ yrs.

Prediction - 5 yrs energy absorption to decrease to 11 psi at $150{ }^{\circ} \mathrm{F} 70 \% \mathrm{RH}$

6. There are now 3 temperatures with estimated time for energy absorption to decrease to 11 psi at $70 \% \mathrm{RH}-125^{\circ} \mathrm{F}, 150$ ${ }^{\circ} \mathrm{F}$ and $185{ }^{\circ} \mathrm{F}$. Fit an exponential curve to these data, and interpolate to additional temperatures of interest.

Prediction for $160{ }^{\circ} \mathrm{F} 70 \% \mathrm{RH}=2.3$ yrs Prediction for $137.4{ }^{\circ} \mathrm{F} 70 \% \mathrm{RH}=15 \mathrm{yrs}$
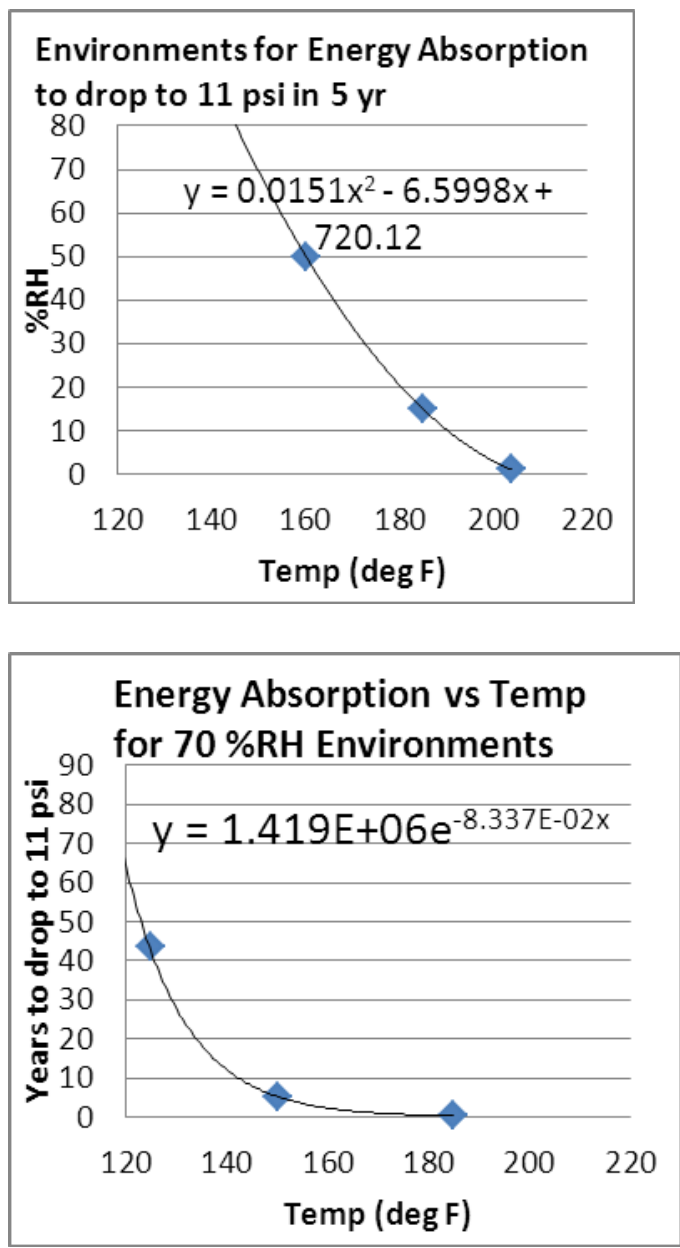

7. There are now $3 \mathrm{RH}$ values with estimated time for energy absorption to decrease to 11 psi at $160{ }^{\circ} \mathrm{F}$ - dry (2\%RH), $50 \% \mathrm{RH}$ and $70 \% \mathrm{RH}$. Fit an exponential curve to these data, and interpolate to additional humidity levels of interest.

Prediction for $160{ }^{\circ} \mathrm{F} 16.2 \% \mathrm{RH}=15 \mathrm{yrs}$

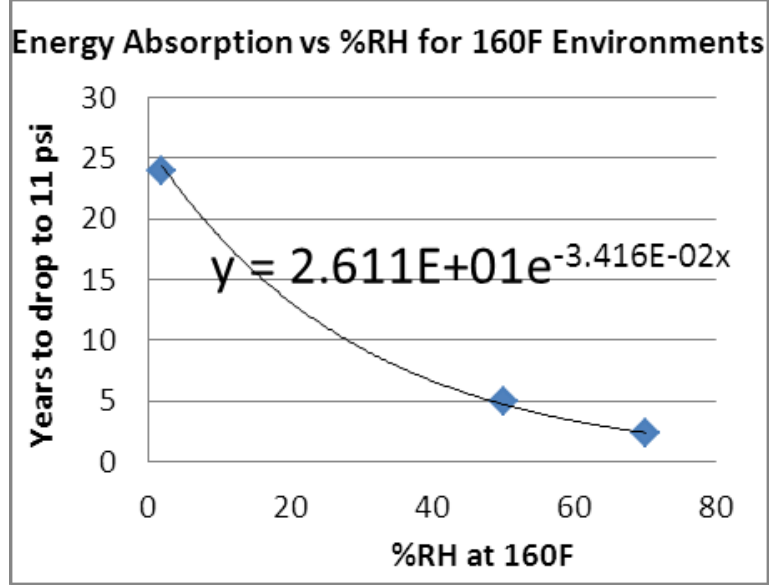


Rev. 0

8. There are now 3 environments with energy absorption decrease to 11 psi in $~ 15$ yrs $-173{ }^{\circ} \mathrm{F}$ dry, $160{ }^{\circ} \mathrm{F} 16.2 \% \mathrm{RH}$, and $137.4{ }^{\circ} \mathrm{F} 70 \% \mathrm{RH}$. Fit a binomial curve to these environments to describe all environments which will produce a similar drop in energy absorption in $~ 15$ yrs.

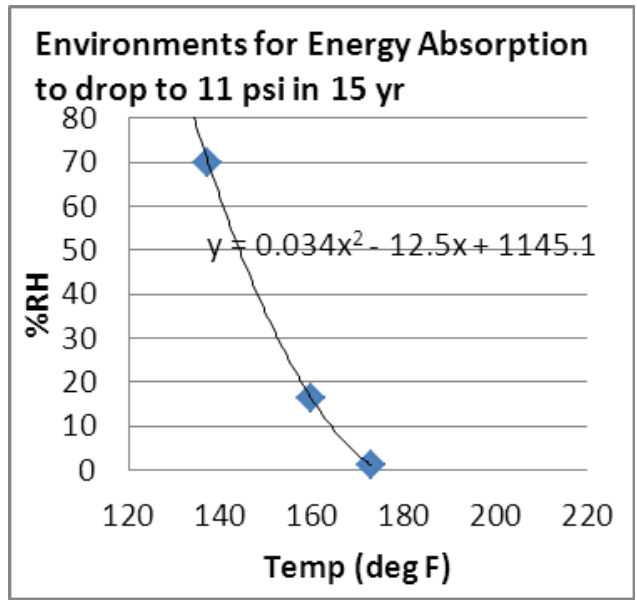

9. The two binomial curve fits developed in steps 5 and 8 provide contour lines describing environments which lead to energy absorption decrease to 11 psi in periods of $\sim 5$ yrs and 15 yrs. These are shown in Figure 23, and identify the environmental ranges within which energy absorption will remain above $\sim 11$ psi for storage periods of $\sim 5$ years or $\sim 15$ years. A similar process could be used to identify environmental ranges corresponding to other storage periods.

As noted above, the limited data from several source packages were not used in identifying the minimum degradation rates for the $125 \mathrm{~F} 70 \% \mathrm{RH}$ and $160 \mathrm{~F} 50 \% \mathrm{RH}$ environments. Due to the limited aging time and scatter of the results, a curve fit to data from several source packages showed a positive increase over time, although such behavior is not expected to actually occur. This includes samples from source package LD2, which are typically among the weakest samples tested after aging in other environments. Therefore, it is noted that having insufficient data to demonstrate realistic behavior for this source package may represent a potential non-conservative aspect of the above model. To address this situation, additional compression samples from the LD1 and LD2 source packages will be added to the 125F 70\%RH and 160F 50\%RH environments.

A further consideration in the implementation of any acceptance criterion is that degradation will not occur uniformly throughout the fiberboard. The temperature gradient across the side wall of the fiberboard assembly is modest. For a 19 watt load in a 3013 container, the maximum steady state temperature difference across the fiberboard and drum (in the radial direction) is $47^{\circ} \mathrm{F}$ [16]. Coincident with this thermal gradient, there will tend to be a moisture gradient in the opposite direction (higher moisture content in the lower temperature regions). Since degradation rates are typically dependent on the temperature and moisture content, any gradient in these conditions within the fiberboard assembly will produce a corresponding gradient in the degradation rate. In some cases, the opposite effects of these two gradients may offset each other. More likely, there will be a partial offset, but a net difference in degradation rate across the fiberboard.

The fiberboard environment within the 9975 packages stored in KAMS will vary. The temperature and temperature gradient within a package will vary with the ambient temperature and internal heat load. The moisture content of the fiberboard will largely be 
Rev. 0

determined by the initial fiberboard condition (barring significant water intrusion during service), and the distribution of that moisture will be driven by the temperature gradient.

With an ambient temperature of $85^{\circ} \mathrm{F}$ and a maximum internal heat load, the maximum fiberboard temperature will be $\sim 135^{\circ} \mathrm{F}$ (along the ID surface) [17]. Based on data from instrumented packages, the temperature along the fiberboard OD is $\sim 40{ }^{\circ} \mathrm{F}$ cooler than the ID, or $\sim 95^{\circ} \mathrm{F}$ for an ambient temperature of $85^{\circ} \mathrm{F}$. The total moisture content will vary from package to package, but it might be assumed that the typical package will have no more moisture than would be absorbed from the air at $75{ }^{\circ} \mathrm{F}$ and $100 \% \mathrm{RH}$. Without any redistribution of moisture, the elevated service temperatures would reduce the relative humidity inside the package to $~ 55 \%$ along the fiberboard OD surface and $\sim 17 \%$ along the fiberboard ID surface. These are two environments that might exist along the OD or ID surfaces of 9975 packages. The intermediate fiberboard regions would be at intermediate environments. The overall degradation rate would be an average over a continuum of local behaviors for a range of intermediate environments.

In reality, moisture within the package will re-distribute. Moisture levels near the ID surface will be further reduced, while the OD surfaces will become wetter. In addition, there will likely be a net transfer of moisture from the central elevations to the bottom of the fiberboard if a significant heat load is present. In local regions where the moisture level increases further (e.g. above 55\% RH), fiberboard weight, density, compressive strength and axial thermal conductivity are expected to decrease at a faster rate.

These changes will have a local (near-surface) effect only, since the moisture extremes will be local. The property limits are developed as bulk average properties. It is judged that even with local surface regions degrading at a significant rate, the overall average rate of change in the bulk fiberboard property will still be low. This judgement is supported by observation of packages removed from service after up to 7 years storage in KAMS. Examination of these packages has shown a range of fiberboard properties (density, thermal conductivity, specific heat capacity and compression strength) consistent with that of un-aged fiberboard, with no discernable change in the fiberboard exterior surface compared to the rest of the assembly.

The limiting need for fiberboard compressive strength is the postulated forklift impact event in KAMS. In this scenario, an impact of the forklift tine near the elevation of the containment vessel closure can compromise the containment vessel leak-tight seal without sufficient energy absorption by the fiberboard. As a significant moisture gradient develops in the fiberboard, some of the moisture migrates toward the bottom of the package, with the result that the fiberboard near the seal elevation is relatively drier and stronger, even along the OD surface.

Additional data continue to be collected for each property, following successive conditioning intervals. In time, the models will be re-visited based on the additional data, and revised service life predictions can be developed. Note, however, that since the compression tests are destructive, most of the available samples being aged have been tested, and relatively little additional compression test data will become available in the future. 
Rev. 0

An improved understanding of the environment within the 9975 drum in storage should be developed. KAMS personnel have begun collecting fiberboard moisture data during field surveillance activities. These data should help understand the actual range of moisture conditions among the many packages in storage. Humidity readings are also taken within the package during field surveillance. However, these data are less useful since the package is moved from its storage location prior to measuring relative humidity, and any change in the ambient temperature around the drum will alter the humidity reading. It is expected that this shortcoming could be avoided if the humidity measurement could be taken before the package is moved from its storage location (by inserting the humidity probe through a caplug hole). Further efforts to define moisture content and relative humidity within the packages in storage should provide for a more realistic application of the models.

\section{Conclusions and Recommendations}

Thermal, mechanical and physical property data for cane fiberboard samples have been summarized following aging in several environments (elevated temperature and/or humidity) for periods up to $\sim 7$ years. Most of the aging environments are bounding to the conditions expected within the 9975 shipping package during storage in KAMS. Initial models have been developed from this data to provide estimates of degradation rate and/or service life under potential storage conditions for several fiberboard properties, including thermal conductivity, energy absorption, weight loss and height change. Development of the predictive models considers the effect of temperature, humidity, time and material source.

Additional data continue to be collected to permit future refinements to the models and assumptions. This includes placing additional compression test samples from the LD1 and LD2 source packages in the $125^{\circ} \mathrm{F} 70 \% \mathrm{RH}$ and $160^{\circ} \mathrm{F} 50 \% \mathrm{RH}$ environments.

The prediction of service life for packages stored in KAMS would utilize the degradation rate models developed within this report, along with specific allowable ranges on each property under consideration. For potential storage environments, package service life is dependent on the most limiting service life estimate based on each of the relevant fiberboard properties. This process needs to continue as a joint effort between SRNL and NMM.

Some of the degradation rates and model predictions presented in this report are extreme and may not represent the behavior of the typical package in KAMS. The internal heat load and temperature profiles within many packages in storage are such as to produce milder conditions in storage than in any of the aging environments. Nevertheless, the possibility of accelerated degradation to a limited number of packages, whether from high heat load, elevated moisture levels, or other conditions, should be recognized. Further efforts will help understand some of these extreme conditions and provide more realistic predictions.

The assumptions and inputs behind the predictions in this report should be well understood before attempting to identify an actual service life in KAMS. Improvement in understanding the impact of these models might be realized with a change in the way humidity data are collected during field surveillances. If the humidity were measured through a caplug hole before the package is removed from its storage location, the package would remain at thermal equilibrium, and the data should better represent actual storage conditions. 
Rev. 0

A limited number of 9975 packages have been found with non-conforming conditions (e.g. moldy fiberboard). The analysis and predictions of this report should not be applied to these packages. Additional efforts would be needed to address the integrity of the fiberboard in such packages.

\section{References}

[1] WSRC-SA-2002-00005, "Material Storage Facilities Documented Safety Analysis", Rev. 3 (SRNS Approved)

[2] WSRC-TR-2003-00325, Rev. 4, “Task Technical and Quality Assurance Plan for Characterization and Surveillance of Model 9975 Package O-Rings and Celotex ${ }^{\circledR}$ Materials”, K. A. Dunn, January 2009

[3] WSRC-TR-2007-00441, "Properties for Fiberboard in Model 9975 Package Following Environmental Conditioning - FY07 Status Report”, W. L. Daugherty, November 2007

[4] PVP2010-25118, “Aging Model for Cane Fiberboard Overpack in the 9975 Shipping Package”, W. L. Daugherty and S. P. Harris, Proceedings of the ASME 2010 Pressure Vessels and Piping Division / K PVP Conference PVP2010, July 18-22, 2010, Bellevue, Wa

[5] SRNL-MST-2007-00100, “Temperature Variation During Conditioning of Fiberboard Samples”, W. L. Daugherty, June 4, 2007

[6] M-CLC-K-00657, Rev. 1 Addendum, "Structural Analysis of 9975 Package Subjected to Two Forklift Truck Impact”, T. Wu, December 16, 2005

[7] WSRC-TR-2004-00523, "Baseline Mechanical Property Data for Model 9975 Package Celotex® Material”, W. L. Daugherty, December 2004

[8] WSMS-CRT-03-0158, “9975 Surveillance Program - Assessment of Celotex® Properties”, D. Biswas, December 16, 2003

[9] SRNL-L7200-2008-00007, “Correlation between Cane Fiberboard Moisture Content and Relative Humidity”, W. L. Daugherty, November 18, 2008

[10] SRNS-TR-2008-00290, Rev. 0, "Summary and Matrix 9975 Shipping Package Qualification Program for Extended Storage of Plutonium in the K Area Complex”, J. A. Radder, Savannah River Nuclear Solutions, Aiken, SC, November 2008.

[11] M-CLC-K-00727, Rev. 0, “Thermal Model Study for the 9975 Package in KAMS during Facility Fire”, N. K. Gupta and D. Tamburello, June 11, 2008 
Rev. 0

[12] DOE/USDA-21697/1, ORNL/Sub/87-21697/1, “Thermal Properties of Wood and Wood Panel Products for Use in Buildings”, A. TenWolde, J. D. McNatt and L. Krahn, September 1988

[13] FPL Report \#2136, “Theories of the Combustion of Wood and Its Control a Survey of the Literature”, F. L. Browne, Forest Products Laboratory, USDA

[14] SRNL-STI-2009-00742, “Examination of Shipping Packages 9975-01818, 9975-01903 and 9975-02287”, W. L. Daugherty, November 2009

[15] SRNL-STI-2009-00240, "Examination of Fiberboard from Shipping Package 997501819”, W. L. Daugherty, April 2009

[16] M-CLC-K-00633, "Steady-State Thermal Analysis of Plutonium Storage in K-Area", S. Hensel, January 19, 1999

[17] M-CLC-K-00198, “KAMS 9975 Shipping Package Thermal Sensitivity Analysis”, S. Chow and R. Yeung, October 13, 2004 
Rev. 0

Table 1. Summary of maximum sample exposure times prior to testing, for data through September 2012.

\begin{tabular}{|c|c|c|c|c|}
\hline & \multicolumn{4}{|c|}{ Maximum exposure time (weeks) through September 2012} \\
\hline Environment & $\begin{array}{l}\text { Thermal } \\
\text { Conductivity }\end{array}$ & $\begin{array}{l}\text { Specific Heat } \\
\text { Capacity }\end{array}$ & $\begin{array}{l}\text { Compression } \\
\text { Strength }\end{array}$ & $\begin{array}{l}\text { Physical } \\
\text { Properties }\end{array}$ \\
\hline $250^{\circ} \mathrm{F}$ oven & $255^{1}$ & 258 & 193 & $275^{1}$ \\
\hline $215^{\circ} \mathrm{F}$ oven & 304 & - & 200 & 334 \\
\hline $185^{\circ} \mathrm{F}$ oven & 337 & 368 & 211 & 367 \\
\hline $185^{\circ} \mathrm{F} 30 \% \mathrm{RH}$ & 192 & 196 & 98 & 210 \\
\hline $185^{\circ} \mathrm{F} 70 \% \mathrm{RH}$ & 22 & 22 & $23^{2}$ & 19 \\
\hline $160^{\circ} \mathrm{F} \mathrm{50 \%} \mathrm{RH}$ & 112 & 32 & 64 & 114 \\
\hline $125^{\circ} \mathrm{F}$ oven & 337 & $379^{3}$ & $133^{4}$ & 312 \\
\hline $125^{\circ} \mathrm{F} 70 \% \mathrm{RH}$ & 80 & 17 & 64 & 90 \\
\hline $77^{\circ} \mathrm{F} 70 \% \mathrm{RH}$ & - & - & 8 & - \\
\hline $50^{\circ} \mathrm{F}$ refrigerator & - & - & - & 288 \\
\hline $15^{\circ} \mathrm{F}$ freezer & - & - & - & 288 \\
\hline $\begin{array}{l}\text { Other } \\
\text { environments }\end{array}$ & & & 5 & \\
\hline
\end{tabular}

1 Due to a thermal gradient in the $250{ }^{\circ} \mathrm{F}$ oven, the temperature of the thermal conductivity samples ranged from $\sim 242-279^{\circ} \mathrm{F}$ during the first 56 weeks, and the temperature of the physical property samples was $\sim 236^{\circ} \mathrm{F}$ during the first 26 weeks.

2 Some of these samples were tested after aging at $70 \% \mathrm{RH}$ for the stated period, but also include additional aging time at the same temperature in a dry oven. No significant degradation is observed for samples at these temperatures $\left(125,185^{\circ} \mathrm{F}\right)$ in a dry oven.

3 Exposure time for these SHC samples is through November 2012.

4 Some of these samples were tested after aging in a $125{ }^{\circ} \mathrm{F}$ oven for the stated period, but also include additional aging time at $125{ }^{\circ} \mathrm{F}$ and $70 \% \mathrm{RH}$. No significant degradation has been observed from the aging periods at $125{ }^{\circ} \mathrm{F} 70 \% \mathrm{RH}$.

5 Additional aging environments, for compression testing only, include 2 weeks exposure in the following environments: $195^{\circ} \mathrm{F}$ oven, $195^{\circ} \mathrm{F} 40 \% \mathrm{RH}, 195^{\circ} \mathrm{F} 100 \% \mathrm{RH}, 125^{\circ} \mathrm{F} 40 \% \mathrm{RH}, 125^{\circ} \mathrm{F}$ $100 \% \mathrm{RH}, 77^{\circ} \mathrm{F} 40 \% \mathrm{RH}$, and $77^{\circ} \mathrm{F} 100 \% \mathrm{RH}$. 
Rev. 0

Table 2. Buckling strength for compression test samples tested in the parallel orientation

\begin{tabular}{|c|c|c|c|c|c|c|c|c|c|c|c|c|c|}
\hline \multirow{3}{*}{\multicolumn{2}{|c|}{$\begin{array}{l}\text { Environ- } \\
\text { ment (wks) } \\
\text { Ambient } 0\end{array}$}} & \multicolumn{5}{|c|}{ Buckling Strength (ksi) for } & \multirow{2}{*}{\multicolumn{2}{|c|}{$\begin{array}{l}\text { Environ- } \\
\text { ment (wks) }\end{array}$}} & \multicolumn{5}{|c|}{ Buckling Strength (ksi) for } \\
\hline & & $\begin{array}{l}\text { LD1 } \\
0228\end{array}$ & $\begin{array}{l}\text { LD2 } \\
0185\end{array}$ & MSC & New & KT2 & & & \multirow{2}{*}{$\begin{array}{l}\text { LD1 } \\
\quad 0.269\end{array}$} & \multirow{2}{*}{$\begin{array}{l}\text { LD2 } \\
\quad 0.184\end{array}$} & \multirow{2}{*}{$\begin{array}{l}\text { MSC } \\
0.217\end{array}$} & \multirow[t]{4}{*}{ New } & \multirow[t]{4}{*}{$\mathrm{KT} 2$} \\
\hline & & $\begin{array}{l}0.228 \\
0.200\end{array}$ & $\begin{array}{l}0.185 \\
0.171\end{array}$ & $\begin{array}{l}0.164 \\
0.242\end{array}$ & 0.410 & 0.265 & $185 F$ & 64 & & & & & \\
\hline & & 0.192 & 0.189 & 0.180 & 0.357 & 0.286 & dry & 96 & 0.168 & 0.148 & 0.231 & & \\
\hline & & & 0.152 & & 0.288 & 0.252 & (cont.) & 139 & 0.206 & 0.123 & 0.203 & & \\
\hline $77 \mathrm{~F}$ & 2 & 0.214 & 0.156 & & & & & 179 & 0.209 & & 0.206 & & \\
\hline $70 \%$ & 8 & 0.193 & 0.129 & & & & & 211 & & & 0.204 & & \\
\hline $125 F$ & 2 & 0.242 & 0.152 & 0.246 & & 0.275 & $185 F$ & 2 & 0.200 & & 0.214 & 0.283 & \\
\hline \multirow[t]{16}{*}{ Dry } & & $0.223^{* *}$ & $\begin{array}{r}0.173 \\
0.151^{* *}\end{array}$ & $\begin{array}{l}0.248 \\
0.238\end{array}$ & & & $30 \%$ & 8 & 0.269 & & 0.226 & 0.314 & \\
\hline & & & & 0.231 & & & & 16 & 0.284 & & 0.226 & 0.294 & \\
\hline & & & & 0.266 & & & & 32 & 0.229 & & 0.201 & 0.290 & \\
\hline & 4 & 0.289 & 0.158 & 0.264 & & & & 75 & 0.100 & & 0.109 & 0.224 & \\
\hline & & $0.255^{\star \star}$ & & & & & & 98 & 0.098 & & 0.114 & 0.212 & \\
\hline & 7 & & 0.208 & 0.234 & & & $185 \mathrm{~F}$ & 2 & 0.187 & 0.123 & 0.182 & & \\
\hline & 8 & 0.202 & 0.189 & 0.270 & & & $70 \%$ & & 0.184 & 0.146 & & & \\
\hline & 16 & 0.258 & 0.206 & 0.279 & & & & 4 & 0.150 & 0.053 & 0.159 & & \\
\hline & & & & & & & & 6 & $0.113^{*}$ & $0.110^{*}$ & & & \\
\hline & 21 & & & $0.262^{\star \star}$ & & & & 8 & 0.124 & 0.112 & 0.130 & & \\
\hline & 32 & & 0.160 & 0.257 & & & & 12 & 0.142 & 0.093 & & & \\
\hline & 35 & $0.204^{\star *}$ & $0.176^{\star *}$ & & & & & 23 & & & $0.032^{*}$ & & \\
\hline & 48 & $0.228^{\star *}$ & $0.191^{\star \star}$ & $0.259 * *$ & & & $\begin{array}{l}215 F \\
\text { dry }\end{array}$ & 2 & $\begin{array}{l}0.222 \\
0.306\end{array}$ & 0.147 & $\begin{array}{l}0.223 \\
0.207\end{array}$ & & \\
\hline & 53 & & & $0.234^{\star \star}$ & & & & 8 & 0.296 & 0.115 & 0.200 & & \\
\hline & 64 & & 0.183 & 0.193 & & & & 16 & 0.209 & 0.153 & 0.201 & & \\
\hline & 122 & & & $0.217^{* *}$ & & & & & 0.255 & & 0.206 & & \\
\hline $125 F$ & 2 & & & 0.248 & & 0.263 & & 32 & 0.199 & 0.152 & 0.185 & & \\
\hline $40 \%$ & & & & $\begin{array}{l}0.256 \\
0.240\end{array}$ & & & & 64 & $\begin{array}{l}0.146 \\
0.219\end{array}$ & 0.111 & 0.147 & & \\
\hline $125 \mathrm{~F}$ & 2 & 0.173 & 0.136 & 0.184 & & & & 96 & 0.194 & 0.116 & 0.130 & & \\
\hline \multirow[t]{8}{*}{$70 \%$} & 4 & 0.178 & 0.136 & 0.186 & & & & 148 & 0.157 & & 0.109 & & \\
\hline & 6 & $0.165^{\star}$ & $0.079 *$ & & & & & 200 & 0.146 & & 0.098 & & \\
\hline & 8 & $\begin{array}{r}0.183 \\
0.146^{*}\end{array}$ & $\begin{array}{r}0.136 \\
0.146^{*}\end{array}$ & 0.170 & 0.197 & & $250 \mathrm{~F}$ & 2 & 0.214 & 0.212 & 0.288 & & \\
\hline & 10 & $0.185^{\star}$ & 0.120 * & & & & & & 0.187 & & & & \\
\hline & & & $0.1 \angle 0$ & & & & & 4 & 0.173 & & & & \\
\hline & & $0.1 / 5$ & 0.102 & & 0.191 & & & 7 & & & 0.222 & & \\
\hline & 32 & & & & 0.217 & & & 8 & 0.125 & 0.132 & & 0.255 & \\
\hline & 64 & & & & 0.214 & & & & & & & 0.257 & \\
\hline $125 \mathrm{~F}$ & 2 & & & 0.031 & & 0.062 & & 16 & 0.109 & 0.121 & & & \\
\hline \multirow[t]{2}{*}{$100 \%$} & & & & 0.026 & & & & 32 & & 0.095 & 0.094 & 0.135 & \\
\hline & 2 & 0.243 & 0.126 & $\begin{array}{l}0.030 \\
0.203\end{array}$ & & 0.148 & & 47 & & & 0.058 & & \\
\hline \multirow[t]{8}{*}{$50 \%$} & & 0.218 & & 0.220 & & 0.148 & & 64 & & 0.071 & 0.049 & & \\
\hline & 4 & 0.181 & & & & 0.240 & & 96 & 0.074 & & & & \\
\hline & & 0.257 & & & & & & 134 & & 0.024 & 0.029 & & \\
\hline & 8 & 0.184 & 0.113 & 0.201 & 0.245 & 0.198 & & 153 & 0.044 & & & & \\
\hline & & 0.216 & & 0.231 & O 275 & 0.215 & & 193 & & 0.012 & 0.033 & & \\
\hline & 16 & & & & 0.275 & & \multicolumn{6}{|c|}{ Additional Environments } & \\
\hline & 32 & & & & 0.260 & & & & KT2 & & KT2 & & KT2 \\
\hline & 64 & & & & 0.168 & & $77 \mathrm{~F}$ & 2 & 0.264 & 195F 2 & 0.172 & 195F 2 & 0.025 \\
\hline $185 F$ & 2 & 0.196 & 0.170 & 0.187 & 0.308 & & dry & & 0.269 & dry & 0.264 & $100 \%$ & 0.028 \\
\hline \multirow[t]{4}{*}{ dry } & 4 & 0.240 & 0.196 & 0.148 & & & & & 0.248 & & 0.221 & & 0.027 \\
\hline & 8 & 0.212 & 0.155 & 0.196 & & & \multirow{3}{*}{$\begin{array}{l}77 F \\
100 \%\end{array}$} & & 0.331 & & 0.239 & & 0.041 \\
\hline & 16 & 0.206 & 0.089 & & & & & 2 & 0.072 & 195F 2 & 0.273 & & \\
\hline & 32 & 0.227 & 0.080 & 0.222 & $\begin{array}{l}0.346 \\
0.348\end{array}$ & & & & 0.068 & & & & \\
\hline
\end{tabular}


Rev. 0

Table 3. Area under stress-strain curve to $40 \%$ strain for compression test samples, parallel orientation

\begin{tabular}{|c|c|c|c|c|c|c|}
\hline \multirow{2}{*}{\multicolumn{2}{|c|}{$\begin{array}{l}\text { Environ- } \\
\text { ment (wks) }\end{array}$}} & \multicolumn{3}{|c|}{ Area under Curve (ksi) for } & \multirow[b]{2}{*}{ New } & \multirow[b]{2}{*}{ KT2 } \\
\hline & & LD1 & LD2 & MSC & & \\
\hline \multirow{3}{*}{\multicolumn{2}{|c|}{ Ambient 0}} & 0.0359 & 0.0424 & 0.0458 & 0.0698 & 0.0732 \\
\hline & & 0.0460 & 0.0490 & 0.0419 & 0.0779 & 0.0673 \\
\hline & & & 0.0378 & & 0.0595 & 0.0713 \\
\hline 77F & 2 & 0.0463 & 0.0419 & & & \\
\hline $70 \%$ & 8 & 0.0419 & 0.0367 & & & \\
\hline 125F & 2 & 0.0462 & 0.0378 & 0.0410 & & 0.0731 \\
\hline \multirow[t]{18}{*}{ Dry } & & $0.0512^{\star *}$ & 0.0427 & 0.0472 & & \\
\hline & & & $0.0305^{\star \star}$ & 0.0618 & & \\
\hline & & & & 0.0631 & & \\
\hline & & & & 0.0682 & & \\
\hline & 4 & 0.0558 & 0.0460 & 0.0568 & & \\
\hline & & 0.0450 ** & $0.0451^{\star \star}$ & & & \\
\hline & 7 & & 0.0435 & 0.0374 & & \\
\hline & 8 & 0.0359 & 0.0449 & 0.0583 & & \\
\hline & 16 & 0.0404 & 0.0416 & 0.0404 & & \\
\hline & & & 0.0363 & & & \\
\hline & 21 & & & $0.0457^{\star *}$ & & \\
\hline & 32 & & 0.0418 & 0.0348 & & \\
\hline & 35 & $0.0380 * *$ & $0.0411^{\star *}$ & & & \\
\hline & 48 & $0.0395^{\star \star}$ & $0.0413^{\star *}$ & & & \\
\hline & 53 & & & $0.0590 * *$ & & \\
\hline & & & & $0.0404^{\star *}$ & & \\
\hline & 64 & & 0.0486 & 0.0516 & & \\
\hline & 122 & & & $0.0444^{\star *}$ & & \\
\hline $125 F$ & 2 & & & 0.0720 & & 0.0639 \\
\hline $40 \%$ & & & & 0.0576 & & \\
\hline & & & & 0.0633 & & \\
\hline $125 \mathrm{~F}$ & 2 & 0.0438 & 0.0283 & 0.0417 & & \\
\hline \multirow[t]{8}{*}{$70 \%$} & 4 & 0.0373 & 0.0371 & 0.0436 & & \\
\hline & 6 & $0.0344^{*}$ & $0.0256^{*}$ & & & \\
\hline & 8 & 0.0373 & 0.0372 & 0.0380 & 0.0443 & \\
\hline & & 0.0503 & 0.0362 & & & \\
\hline & 10 & $0.0334^{*}$ & $0.0345^{*}$ & & & \\
\hline & 16 & 0.0453 & 0.0255 & & 0.0467 & \\
\hline & 32 & & & & 0.0562 & \\
\hline & 64 & & & & 0.0480 & \\
\hline $125 \mathrm{~F}$ & 2 & & & 0.0084 & & 0.0168 \\
\hline $100 \%$ & & & & 0.0079 & & \\
\hline & & & & 0.0078 & & \\
\hline \multirow{9}{*}{$\begin{array}{l}160 F \\
50 \%\end{array}$} & 2 & 0.0571 & 0.0318 & 0.0365 & & 0.0248 \\
\hline & & 0.0524 & & 0.0410 & & \\
\hline & 4 & 0.0334 & & & & 0.0433 \\
\hline & & 0.0506 & & & & \\
\hline & 8 & 0.0565 & 0.0365 & 0.0466 & 0.0551 & 0.0597 \\
\hline & & 0.0519 & & 0.0626 & & 0.0425 \\
\hline & 16 & & & & 0.0524 & \\
\hline & 32 & & & & 0.0508 & \\
\hline & 64 & & & & 0.0381 & \\
\hline $185 F$ & 2 & 0.0353 & 0.0349 & 0.0332 & 0.0470 & \\
\hline \multirow[t]{5}{*}{ dry } & 4 & 0.0311 & 0.0459 & 0.0248 & & \\
\hline & 8 & 0.0380 & 0.0366 & 0.0374 & & \\
\hline & 16 & 0.0457 & 0.0251 & & & \\
\hline & 32 & 0.0312 & 0.0190 & 0.0458 & $\begin{array}{l}0.0673 \\
0.0653\end{array}$ & \\
\hline & 64 & 0.0243 & 0.0362 & 0.0462 & & \\
\hline
\end{tabular}

\begin{tabular}{|c|c|c|c|c|c|c|}
\hline \multirow{2}{*}{\multicolumn{2}{|c|}{$\begin{array}{l}\text { Environ- } \\
\text { ment (wks) }\end{array}$}} & \multicolumn{3}{|c|}{ Area under Curve (ksi) for } & \multirow{3}{*}{ New } & \multirow[b]{2}{*}{ KT2 } \\
\hline & & \multirow{2}{*}{$\frac{\text { LD1 }}{0.0295}$} & \multirow{2}{*}{$\begin{array}{l}\text { LD2 } \\
0.0291\end{array}$} & \multirow{2}{*}{$\frac{\text { MSC }}{0.0386}$} & & \\
\hline $185 F$ & 96 & & & & & \\
\hline dry & 139 & 0.0330 & 0.0298 & 0.0382 & & \\
\hline \multicolumn{2}{|c|}{ (cont.)179 } & 0.0228 & & 0.0325 & & \\
\hline \multicolumn{2}{|c|}{211} & & & 0.0325 & & \\
\hline $185 F$ & 2 & 0.0504 & & 0.0485 & 0.0688 & \\
\hline \multirow[t]{5}{*}{$30 \%$} & 8 & 0.0273 & & 0.0398 & 0.0671 & \\
\hline & 16 & 0.0248 & & 0.0321 & 0.0514 & \\
\hline & 32 & 0.0276 & & 0.0431 & 0.0418 & \\
\hline & 75 & 0.0167 & & 0.0148 & 0.0283 & \\
\hline & 98 & 0.0105 & & 0.0117 & 0.0255 & \\
\hline \multirow{7}{*}{$\begin{array}{l}185 F \\
70 \%\end{array}$} & 2 & 0.0499 & 0.0276 & & & \\
\hline & & $0.0402^{*}$ & $0.0298 *$ & 0.0433 & & \\
\hline & 4 & 0.0367 & 0.0180 & 0.0242 & & \\
\hline & 6 & $0.0214^{*}$ & $0.0271^{*}$ & & & \\
\hline & 8 & 0.0181 & 0.0248 & 0.0253 & & \\
\hline & 12 & 0.0180 & 0.0215 & & & \\
\hline & 23 & & & $0.0060 *$ & & \\
\hline \multirow[t]{6}{*}{$\begin{array}{l}\text { 215F } \\
\text { dry }\end{array}$} & 2 & $\begin{array}{l}0.0493 \\
0.0416\end{array}$ & 0.0258 & $\begin{array}{l}0.0398 \\
0.0354\end{array}$ & & \\
\hline & $\begin{array}{r}8 \\
16\end{array}$ & $\begin{array}{l}0.0335 \\
0.0418 \\
0.0342\end{array}$ & $\begin{array}{l}0.0287 \\
0.0280\end{array}$ & $\begin{array}{l}0.0188 \\
0.0264 \\
0.0374\end{array}$ & & \\
\hline & $\begin{array}{l}32 \\
64\end{array}$ & $\begin{array}{l}0.0302 \\
0.0327 \\
0.0316\end{array}$ & $\begin{array}{l}0.0291 \\
0.0313\end{array}$ & $\begin{array}{l}0.0286 \\
0.0237\end{array}$ & & \\
\hline & 96 & 0.0168 & 0.0195 & 0.0141 & & \\
\hline & 148 & 0.0150 & & 0.0136 & & \\
\hline & 200 & 0.0164 & & 0.0058 & & \\
\hline \multirow[t]{12}{*}{$\begin{array}{l}\text { 250F } \\
\text { dry }\end{array}$} & 2 & $\begin{array}{l}0.0399 \\
0.0507\end{array}$ & & 0.0472 & 0.0522 & \\
\hline & 4 & 0.0273 & & & & \\
\hline & 7 & & & 0.0410 & & \\
\hline & 8 & 0.0112 & 0.0199 & & $\begin{array}{l}0.0400 \\
0.0356\end{array}$ & \\
\hline & 16 & 0.0113 & 0.0178 & & & \\
\hline & 32 & & 0.0159 & 0.0158 & 0.0206 & \\
\hline & 47 & & & 0.0069 & & \\
\hline & 64 & & 0.0110 & 0.0092 & & \\
\hline & 96 & 0.0090 & & & & \\
\hline & 134 & & 0.0034 & 0.0063 & & \\
\hline & 153 & 0.0066 & & & & \\
\hline & 193 & & 0.0018 & 0.0050 & & \\
\hline \multicolumn{7}{|c|}{ Additional Environments } \\
\hline & & KT2 & & KT2 & & KT2 \\
\hline $\begin{array}{l}\text { 77F } \\
\text { dry }\end{array}$ & 2 & $\begin{array}{l}0.0688 \\
0.0654 \\
0.0619 \\
0.0607\end{array}$ & $\begin{array}{l}\text { 195F } 2 \\
\text { dry }\end{array}$ & $\begin{array}{l}0.0453 \\
0.0484 \\
0.0589 \\
0.0461\end{array}$ & $\begin{array}{l}195 F 2 \\
100 \%\end{array}$ & $\begin{array}{l}0.0064 \\
0.0075 \\
0.0078 \\
0.0095\end{array}$ \\
\hline $\begin{array}{l}77 F \\
100 \%\end{array}$ & 2 & $\begin{array}{l}0.0189 \\
0.0188 \\
0.0171\end{array}$ & $\begin{array}{ll}195 F & 2 \\
40 \% & \end{array}$ & 0.0482 & & \\
\hline
\end{tabular}

* Samples tested after aging at $70 \% \mathrm{RH}$ for stated period, but also include additional time at the same temperature in a dry oven. ** Samples tested after aging in a dry oven for stated period, but also include additional time at 125 F $70 \% \mathrm{RH}$. 
Rev. 0

Table 4. Area under stress-strain curve to $40 \%$ strain for compression test samples, perpendicular orientation

\begin{tabular}{llllll}
$\begin{array}{l}\text { Environ- } \\
\text { ment (wks) }\end{array}$ & LD1 & LD2 & MSC & New & KT2 \\
\hline Ambient 0 & 0.0461 & 0.0308 & 0.0331 & 0.0527 & 0.0493 \\
& 0.0368 & 0.0297 & 0.0294 & 0.0517 & 0.0594 \\
& & 0.0253 & & & 0.0528 \\
& & & & & 0.0536 \\
\hline 77F & 0.0420 & 0.0263 & & &
\end{tabular}

\begin{tabular}{|c|c|c|c|c|c|c|}
\hline $77 F$ & 2 & 0.0420 & 0.0263 & & & \\
\hline $70 \%$ & 8 & 0.0381 & & & & \\
\hline $125 \mathrm{~F}$ & 2 & 0.0575 & 0.0252 & 0.0539 & & 0.0626 \\
\hline Dry & & $0.0575^{\star \star}$ & $0.0348^{\star \star}$ & 0.0420 & & \\
\hline & & & & 0.0376 & & \\
\hline & & & & 0.0409 & & \\
\hline & 4 & $0.0541^{\star *}$ & $0.0345^{\star \star}$ & & & \\
\hline & 8 & 0.0559 & & & & \\
\hline & & 0.0557 & & & & \\
\hline & 16 & 0.0582 & & & & \\
\hline & & 0.0565 & & & & \\
\hline & 21 & & & $0.0363^{\star \star}$ & & \\
\hline & 32 & & & 0.0554 & & \\
\hline & 35 & $0.0537^{\star *}$ & $0.0395^{\star *}$ & & & \\
\hline & 48 & $0.0492^{\star *}$ & $0.0320^{* *}$ & & & \\
\hline & 53 & & & $0.0566^{* *}$ & & \\
\hline & 64 & & & 0.0400 & & \\
\hline & 112 & & & $0.0578 * *$ & & \\
\hline $125 \mathrm{~F}$ & 2 & & & 0.0345 & & \\
\hline $40 \%$ & & & & 0.0365 & & \\
\hline & & & & 0.0403 & & \\
\hline $125 \mathrm{~F}$ & 2 & 0.0393 & 0.0216 & 0.0279 & & \\
\hline $70 \%$ & 6 & $0.0388^{*}$ & $0.0231^{*}$ & & & \\
\hline & 8 & 0.0323 & & & & \\
\hline & & 0.0363 & & & & \\
\hline & 10 & $0.0334^{*}$ & $0.0236^{*}$ & & & \\
\hline & 16 & 0.0349 & & & & \\
\hline & 32 & & & & & \\
\hline & 64 & & & & & \\
\hline $125 \mathrm{~F}$ & 2 & & & 0.0038 & & \\
\hline $100 \%$ & & & & 0.0055 & & \\
\hline & & & & 0.0090 & & \\
\hline $160 \mathrm{~F}$ & 2 & 0.0446 & 0.3033 & 0.0472 & & 0.0454 \\
\hline $50 \%$ & & 0.0493 & & 0.0332 & & \\
\hline & 8 & 0.0409 & & & 0.0528 & 0.0485 \\
\hline & & 0.0359 & & & & \\
\hline & 16 & & & & 0.0593 & \\
\hline & 32 & & & & 0.0477 & \\
\hline & 64 & & & & 0.0556 & \\
\hline $185 \mathrm{~F}$ & 2 & 0.0480 & 0.0325 & 0.0372 & 0.0690 & \\
\hline dry & 8 & 0.0555 & & & & \\
\hline & & 0.0536 & & & & \\
\hline & 16 & 0.0471 & & & & \\
\hline & & 0.0429 & & & & \\
\hline
\end{tabular}

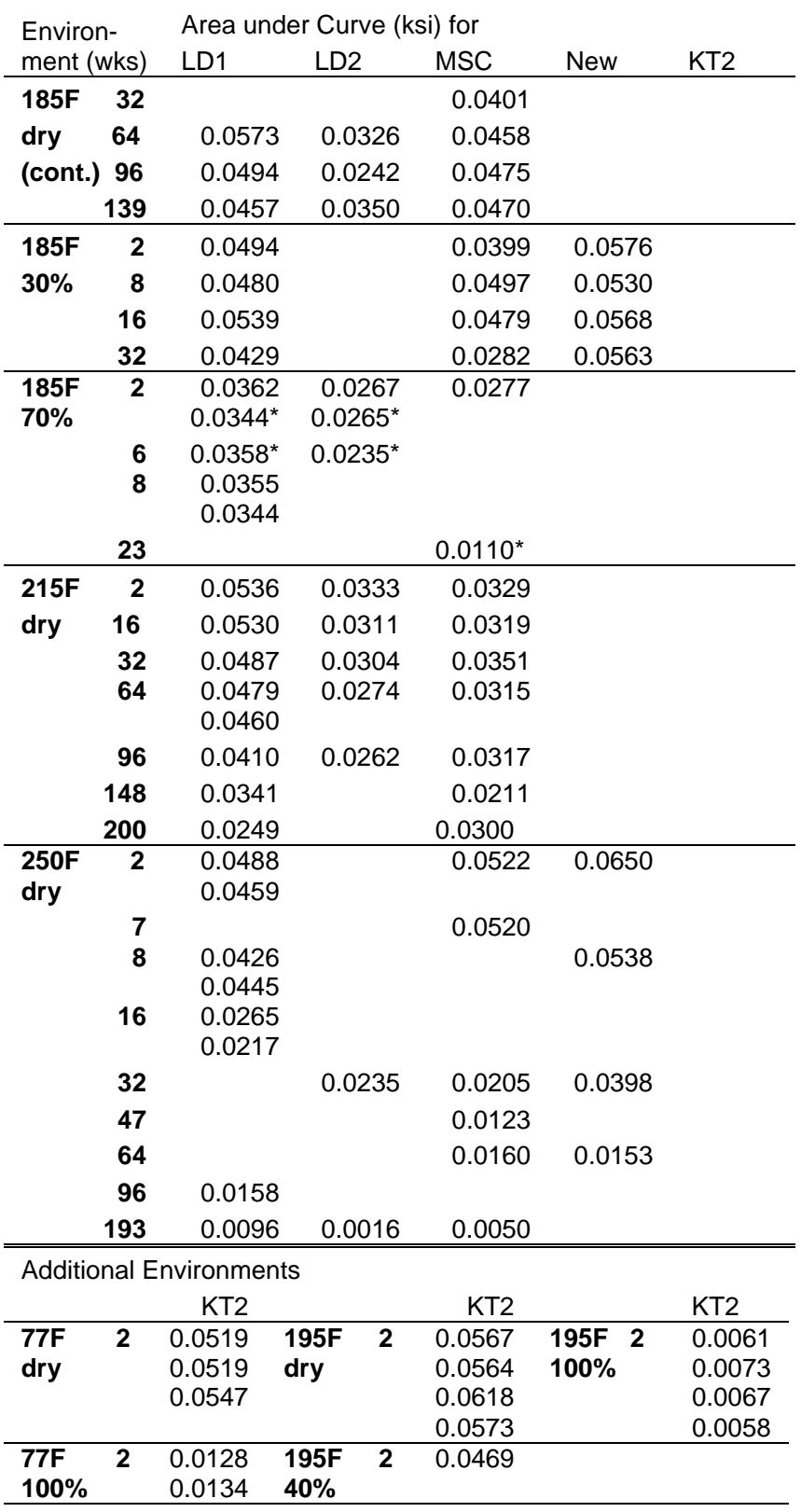

* Samples tested after aging at $70 \% \mathrm{RH}$ for stated period, but also include additional time at the same temperature in a dry oven.

** Samples tested after aging in a dry oven for stated period, but also include additional time at $125{ }^{\circ} \mathrm{F} 70 \% \mathrm{RH}$. 
Rev. 0

Table 5. Thermal conductivity data at $25{ }^{\circ} \mathrm{C}$ mean temperature for each sample following initial period in the aging environment. Variation results primarily from moisture level and sample source package. The source package is identified within the sample ID, except for samples TCxx which are from MSC source packages.

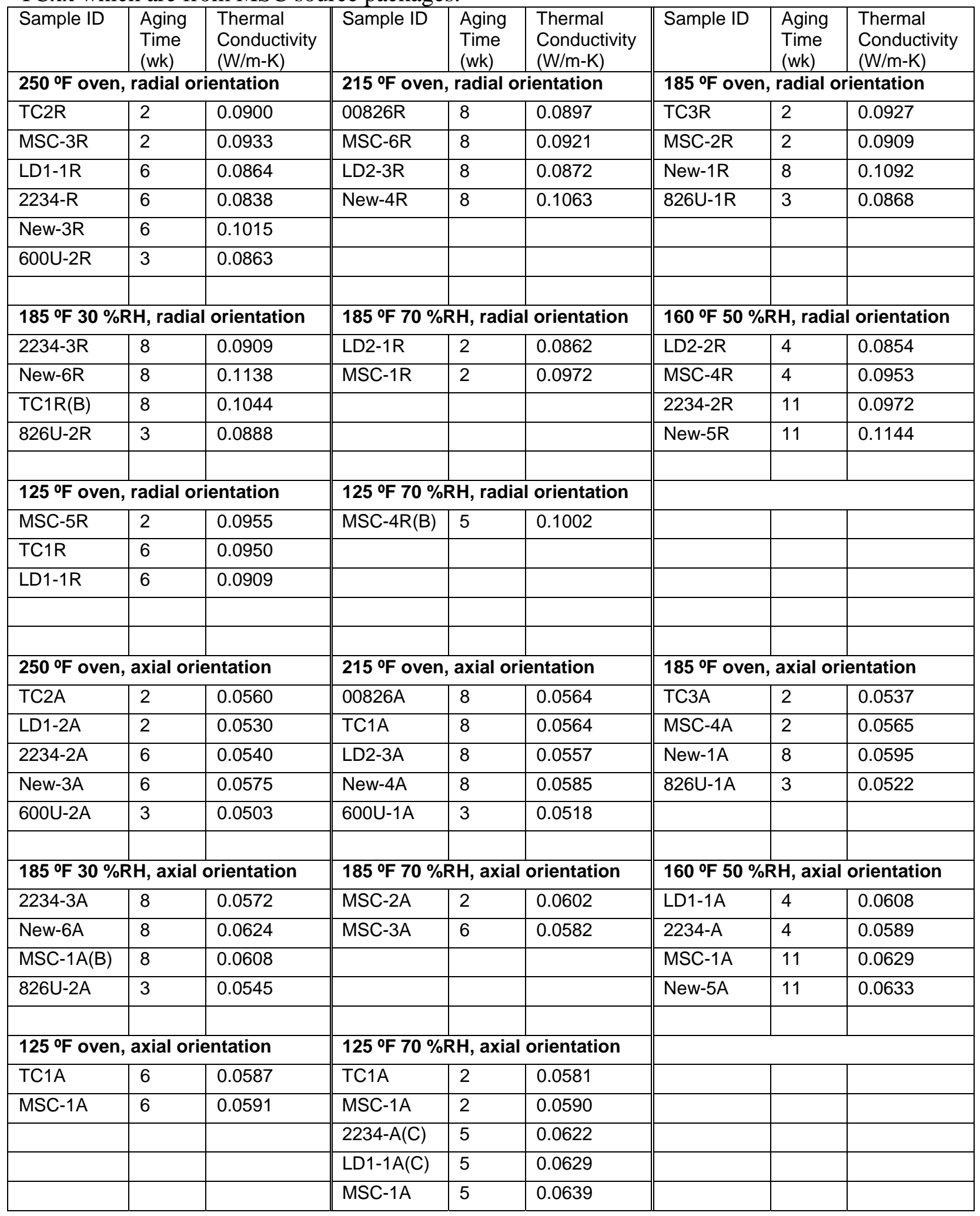


Rev. 0

Table 6. Summary of thermal and physical property changes upon termination of $250^{\circ} \mathrm{F}$ conditioning

\begin{tabular}{|l|l|l|}
\hline Property & $\begin{array}{l}\text { Duration of Conditioning at } \\
250^{\circ} \mathrm{F} \text {, at time of last test }\end{array}$ & $\begin{array}{l}\text { Final Property Value, } \\
\text { Normalized* }\end{array}$ \\
\hline Thermal cond. @ 25 ${ }^{\circ} \mathrm{C}$, radial & $199-255$ wks & $60.1-64.1 \%$ (4 samples) \\
\hline Thermal cond. @ 25 ${ }^{\circ} \mathrm{C}$, axial & $199-255$ wks & $72.2-73.8 \%$ (3 samples) \\
\hline Specific heat capacity @ 52 ${ }^{\circ} \mathrm{C}$ & 258 wks & $75.0 \% * *$ \\
\hline & & \\
\hline Physical properties (8 samples) & $225-275$ wks & $41.6-48.3 \%$ (weight) \\
\cline { 3 - 3 } & & $72.1-82.4 \%$ (height) \\
\cline { 2 - 3 } & & $68.0-76.8 \%$ (density) \\
\hline
\end{tabular}

* Values are reported as a percentage of the value measured after the first nominal conditioning period.

** Due to data scatter, this value is the average change based on a linear curve fit to all the data.

Table 7 Change in physical properties during initial transition to aging environment

\begin{tabular}{|c|c|c|c|c|}
\hline & \multicolumn{4}{|c|}{ Approximate initial change in } \\
\hline Environment & Weight & Density & Height & Length, Width \\
\hline $250^{\circ} \mathrm{F}$, dry oven & $8-10 \%$ decr & $3-6 \%$ decr & $2-3 \%$ decr & $0-2 \%$ decr \\
\hline $215^{\circ} \mathrm{F}$, dry oven & $7-9 \%$ decr & $3-6 \%$ decr & $0.5-3 \%$ decr & $0-2 \%$ decr \\
\hline $200^{\circ} \mathrm{F}$, dry oven & $7 \%$ decr & $5 \%$ decr & $2 \%$ decr & $<0.5 \%$ decr \\
\hline $185^{\circ} \mathrm{F}$, dry oven & $7-8 \%$ decr & $4-5 \%$ decr & $2-3 \%$ decr & $<1 \%(+$ and -$)$ \\
\hline $125^{\circ} \mathrm{F}$, dry oven & $5-6 \%$ decr & $3-4 \%$ decr & $1-2 \%$ decr & $<0.5 \%(+$ and -$)$ \\
\hline $50^{\circ} \mathrm{F}$, dry (desiccated) & $8 \%$ decr & $3-4 \%$ decr & $2-3 \%$ decr & $<1 \%$ decr \\
\hline $15^{\circ} \mathrm{F}$, dry (desiccated) & $6 \%$ decr & $2-3 \%$ decr & $2 \%$ decr & $<0.5 \%$ decr \\
\hline $185^{\circ} \mathrm{F}, 70 \% \mathrm{RH}$ & $<1 \%(+$ and -$)$ & $2-6 \%$ decr & $1-3 \%$ incr & $<1 \%(+$ and -$)$ \\
\hline $185^{\circ} \mathrm{F}, 30 \% \mathrm{RH}$ & $4-5 \%$ decr & $2-3 \%$ decr & $1-2 \%$ decr & $<0.5 \%$ decr \\
\hline $160^{\circ} \mathrm{F}, 50 \% \mathrm{RH}$ & $<1 \%(+$ and -$)$ & $\begin{array}{l}3 \% \text { decr }-2 \% \\
\text { incr }\end{array}$ & $<1 \%(+$ and -$)$ & $\begin{array}{l}<0.5 \% \text { decr }- \\
<1 \% \text { incr }\end{array}$ \\
\hline $50^{\circ} \mathrm{F}, \sim 10 \% \mathrm{RH}$ & $4 \%$ decr & $2-3 \%$ decr & $1-2 \%$ decr & $<0.5 \%(+$ and -$)$ \\
\hline $15^{\circ} \mathrm{F}, \sim 60 \% \mathrm{RH}$ & $<1 \%$ incr & $1 \%(+$ and -$)$ & $1-2 \%$ decr & $<0.5 \%(+$ and -$)$ \\
\hline
\end{tabular}


Rev. 0

Table 8. Comparison of weight changes for physical property and thermal conductivity samples (averaged over all samples in each environment) to model predictions

Average Slope from Actual

Data $(\% / y r)$

\begin{tabular}{|l|c|c|c|}
\hline Environment & $\begin{array}{l}\text { Model } \\
\text { Prediction } \\
(\% / y r)\end{array}$ & $\begin{array}{l}\text { Physical Prop. } \\
\text { Samples data } \\
\text { through 9-12 }\end{array}$ & $\begin{array}{c}\text { Thermal } \\
\text { Conductivity } \\
\text { Samples }\end{array}$ \\
\hline & & & \\
\hline $125^{\circ} \mathrm{F}$ dry (5\%) & $<-0.3$ & -0.30 & -0.17 \\
\hline $185^{\circ} \mathrm{F}$ dry (2\%) & -1.4 & -1.04 & -0.92 \\
\hline $215^{\circ} \mathrm{F}$ dry (1\%) & -3.5 & -3.35 & -2.93 \\
\hline $250^{\circ} \mathrm{F}$ dry (1\%) & -10 & -12.47 & -14.2 \\
\hline & & & $\mathrm{NA}$ \\
\hline $15^{\circ} \mathrm{F} 60 \%$ & 0 & +0.02 & $\mathrm{NA}$ \\
\hline $50^{\circ} \mathrm{F} 10 \%$ & 0 & -0.13 & -0.17 \\
\hline $125^{\circ} \mathrm{F} \mathrm{70 \%}$ & -0.5 & -0.38 & -2.69 \\
\hline $160^{\circ} \mathrm{F} 50 \%$ & -3.3 & -3.62 & -3.74 \\
\hline $185^{\circ} \mathrm{F} 30 \%$ & -3.8 & -3.99 & -21.62 \\
\hline $185^{\circ} \mathrm{F} 70 \%$ & -24 & -33.16 & \\
\hline
\end{tabular}

Table 9. Compression stress-strain data used in the forklift impact calculation [6]

\begin{tabular}{|c|c|c|c|c|}
\hline True strain $^{1}$ & $\begin{array}{l}\text { True stress } \\
(\mathrm{psi})^{2}\end{array}$ & $\begin{array}{l}\text { Engineering } \\
\text { strain }^{3}\end{array}$ & $\begin{array}{l}\text { Engineering } \\
\text { stress (psi) }^{3}\end{array}$ \\
\hline 0.000 & 0 & & 0.000 & 0 \\
\hline-0.001 & 25 & & -0.001 & 25 \\
\hline-0.057 & 35 & & -0.055 & 35 \\
\hline-0.115 & 61 & & -0.109 & 61 \\
\hline-0.178 & 89 & & -0.163 & 89 \\
\hline-0.246 & 124 & & -0.218 & 124 \\
\hline-0.318 & 171 & & -0.272 & 171 \\
\hline-0.399 & 238 & & -0.329 & 238 \\
\hline-0.477 & 323 & & -0.380 & 323 \\
\hline$-0.514^{4}$ & 363 & & -0.400 & 363 \\
\hline-0.574 & 454 & & -0.437 & 454 \\
\hline-0.681 & 643 & & -0.494 & 643 \\
\hline-0.793 & 905 & & -0.548 & 905 \\
\hline-0.923 & 1327 & & -0.603 & 1327 \\
\hline-1.055 & 1978 & & -0.652 & 1978 \\
\hline-1.232 & 3312 & & -0.708 & 3312 \\
\hline-1.309 & 4200 & & -0.730 & 4200 \\
\hline-1.386 & 5327 & & -0.750 & 5327 \\
\hline
\end{tabular}

1. True strain $(\varepsilon)$ is converted from engineering strain (e) by: $\varepsilon=\ln (1+\mathrm{e})$

2. True stress $(\sigma)$ is numerically equal to engineering stress (s) since the material compresses with essentially no change in cross section area.

3. Engineering stress and strain values are generated by the control computer during testing.

4. These values (corresponding to an engineering strain of $40 \%$ ) were not used in the forklift impact calculation, but have been added to the table for reference. 
Rev. 0

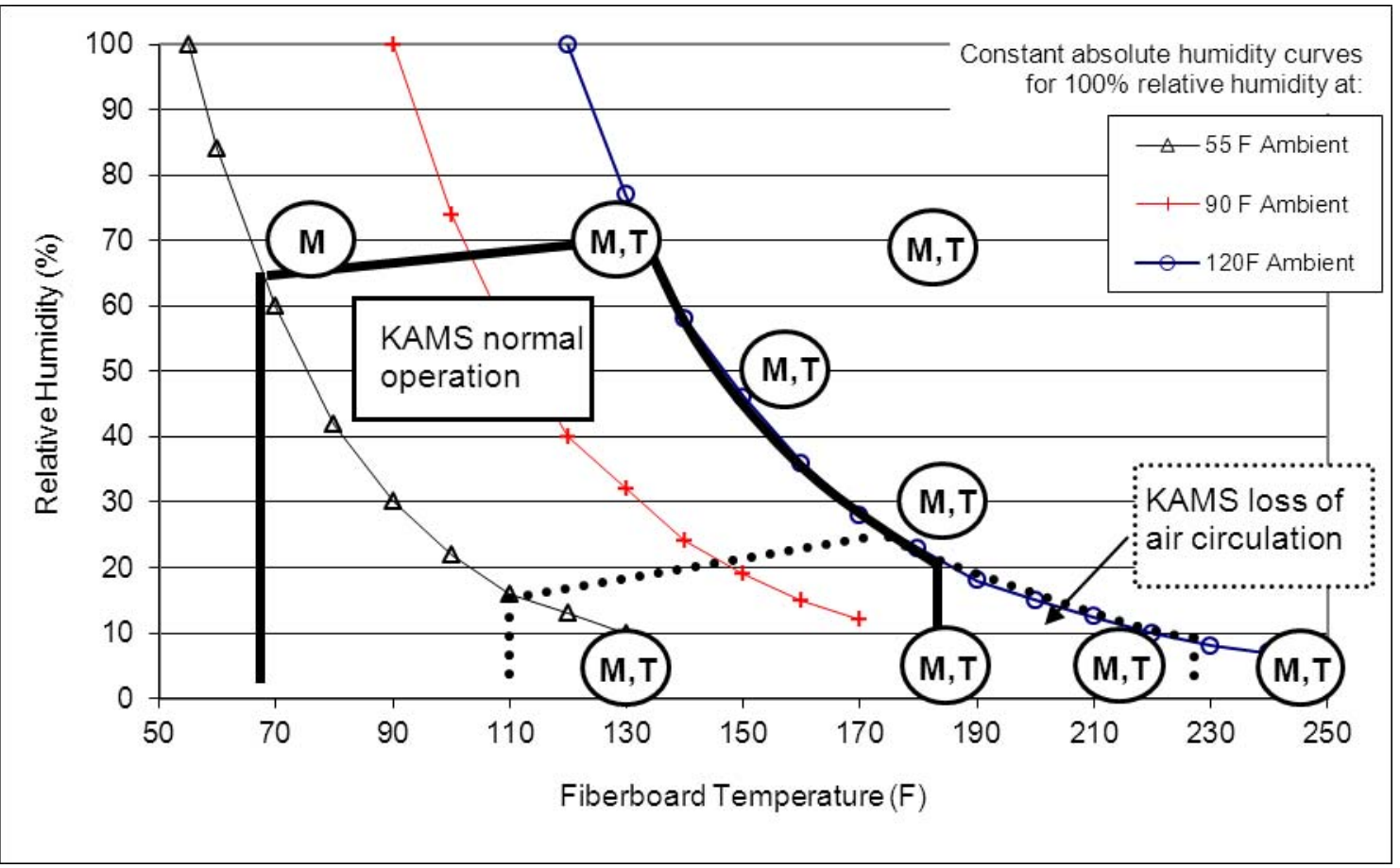

Figure 1. Bounding estimate of the range of environments which fiberboard in KAMS can experience under normal operation and under loss of air circulation (both ventilation and natural convection). Also shown are the environments for longer-term aging and testing (circles). "M" denotes mechanical testing. "T" denotes thermal and physical property testing. Physical property testing (only) has also been conducted following aging at 15 and $50^{\circ} \mathrm{F}$. 
Rev. 0

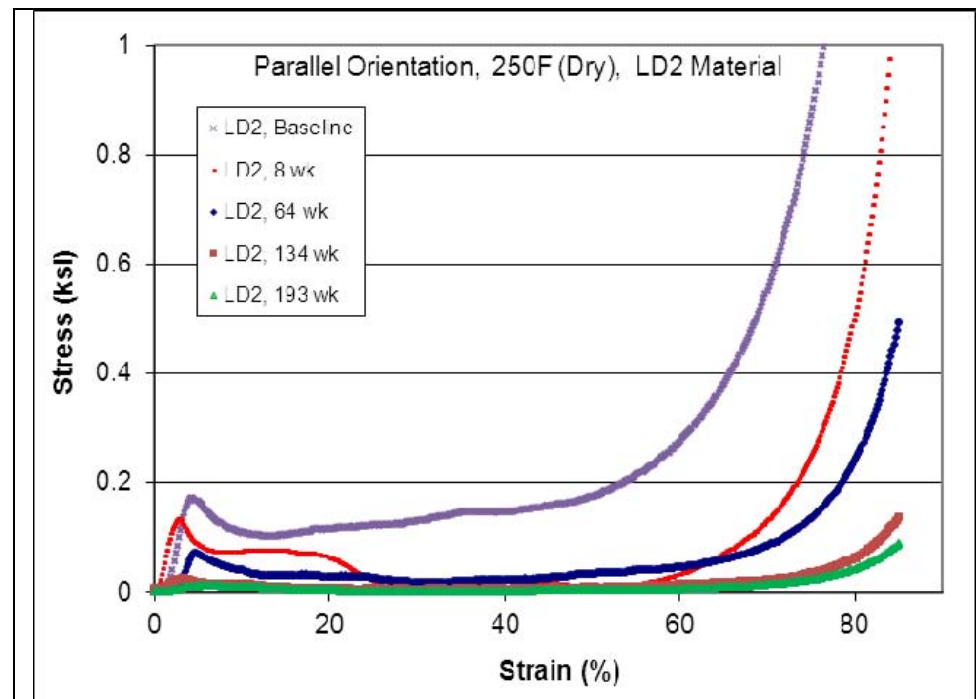

(a) LD2 material, parallel orientation

\begin{tabular}{|l|l|l|}
\hline $\begin{array}{l}\text { Conditioning } \\
\text { Period (wks) }\end{array}$ & $\begin{array}{l}\text { Buckling } \\
\text { Strength } \\
\text { (ksi) }\end{array}$ & $\begin{array}{l}\text { Area under } \\
\text { Curve to 40\% } \\
\text { Strain (ksi) }\end{array}$ \\
\hline 0 & 0.171 & 0.0476 \\
\hline 8 & 0.132 & 0.0199 \\
\hline 64 & 0.071 & 0.0110 \\
\hline 134 & 0.024 & 0.0034 \\
\hline 193 & 0.012 & 0.0018 \\
\hline
\end{tabular}

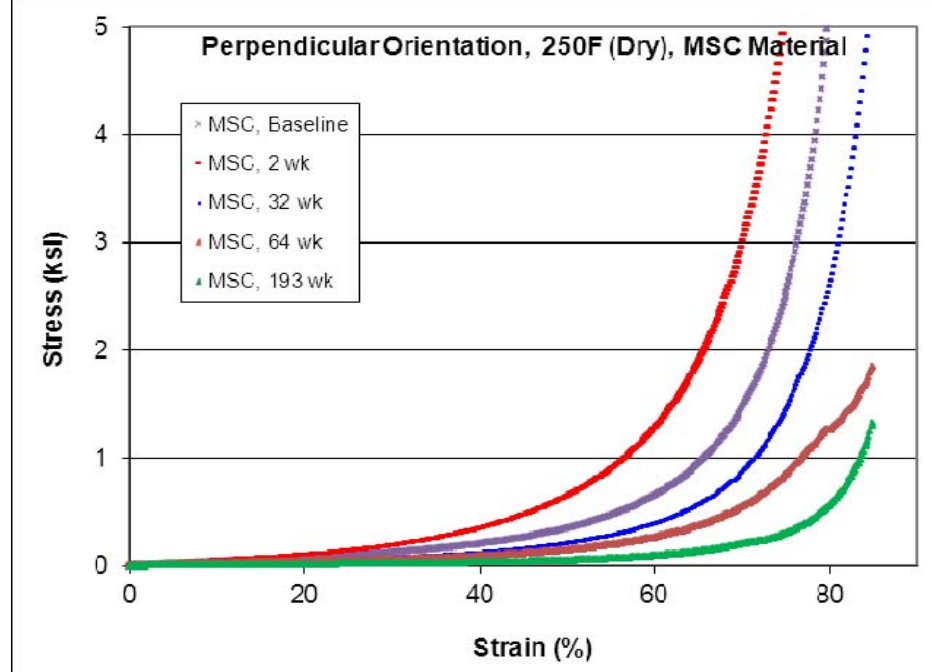

(b) MSC material, perpendicular orientation

\begin{tabular}{|l|l|}
\hline $\begin{array}{l}\text { Conditioning } \\
\text { Period (wks) }\end{array}$ & $\begin{array}{l}\text { Area under Curve to 40\% } \\
\text { Strain (ksi) }\end{array}$ \\
\hline 0 & 0.0338 \\
\hline 2 & 0.0522 \\
\hline 32 & 0.0205 \\
\hline 64 & 0.0160 \\
\hline 193 & 0.0050 \\
\hline & \\
&
\end{tabular}

Figure 2. Engineering stress-strain compression curves for select fiberboard samples conditioned and tested at $250{ }^{\circ} \mathrm{F}$ 
Rev. 0

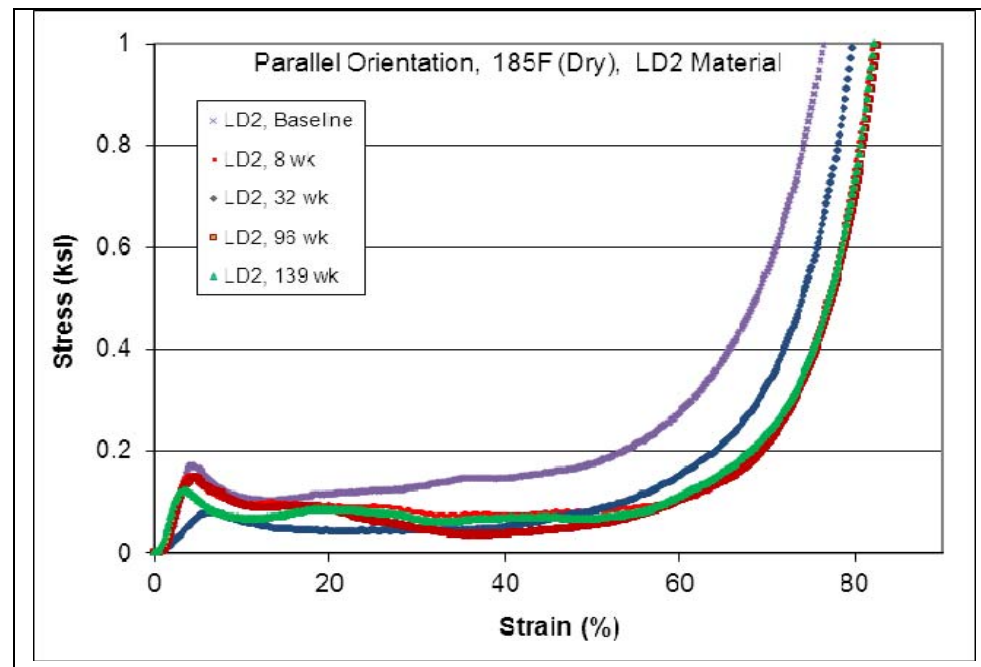

(a) LD2 material, parallel orientation

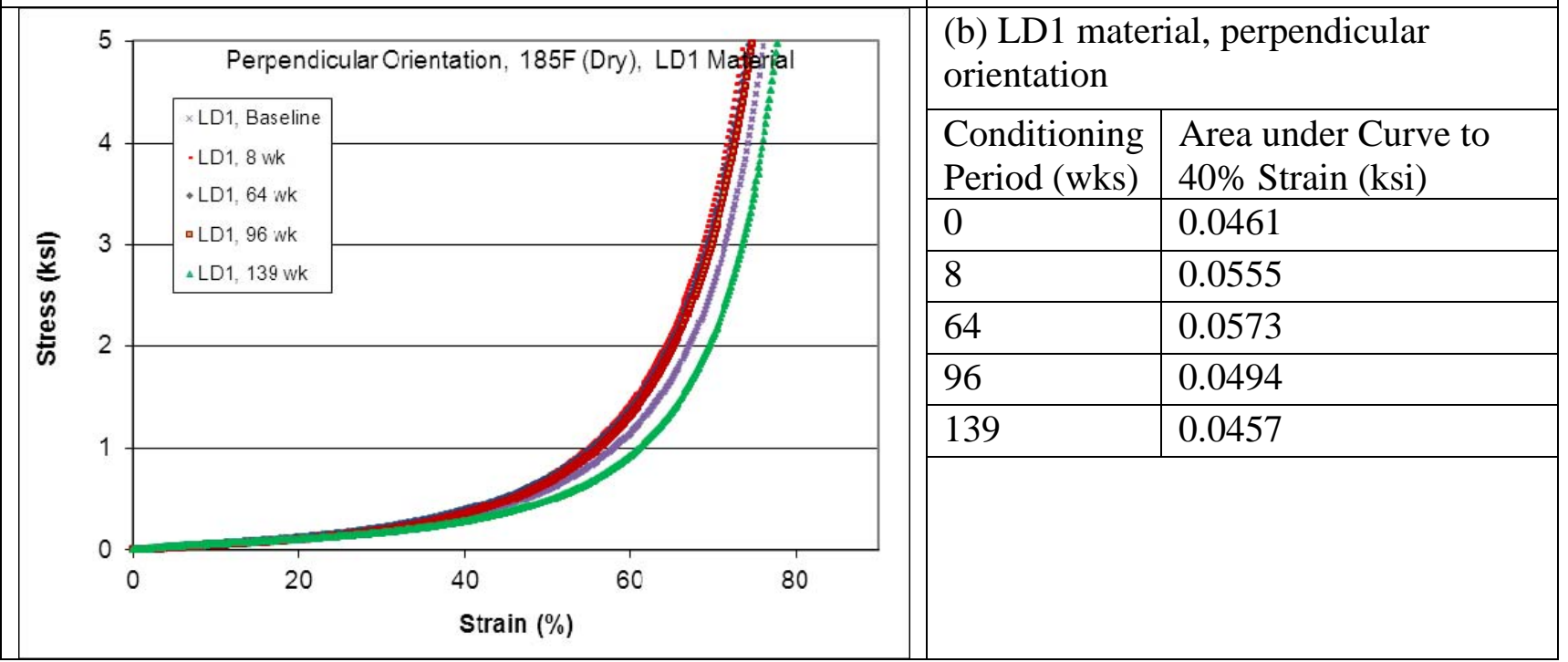

Figure 3. Engineering stress-strain compression curves for select fiberboard samples conditioned and tested at $185^{\circ} \mathrm{F}$ 


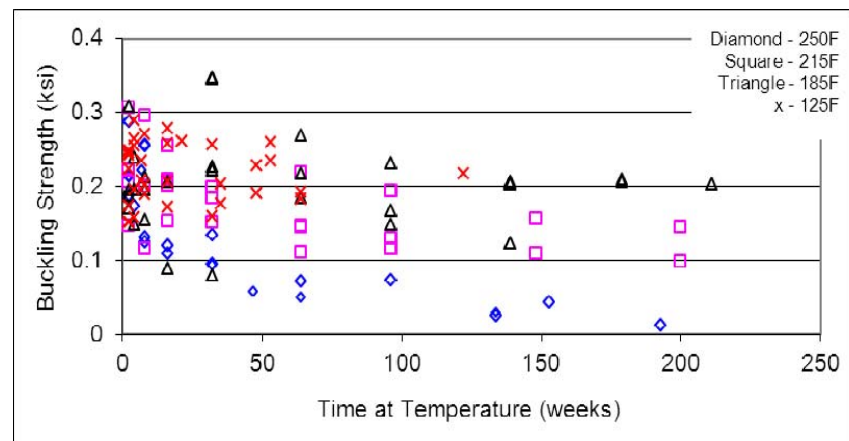

(a)

Figure 4. Buckling strength (ksi) for compression samp were conditioned in dry environments, at the temperatures noted. Samples in (b) were conditioned at $185^{\circ} \mathrm{F}$, at the humidity levels noted.

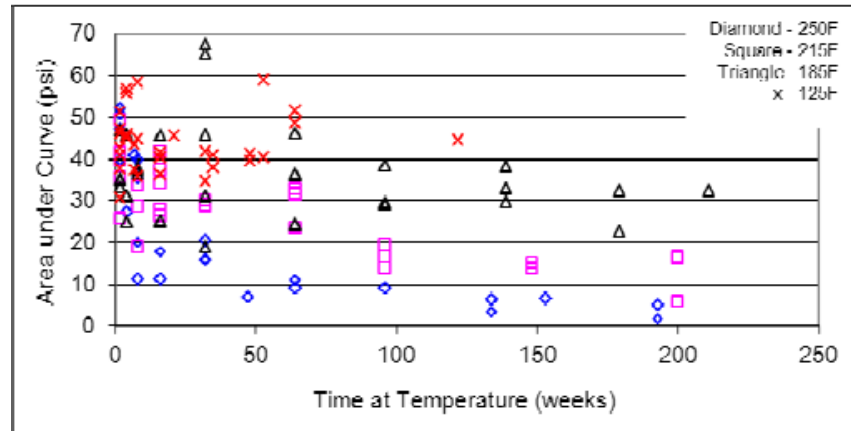

(a)

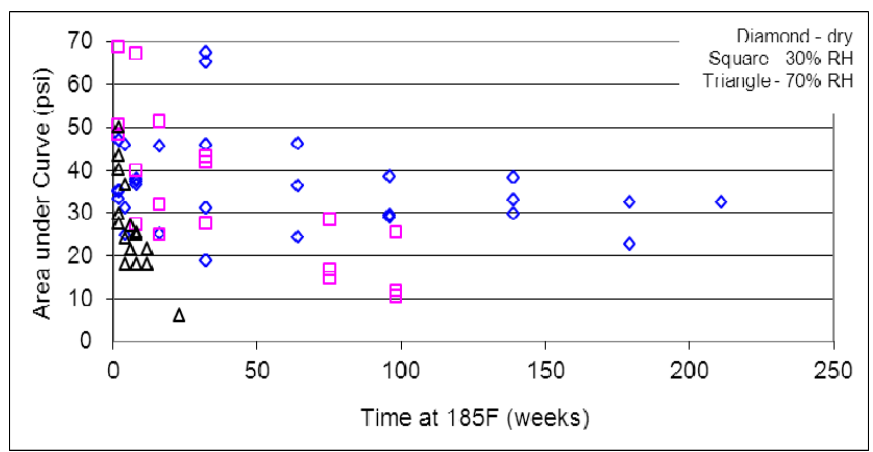

(b)

Figure 5. Area under the stress-strain curve up to $40 \%$ strain, for parallel orientation samples. Samples in (a) were conditioned in dry environments, at the temperatures noted. Samples in (b) were conditioned at $185^{\circ} \mathrm{F}$, at the humidity levels noted.

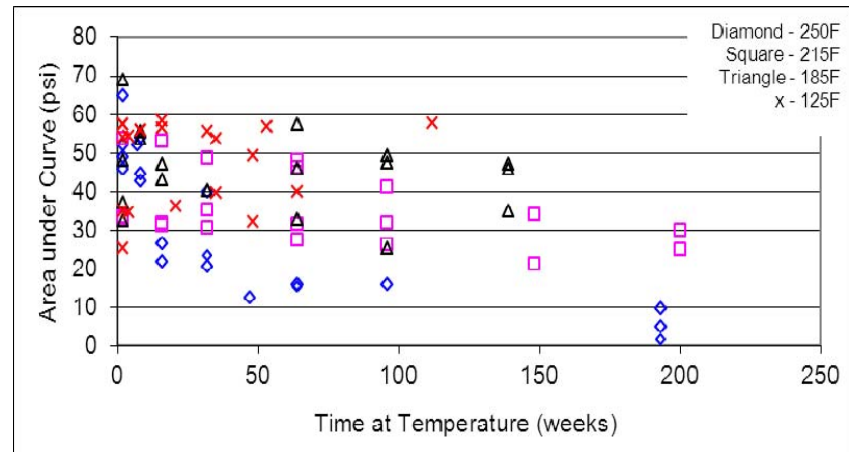

(a)

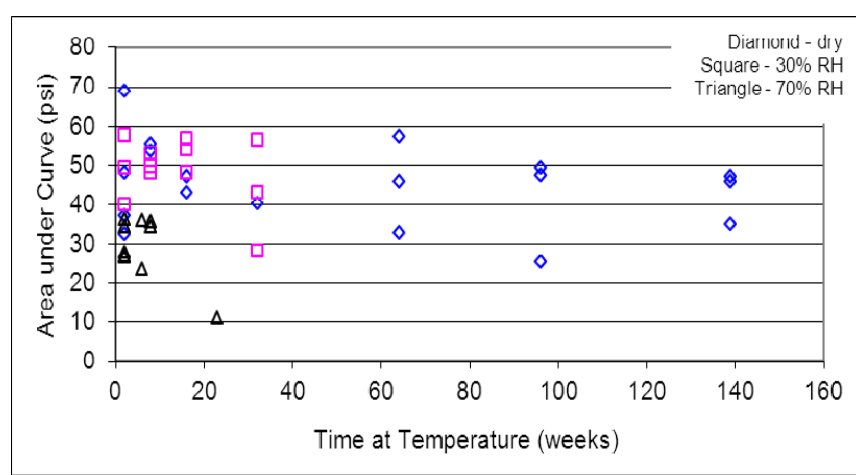

(b)

Figure 6. Area under the stress-strain curve up to $40 \%$ strain, for perpendicular orientation samples. Samples in (a) were conditioned in dry environments, at the temperatures noted. Samples in (b) were conditioned at $185^{\circ} \mathrm{F}$, at the humidity levels noted. 
Rev. 0

(a)

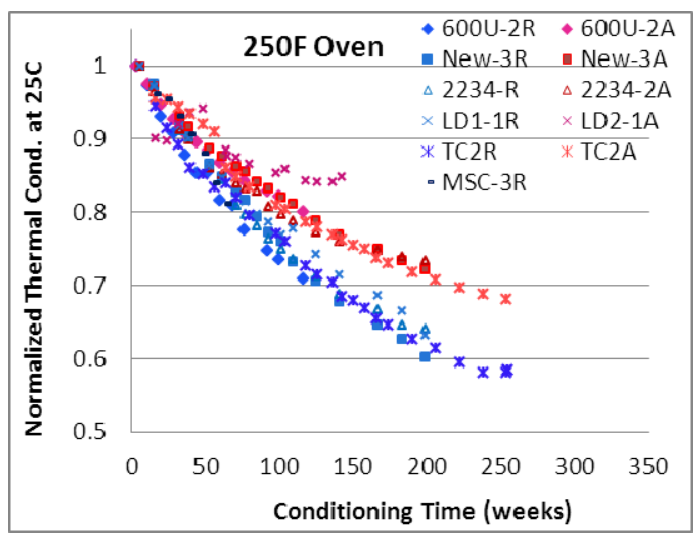

(c)

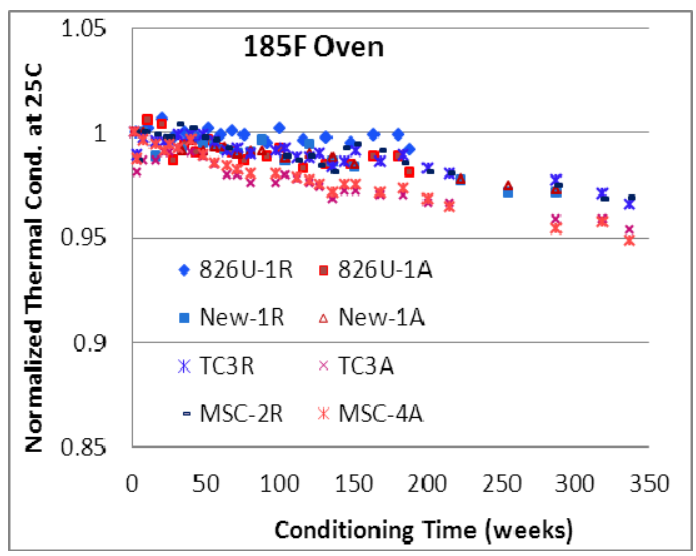

(b)
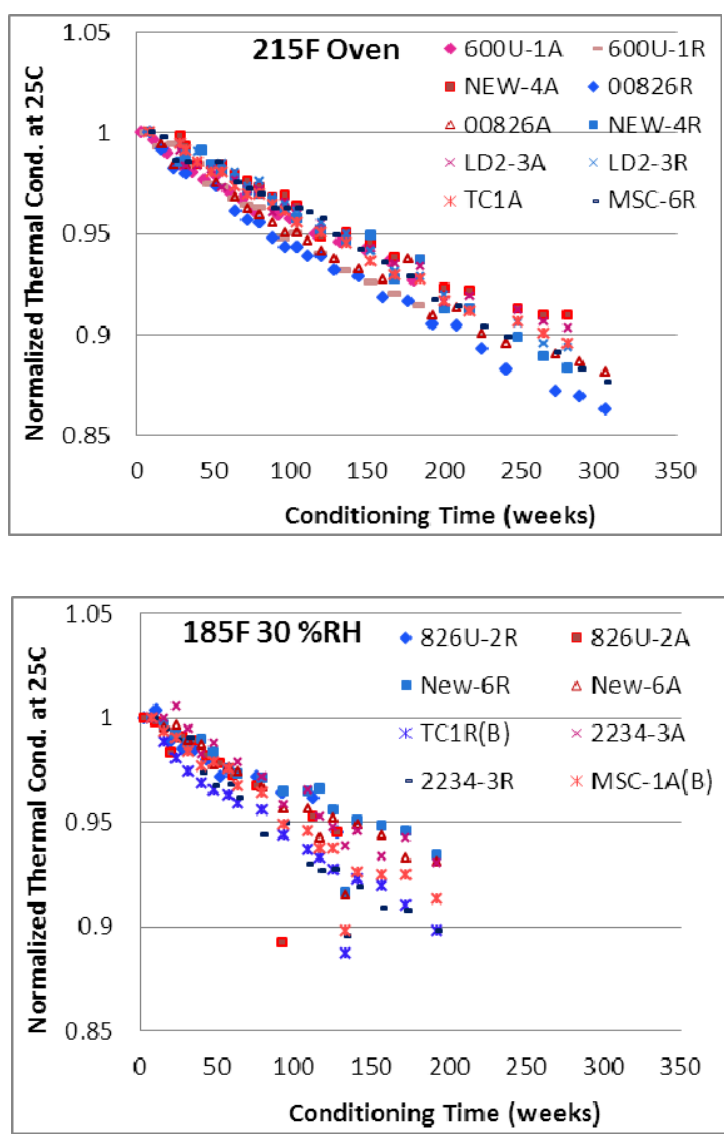

(d)

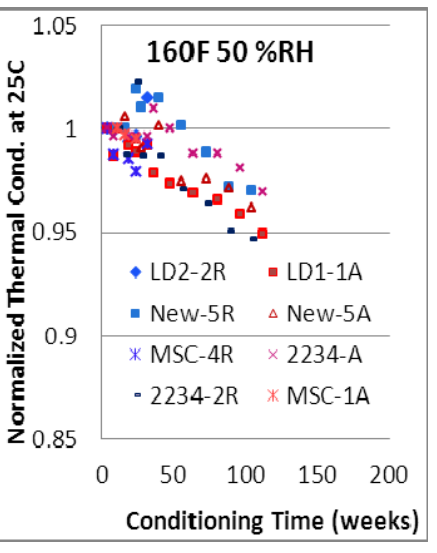

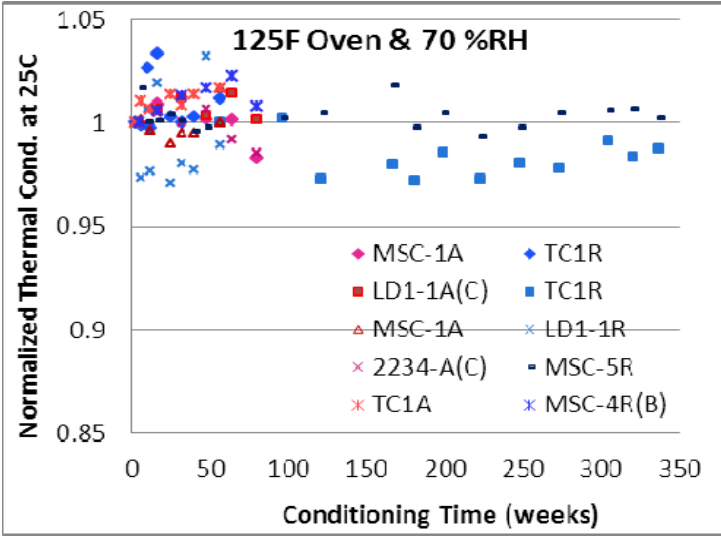

(e)

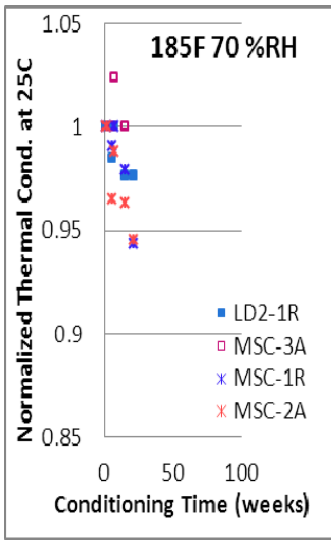

(f)

(g)

Figure 7. Thermal conductivity data measured at $25^{\circ} \mathrm{C}\left(77^{\circ} \mathrm{F}\right)$ mean temperature for each conditioning environment as noted. Data for each sample are normalized to the first conditioned value. The first conditioned value for each sample is identified in Table 5. Axial orientation samples are shown in red, and radial orientation samples are shown in blue. 
Rev. 0

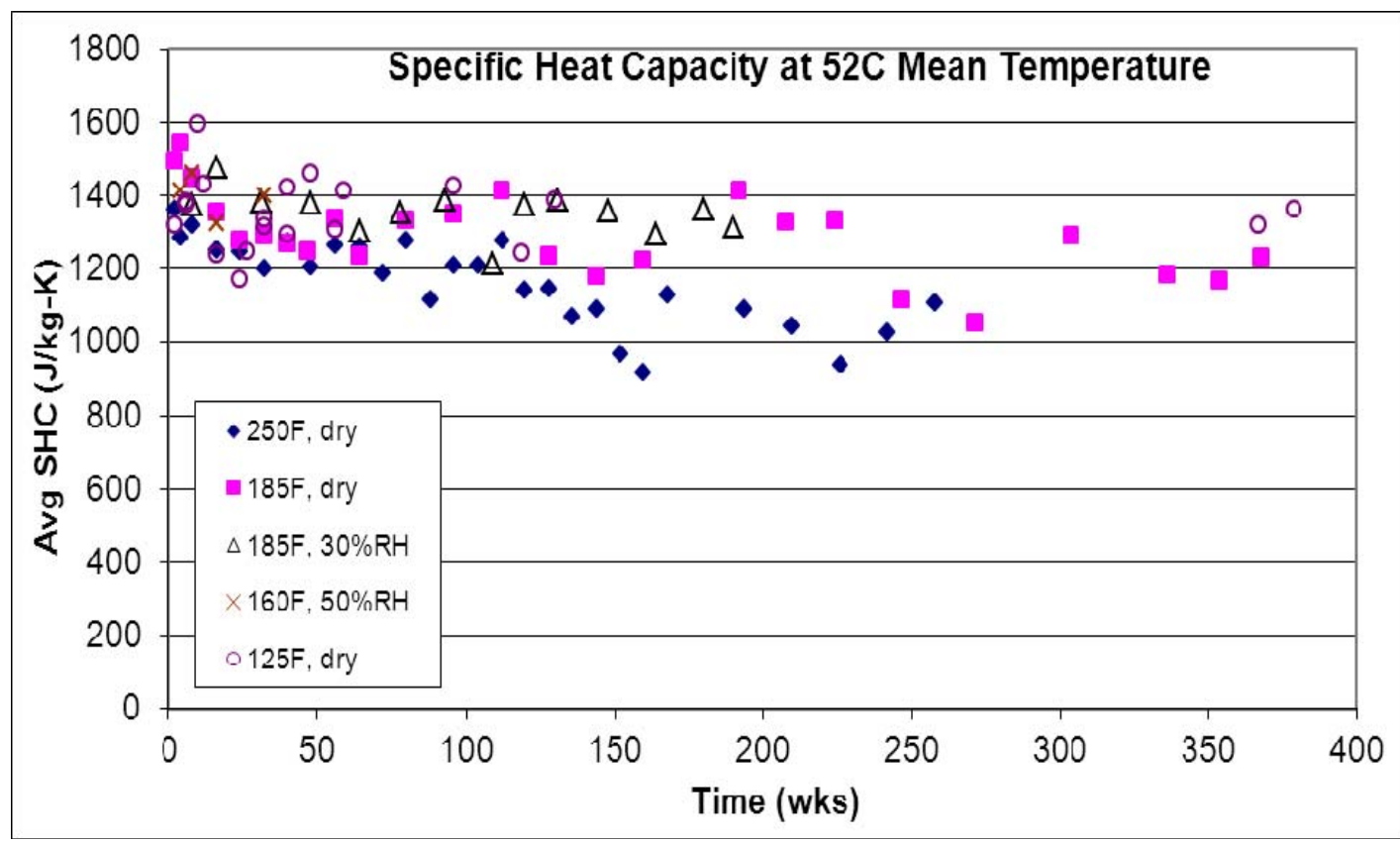

Figure 8. Specific heat capacity data at a mean temperature of $52{ }^{\circ} \mathrm{C}\left(125^{\circ} \mathrm{F}\right)$ for each conditioning environment. A linear fit to the data for each environment produces the following trends:

$250{ }^{\circ} \mathrm{F}$, dry $\quad$ SHC $(\mathrm{J} / \mathrm{kg}-\mathrm{K})=1299.4-1.263 *$ time (weeks)

$185^{\circ} \mathrm{F}$, dry $\quad \mathrm{SHC}(\mathrm{J} / \mathrm{kg}-\mathrm{K})=1373.6-0.567 *$ time (weeks)

$125^{\circ} \mathrm{F}$, dry $\quad$ SHC $(\mathrm{J} / \mathrm{kg}-\mathrm{K})=1355.6-0.047 *$ time (weeks)

$185^{\circ} \mathrm{F}, 30 \% \mathrm{RH} \quad \mathrm{SHC}(\mathrm{J} / \mathrm{kg}-\mathrm{K})=1396.1-0.422 *$ time (weeks)

$160{ }^{\circ} \mathrm{F}, 50 \% \mathrm{RH} \quad \mathrm{SHC}(\mathrm{J} / \mathrm{kg}-\mathrm{K})=1421.3-1.450 *$ time (weeks) 
Rev. 0

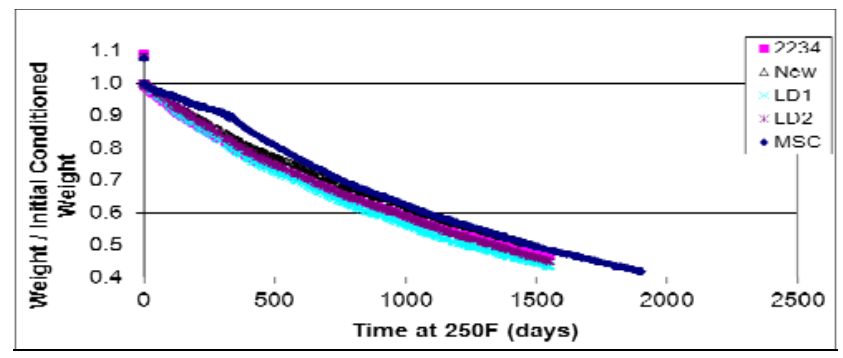

(a) $250^{\circ} \mathrm{F}$, dry

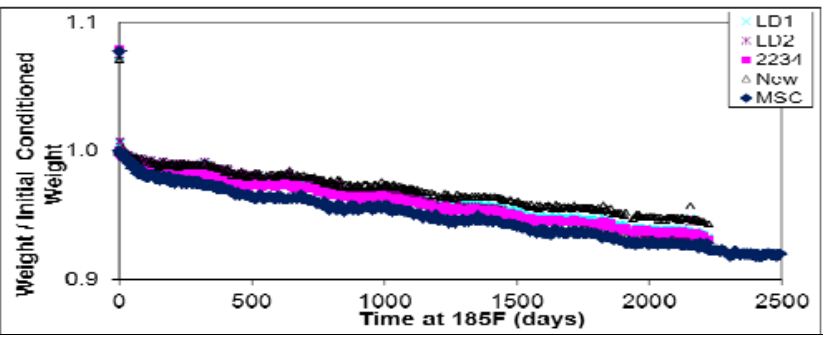

(c) $185^{\circ} \mathrm{F}$, dry

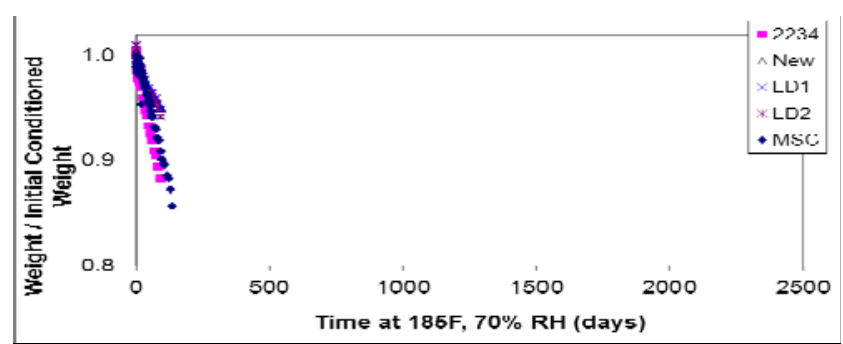

(e) $185^{\circ} \mathrm{F}, 70 \% \mathrm{RH}$

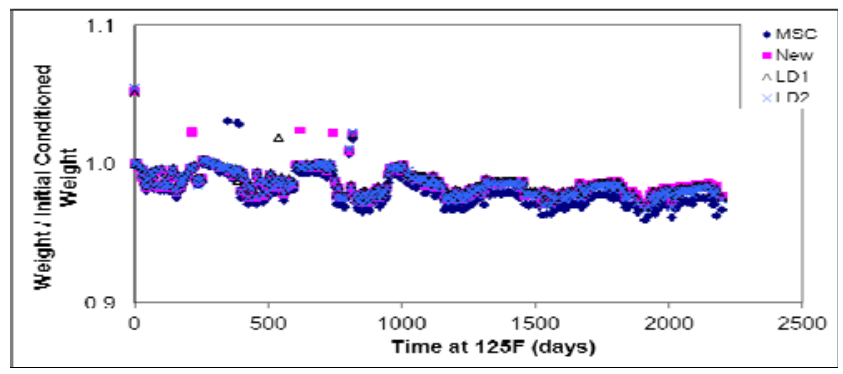

(g) $125^{\circ} \mathrm{F}$, dry

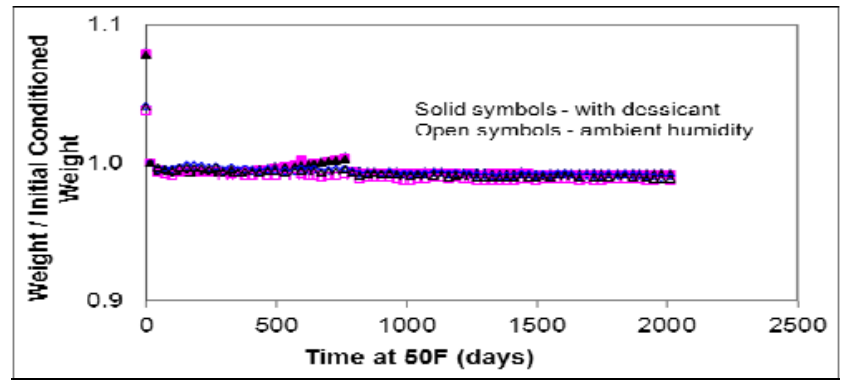

(i) $50{ }^{\circ} \mathrm{F}$

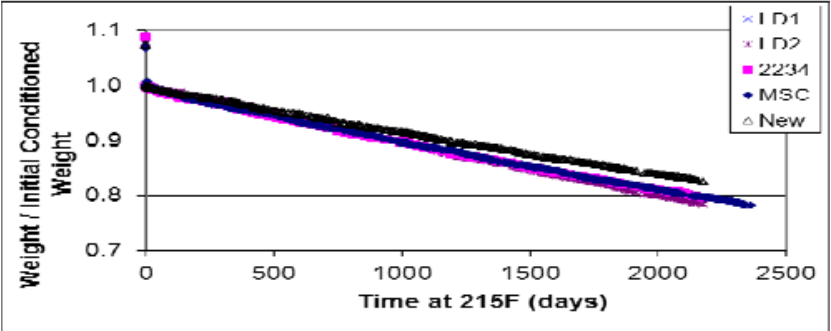

(b) $215^{\circ} \mathrm{F}$, dry

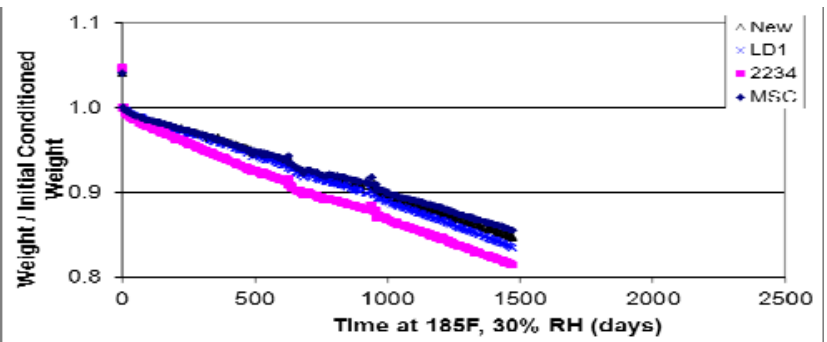

(e) $185^{\circ} \mathrm{F}, 30 \% \mathrm{RH}$

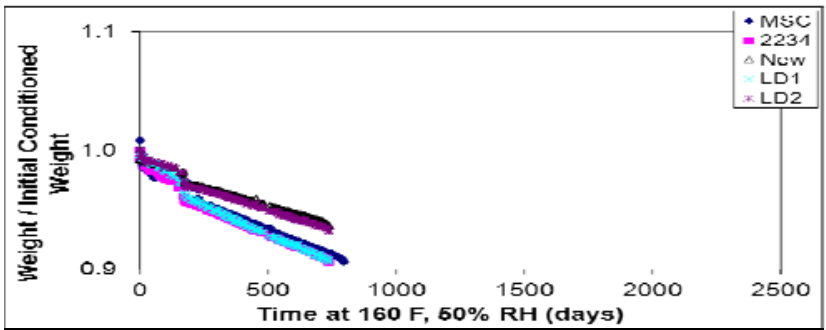

(f) $160{ }^{\circ} \mathrm{F}, 50 \% \mathrm{RH}$

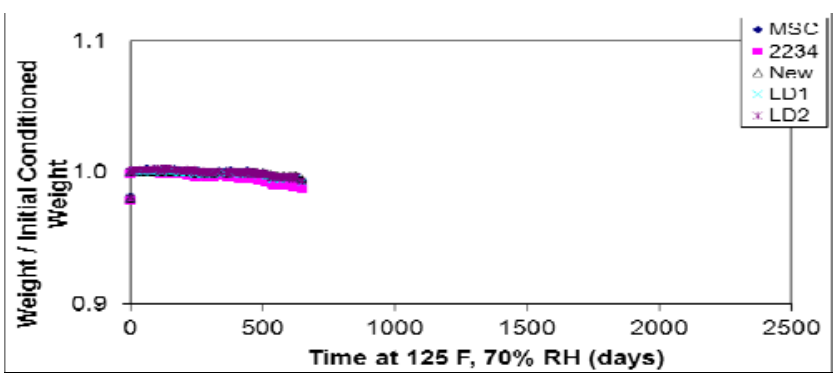

(h) $125^{\circ} \mathrm{F}, 70 \% \mathrm{RH}$

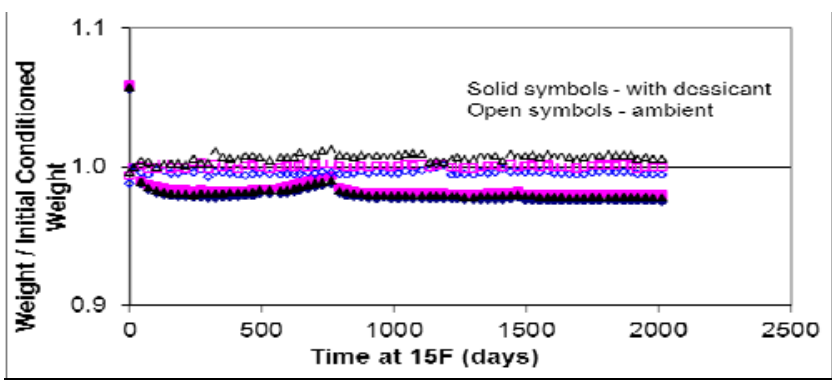

(j) $15^{\circ} \mathrm{F}$

Figure 9. Weight data for physical property samples in the identified environments. 
Rev. 0

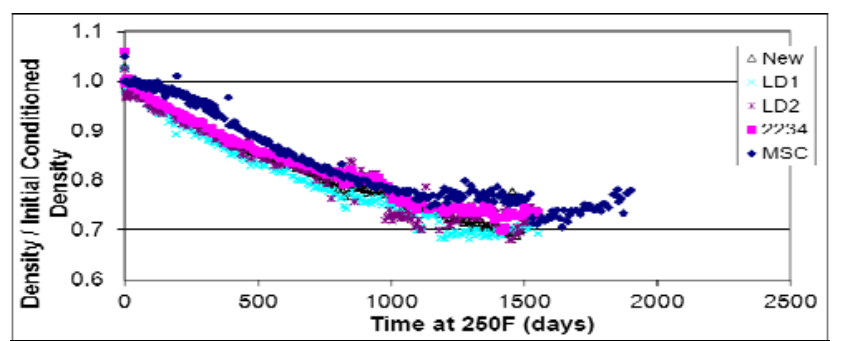

(a) $250^{\circ} \mathrm{F}$, dry

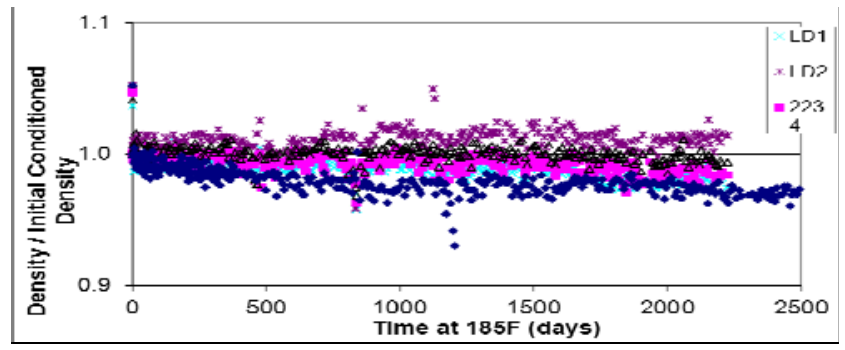

(c) $185^{\circ} \mathrm{F}$, dry

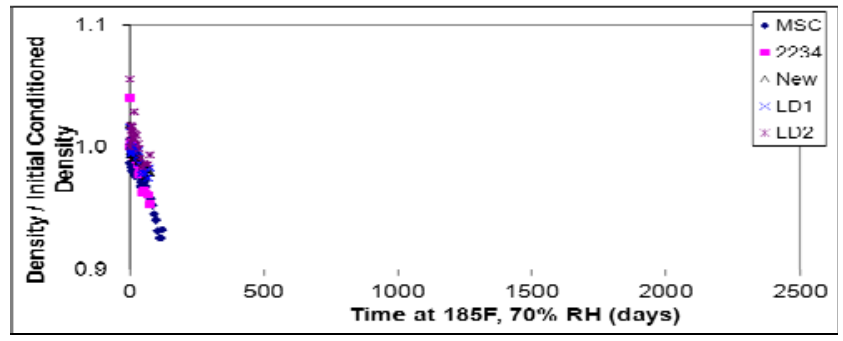

(e) $185^{\circ} \mathrm{F}, 70 \% \mathrm{RH}$

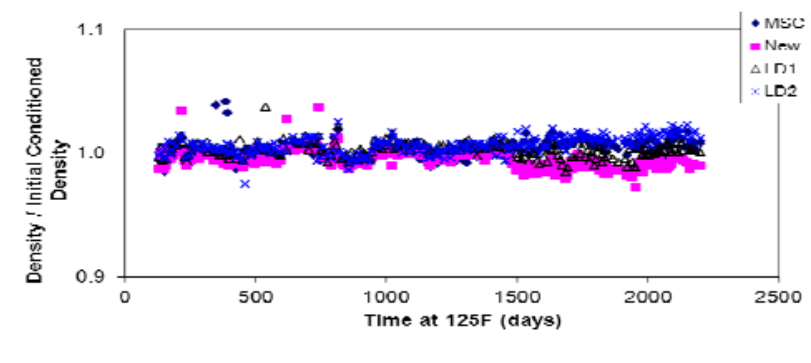

(g) $125^{\circ} \mathrm{F}$, dry

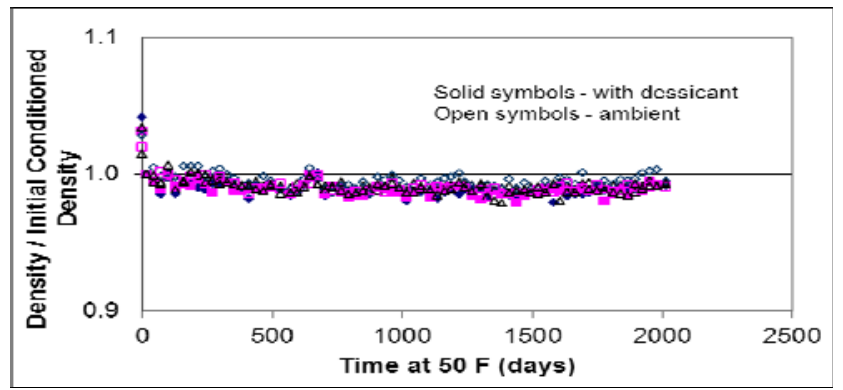

(i) $50^{\circ} \mathrm{F}$

Figure 10. Density data for physical property samples in the identified environments

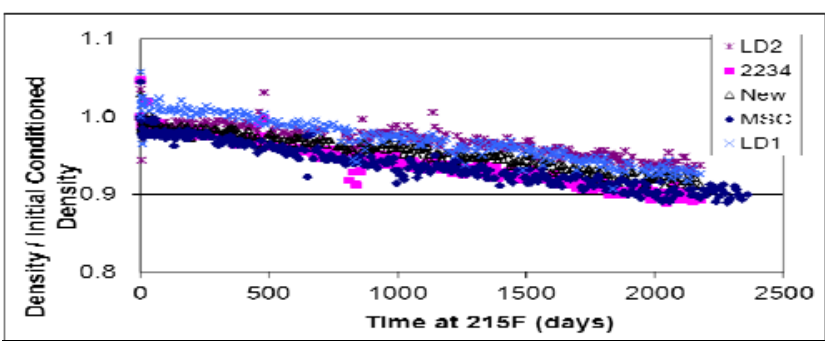

(b) $215^{\circ} \mathrm{F}$, dry

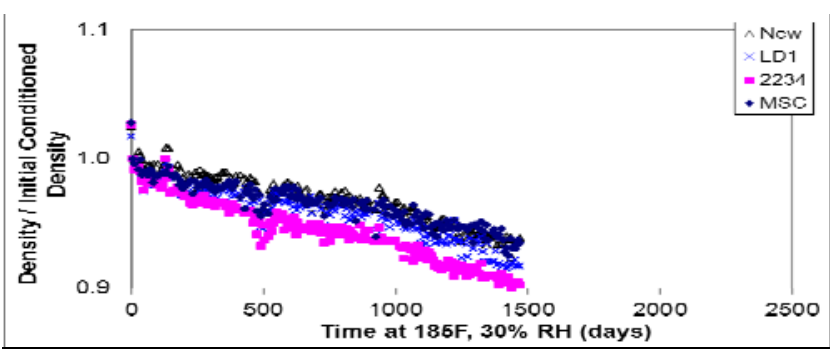

(e) $185^{\circ} \mathrm{F}, 30 \% \mathrm{RH}$

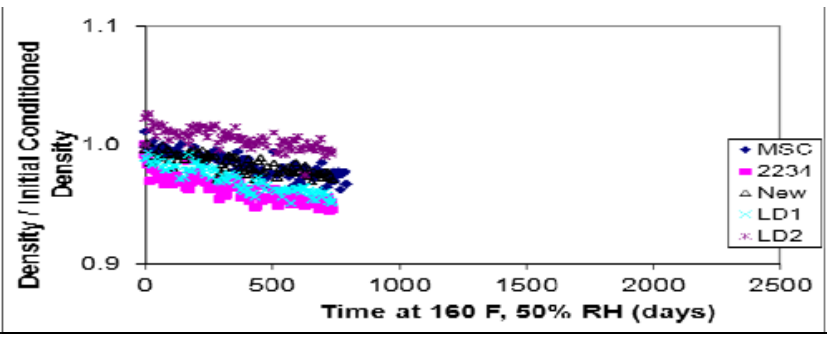

(f) $160^{\circ} \mathrm{F}, 50 \% \mathrm{RH}$

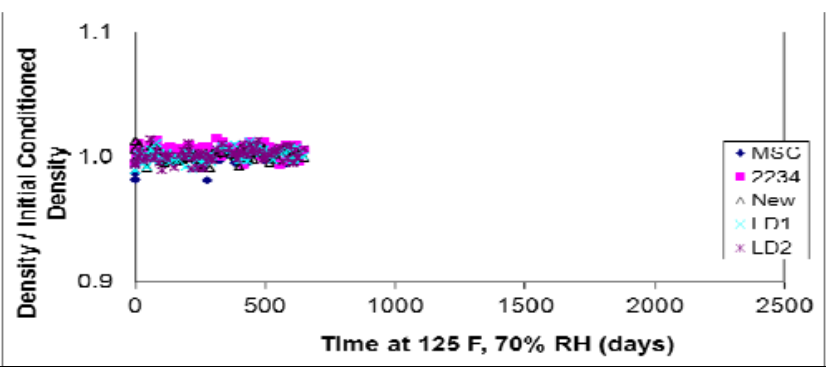

(h) $125^{\circ} \mathrm{F}, 70 \% \mathrm{RH}$

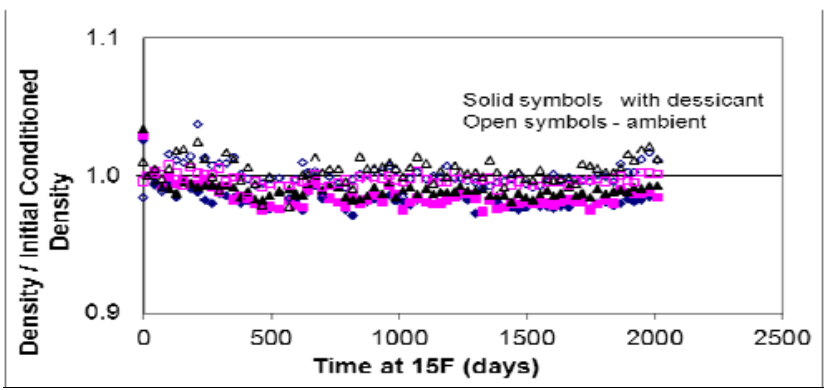

(j) $15^{\circ} \mathrm{F}$ 
Rev. 0

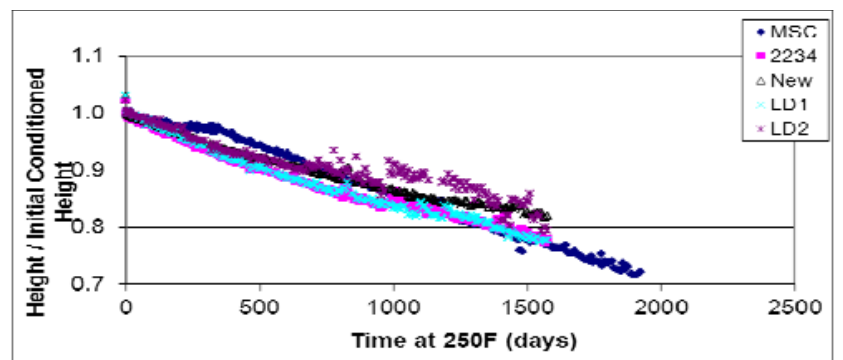

(a) $250^{\circ} \mathrm{F}$, dry

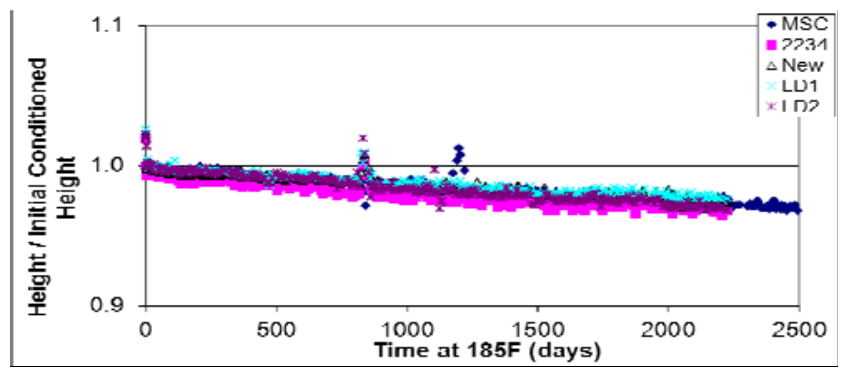

(c) $185^{\circ} \mathrm{F}$, dry

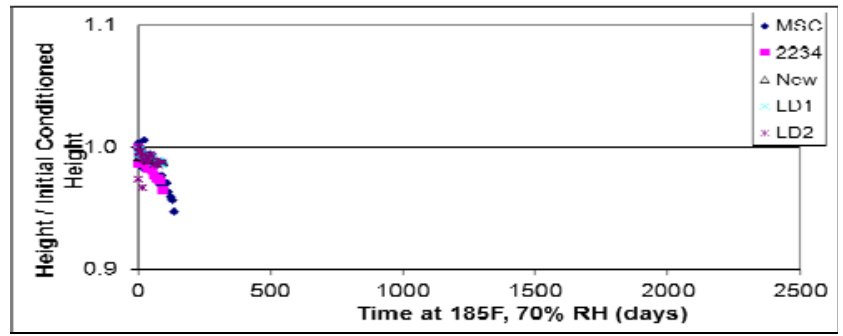

(e) $185^{\circ} \mathrm{F}, 70 \% \mathrm{RH}$

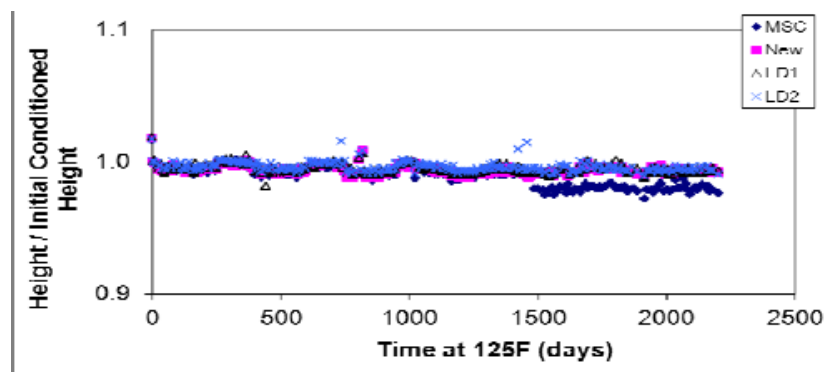

(g) $125^{\circ} \mathrm{F}$, dry

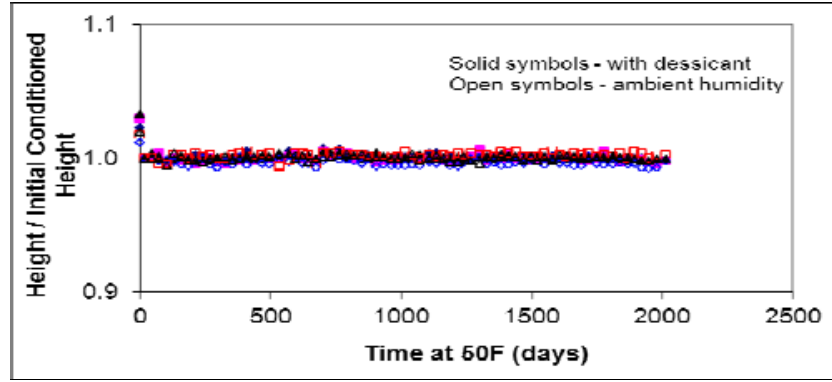

(i) $50{ }^{\circ} \mathrm{F}$

Figure 11. Height data for physical property samples in the identified environments

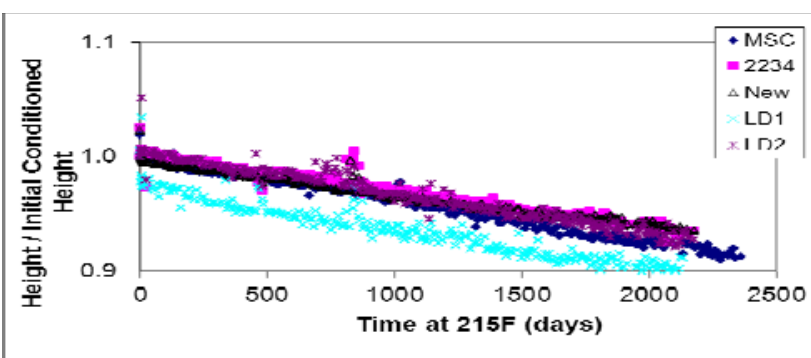

(b) $215^{\circ} \mathrm{F}$, dry

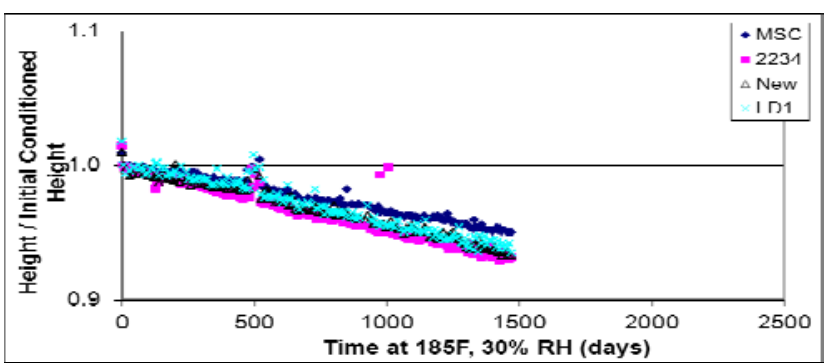

(e) $185^{\circ} \mathrm{F}, 30 \% \mathrm{RH}$

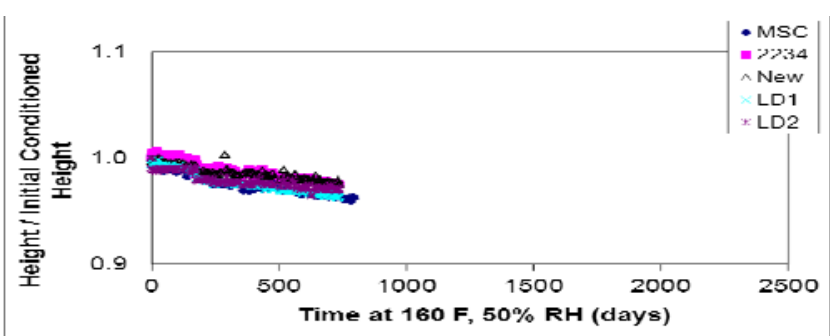

(f) $160{ }^{\circ} \mathrm{F}, 50 \% \mathrm{RH}$

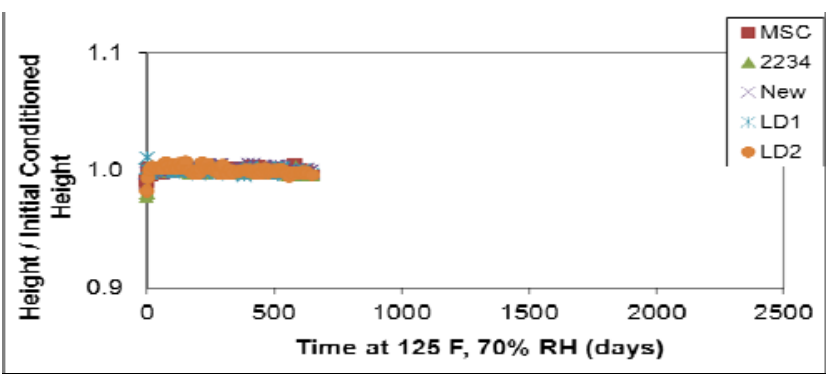

(h) $125^{\circ} \mathrm{F}, 70 \% \mathrm{RH}$

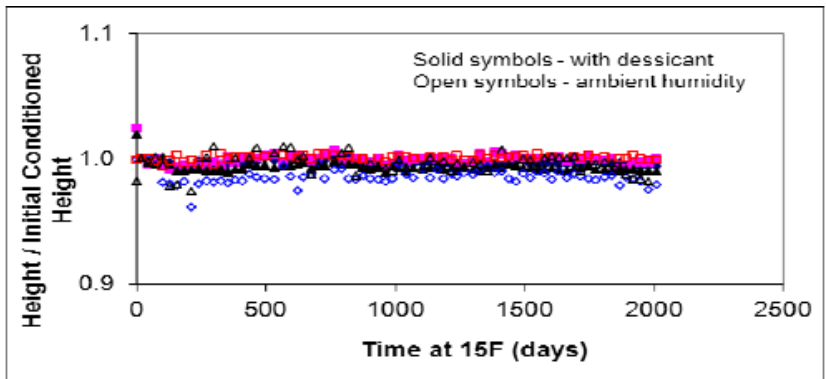

(j) $15^{\circ} \mathrm{F}$ 
Rev. 0

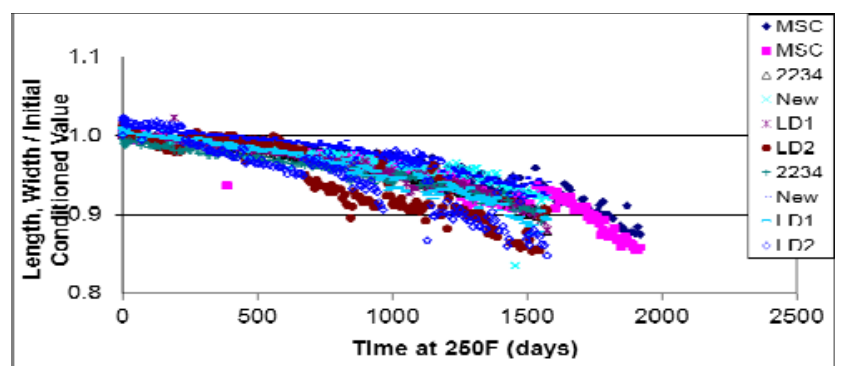

(a) $250^{\circ} \mathrm{F}$, dry

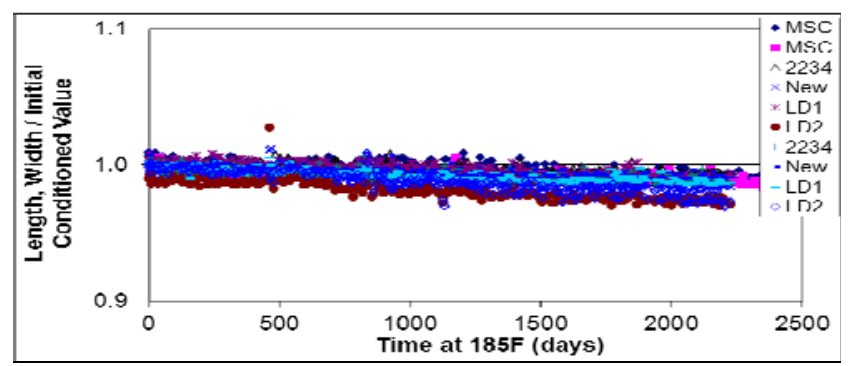

(c) $185^{\circ} \mathrm{F}$, dry

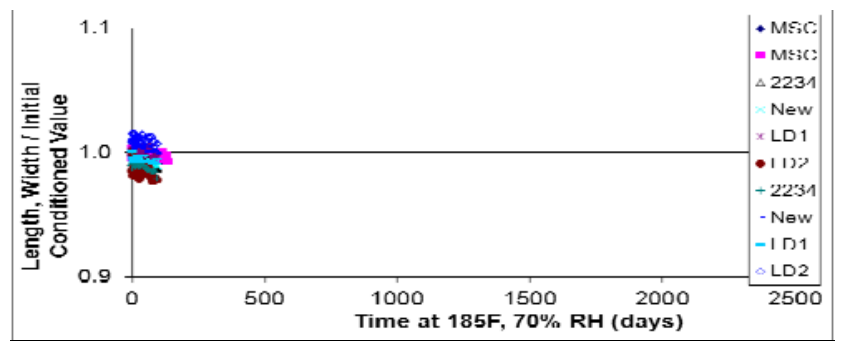

(e) $185^{\circ} \mathrm{F}, 70 \% \mathrm{RH}$

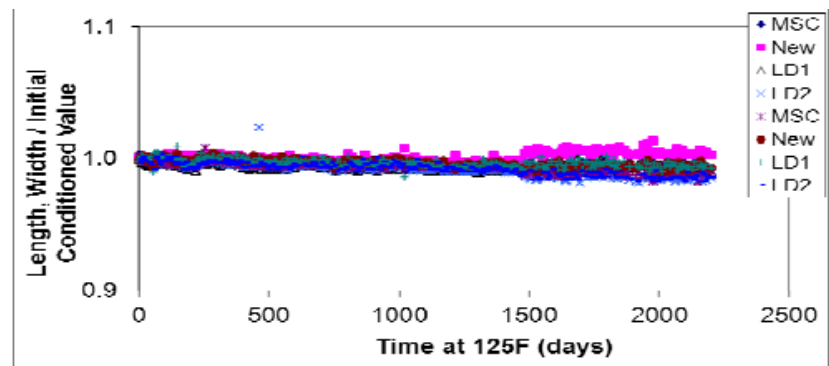

(g) $125^{\circ} \mathrm{F}$, dry

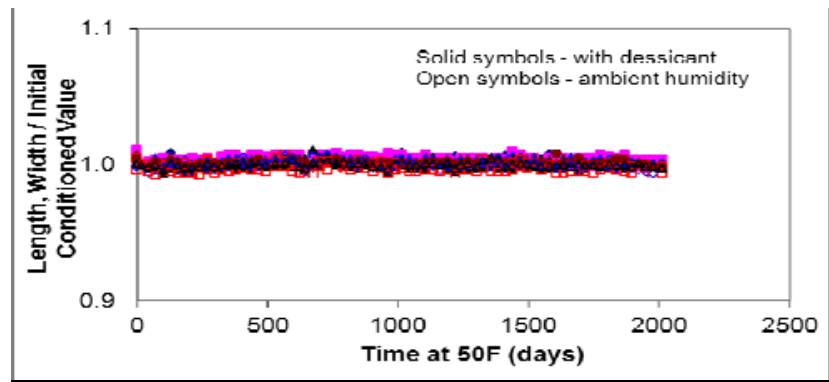

(i) $50^{\circ} \mathrm{F}$

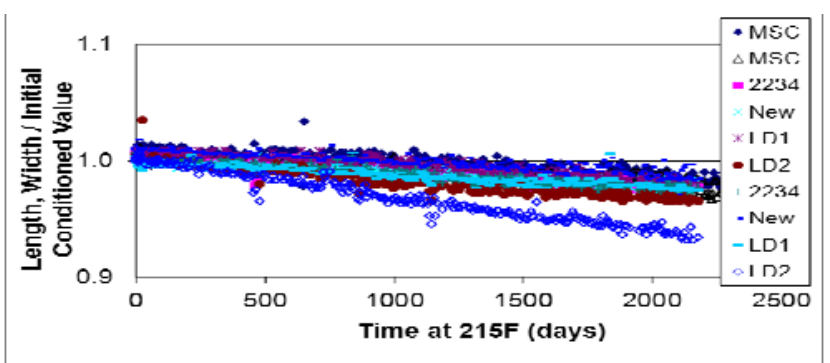

(b) $215^{\circ} \mathrm{F}$, dry

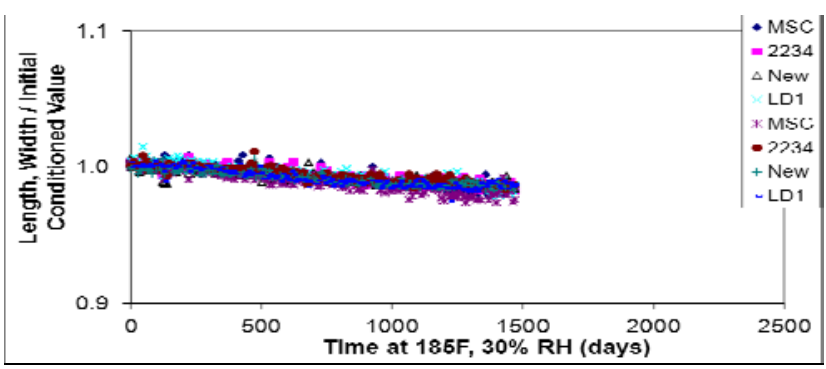

(e) $185^{\circ} \mathrm{F}, 30 \% \mathrm{RH}$

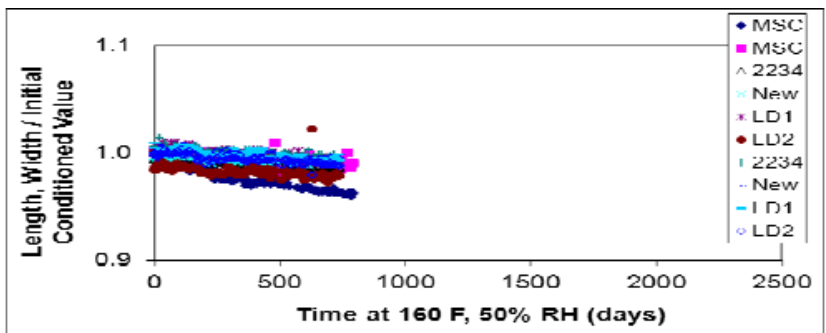

(f) $160{ }^{\circ} \mathrm{F}, 50 \% \mathrm{RH}$

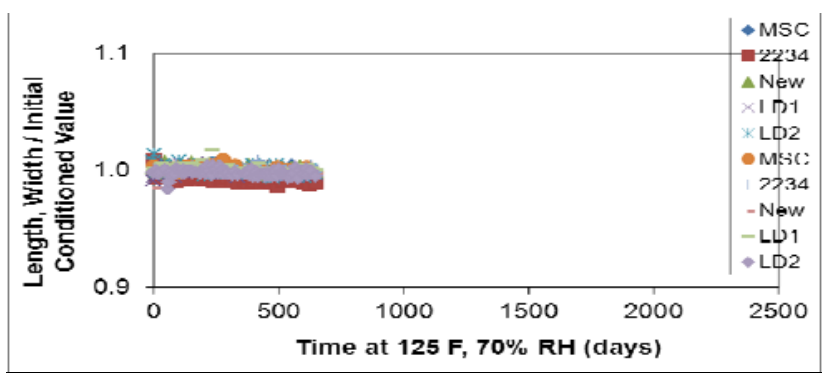

(h) $125^{\circ} \mathrm{F}, 70 \% \mathrm{RH}$

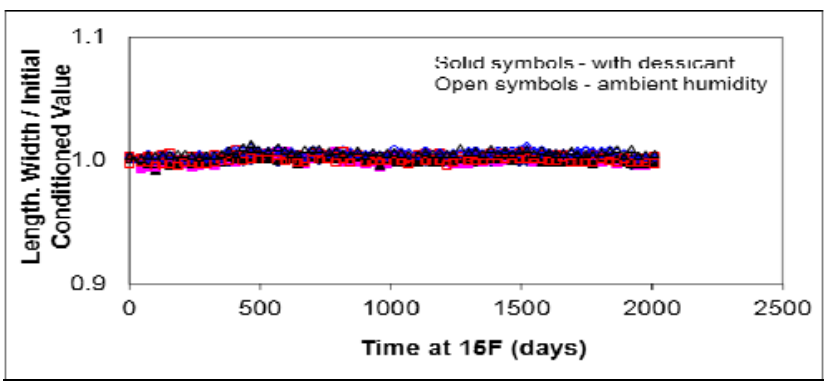

(j) $15^{\circ} \mathrm{F}$

Figure 12. Length \& width data for physical property samples in the identified environments 
Rev. 0

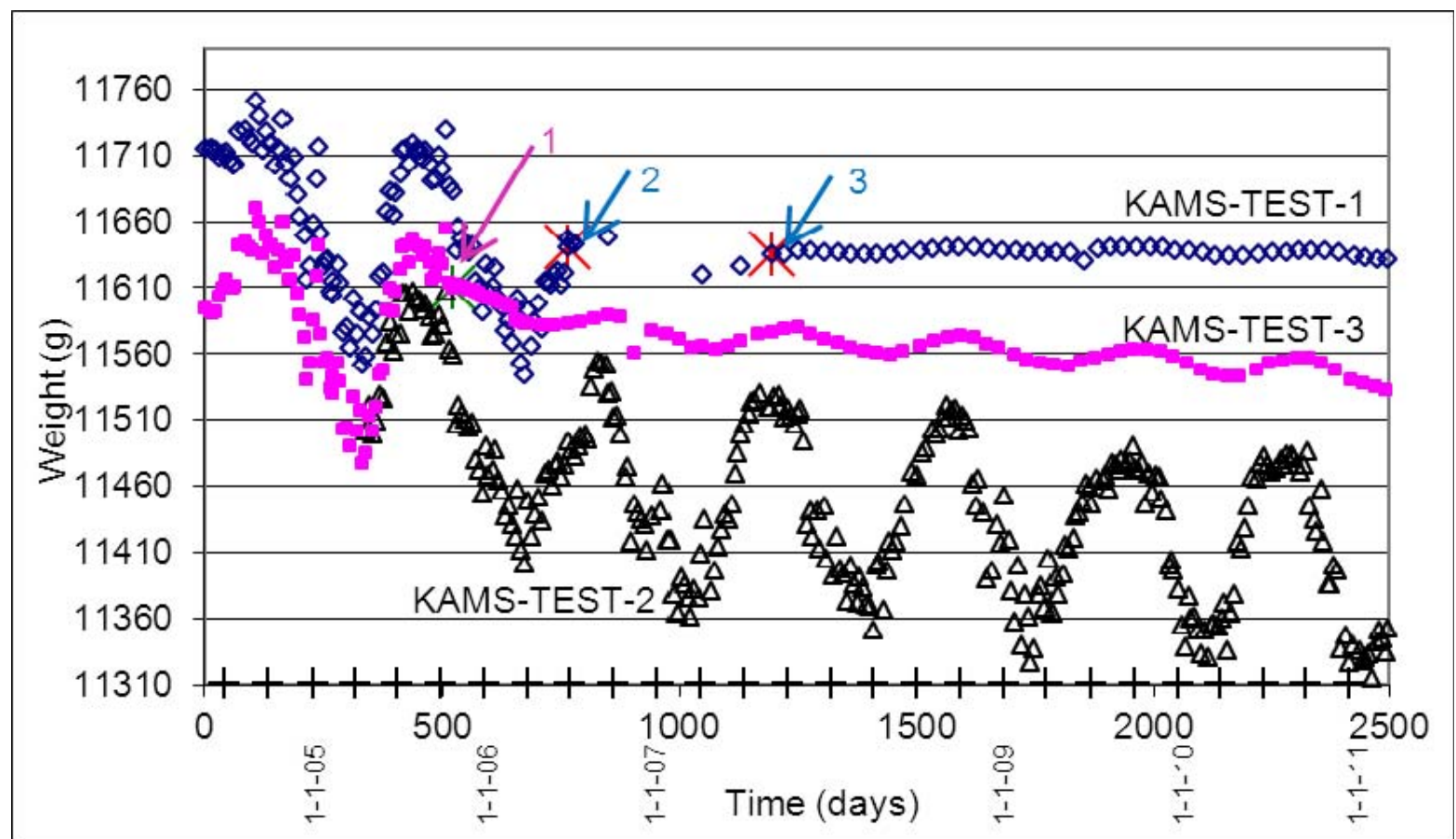

Figure 13. Seasonal weight variation of 3 upper fiberboard subassemblies. All 3 subassemblies were initially exposed to ambient conditions. At point (1), subassembly 3 was returned to its drum with the lid loosely in place. At point (2), subassembly 1 was returned to its drum with the lid loosely in place, and at point (3) the lid for subassembly 1 was bolted tight.

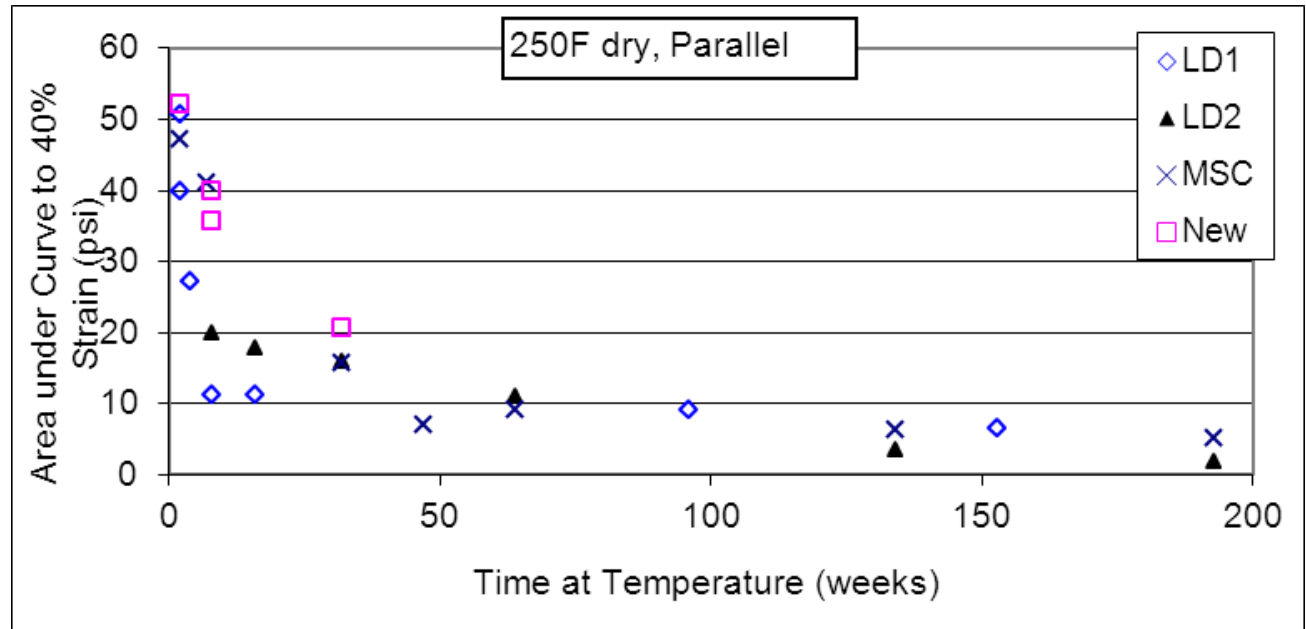

Figure 14. Compression test metric (area under the stress-strain curve up to $40 \%$ strain) for samples conditioned at $250{ }^{\circ} \mathrm{F}$ and tested in the parallel orientation. 
Rev. 0

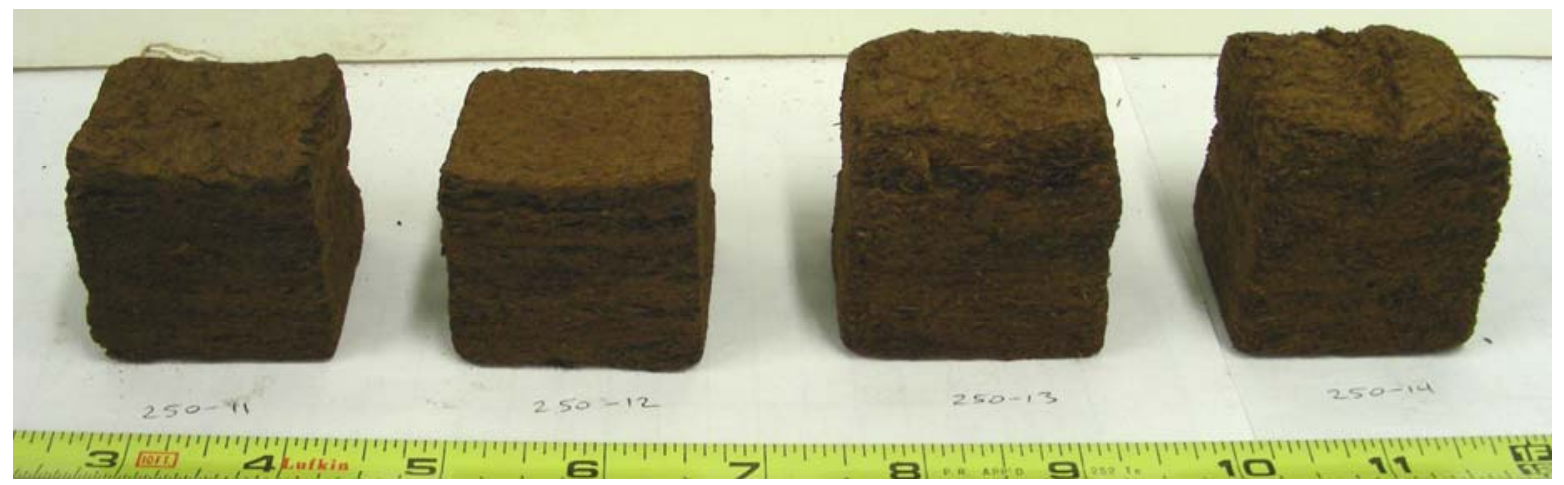

Figure 15. Typical physical property samples after removal from the $250{ }^{\circ} \mathrm{F}$ environment. These samples were conditioned for 225 weeks.

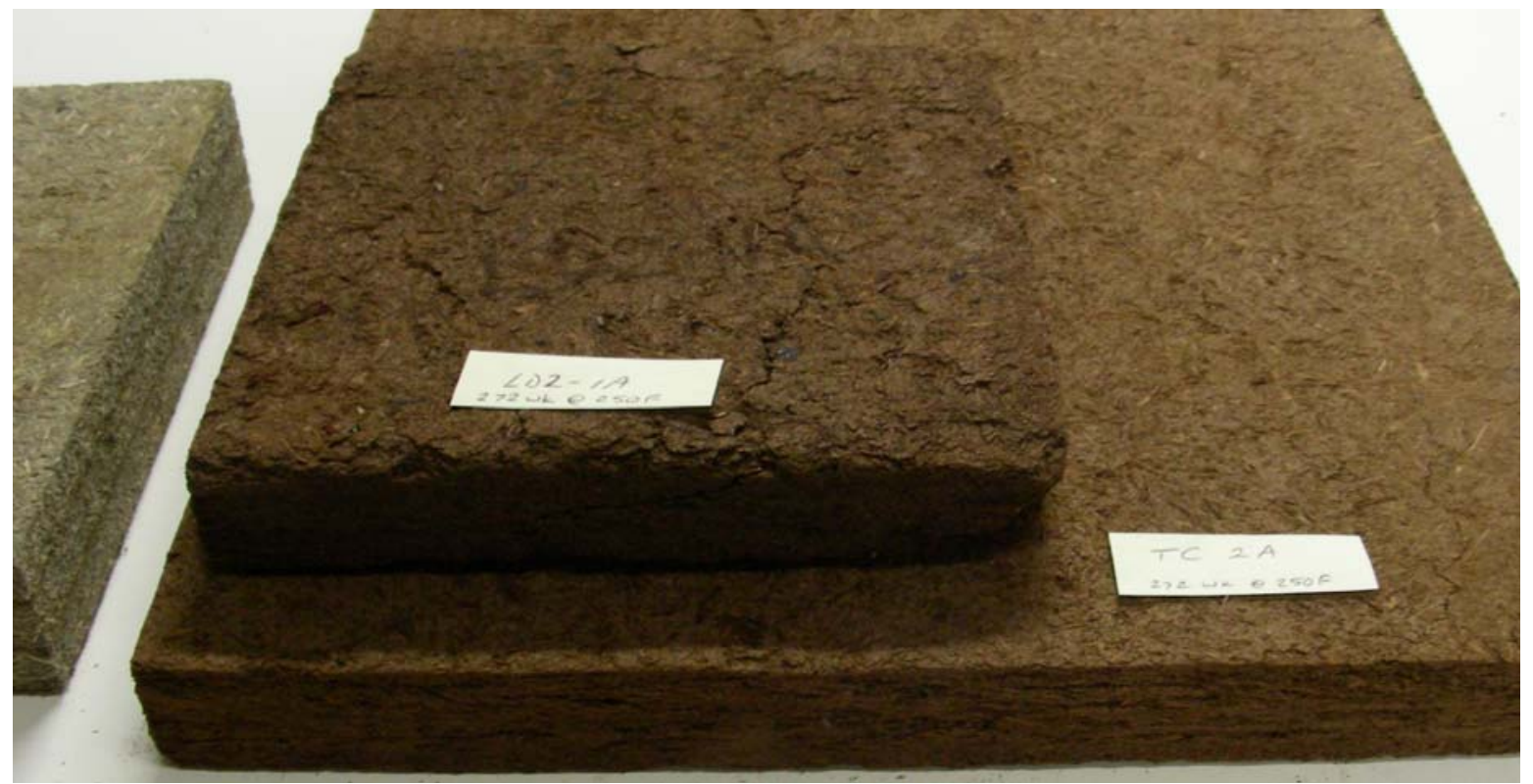

(a)
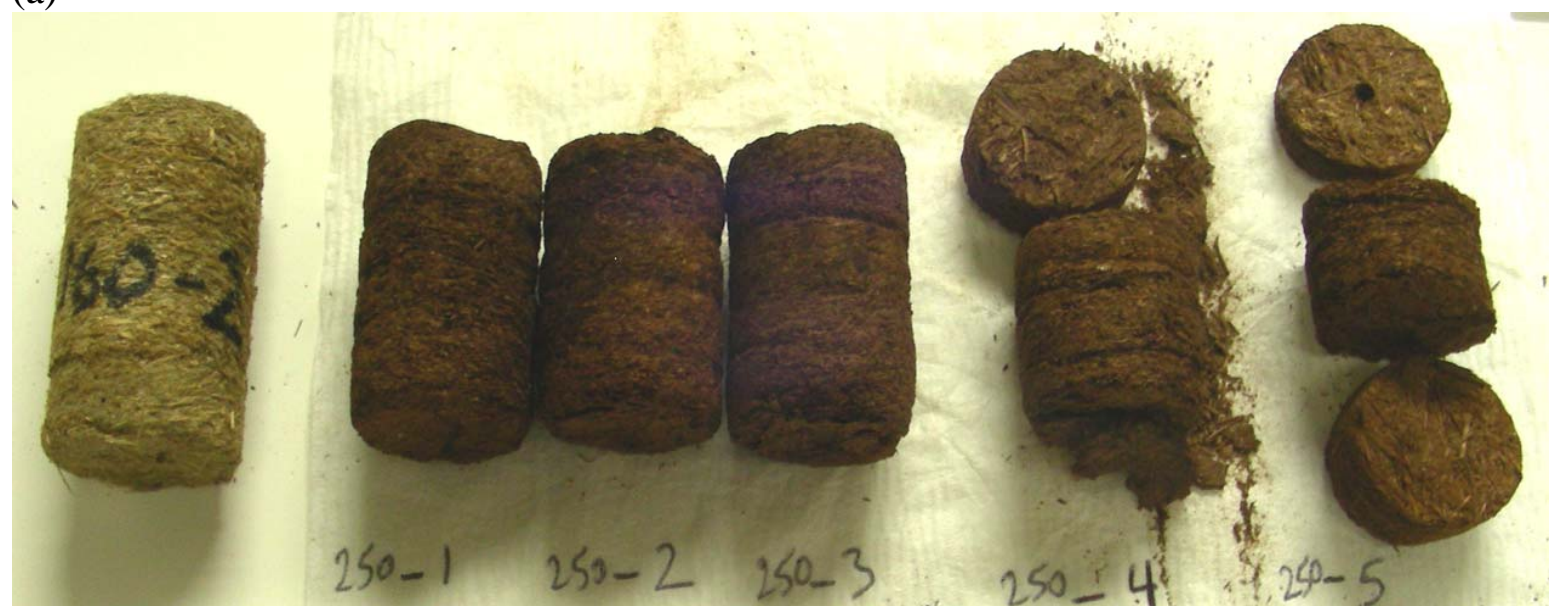

(b)

Figure 16. Typical thermal conductivity samples (a) and specific heat capacity samples (b) after conditioning at $250{ }^{\circ} \mathrm{F}$ for 272 weeks and 268 weeks, respectively. Each is shown with an undegraded sample (on left), for comparison. 
Rev. 0
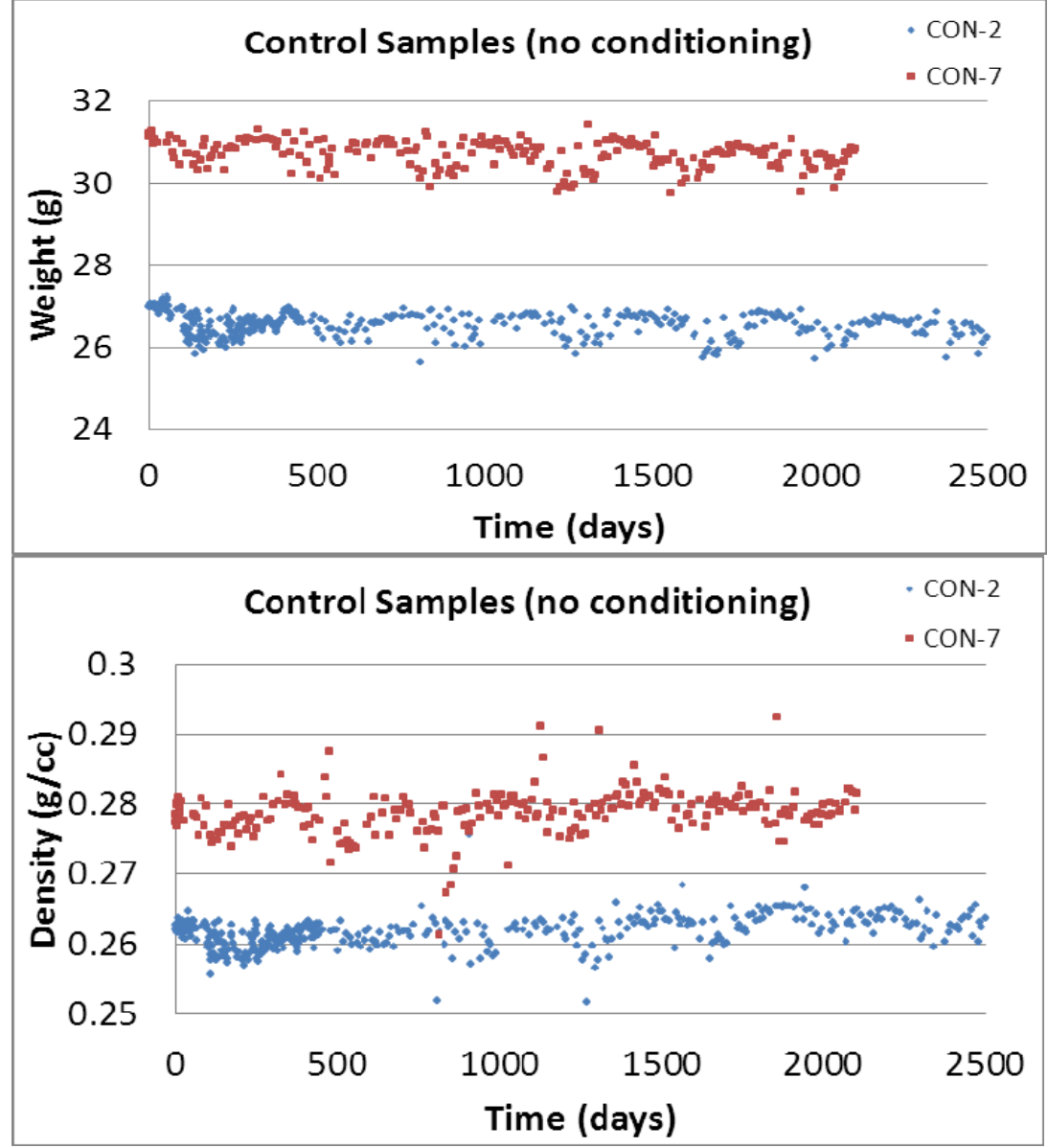

(a) Control sample weight data

Rate of weight change:

CON-2 -2.87 E-4 \%/day

CON-7 -5.63 E-4 \%/day

(a) Control sample density data

Rate of density change:

CON-2 +4.62 E-4 \%/day

CON-7 +5.03 E-4 \%/day

Figure 17. Weight and density data for physical property control samples.

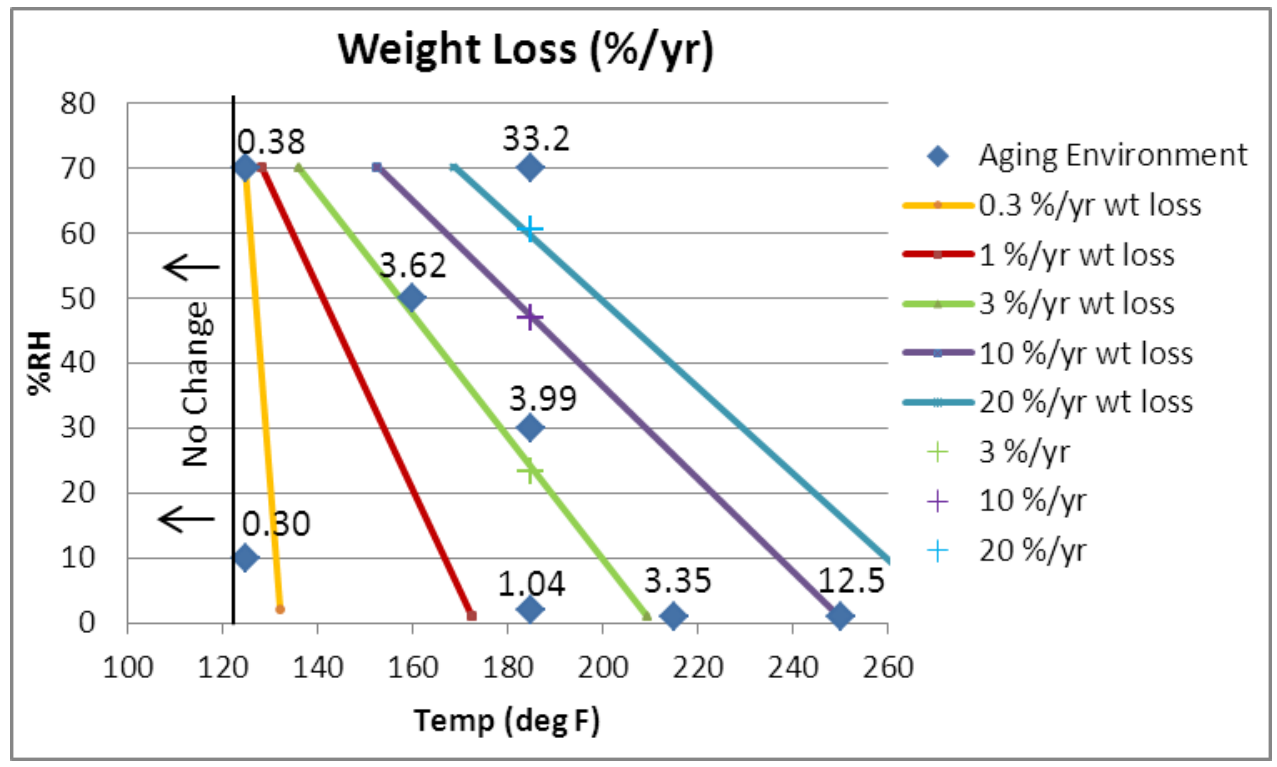

Figure 18. Fiberboard weight loss model. Lines represent contours of equal rate of weight loss. Numerical values are the average degradation rates of aged samples. 


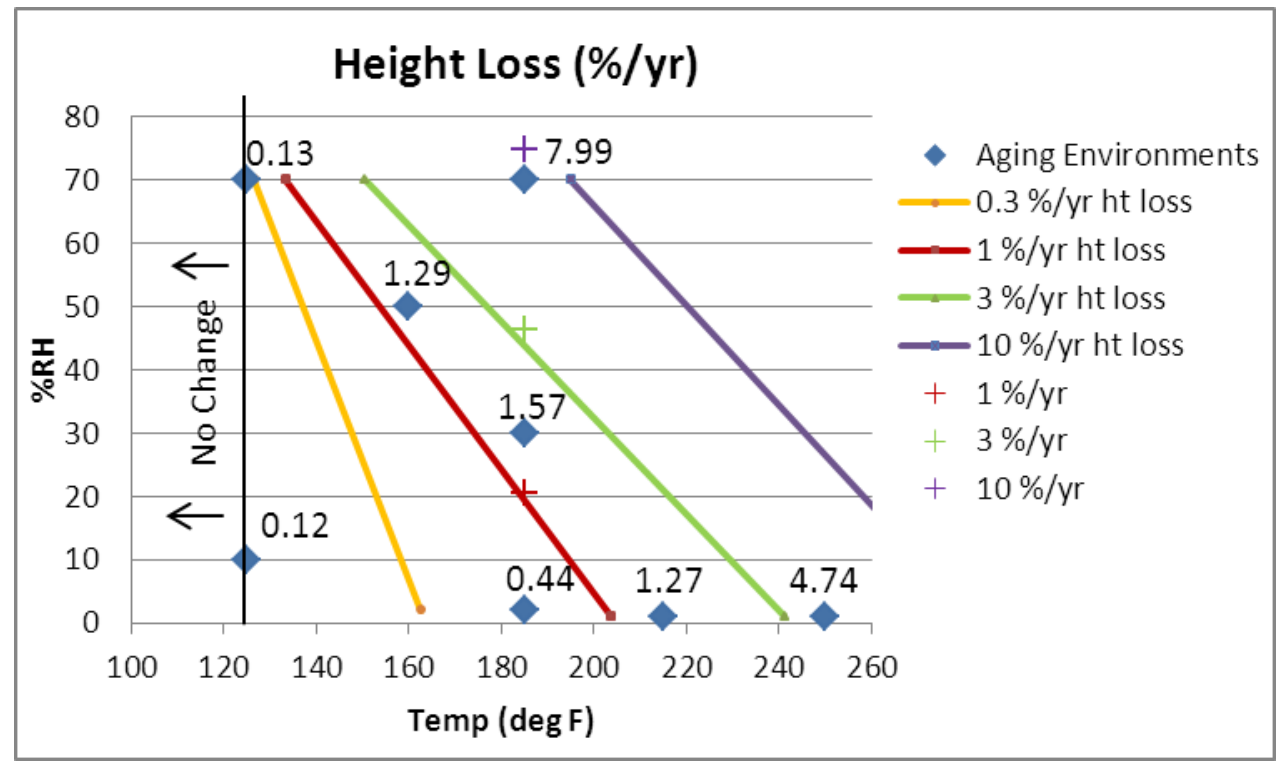

Figure 19. Fiberboard height loss model. Lines represent contours of equal rate of height decrease. Numerical values are the average degradation rates of aged samples.

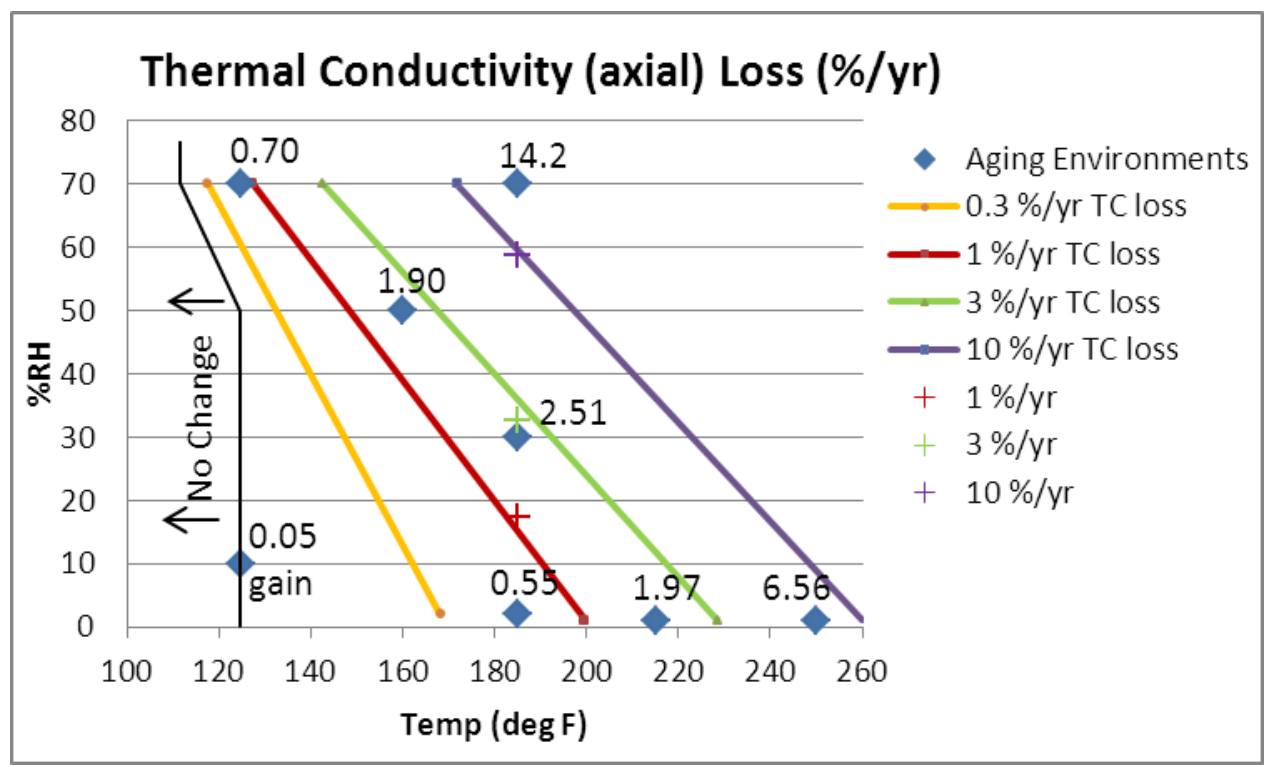

Figure 20. Fiberboard thermal conductivity, axial orientation model. Lines represent contours of equal rate of thermal conductivity decrease in the axial orientation. Numerical values are the average degradation rates of aged samples. The rate of thermal conductivity change was positive in the $125^{\circ} \mathrm{F}$ dry environment. This rate of change was not included in the modeling. 
Rev. 0

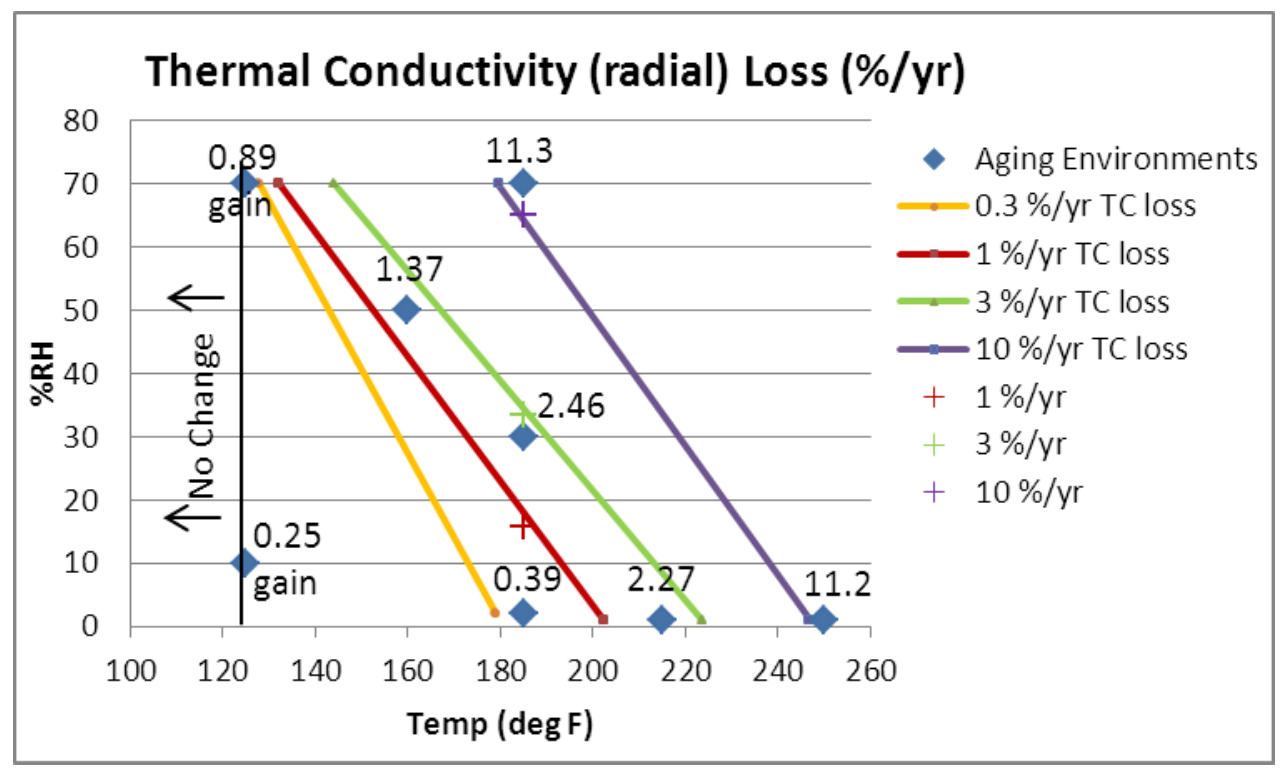

Figure 21. Fiberboard thermal conductivity, radial orientation model. Lines represent contours of equal rate of thermal conductivity decrease in the radial orientation. Numerical values are the average degradation rates of aged samples. The rate of thermal conductivity change was positive in both $125^{\circ} \mathrm{F}$ environments. To facilitate modeling, the $125{ }^{\circ} \mathrm{F}$ dry rate of change was not included, and the $125^{\circ} \mathrm{F} 70 \% \mathrm{RH}$ rate of change was adjusted to $-0.0001 \%$ year.

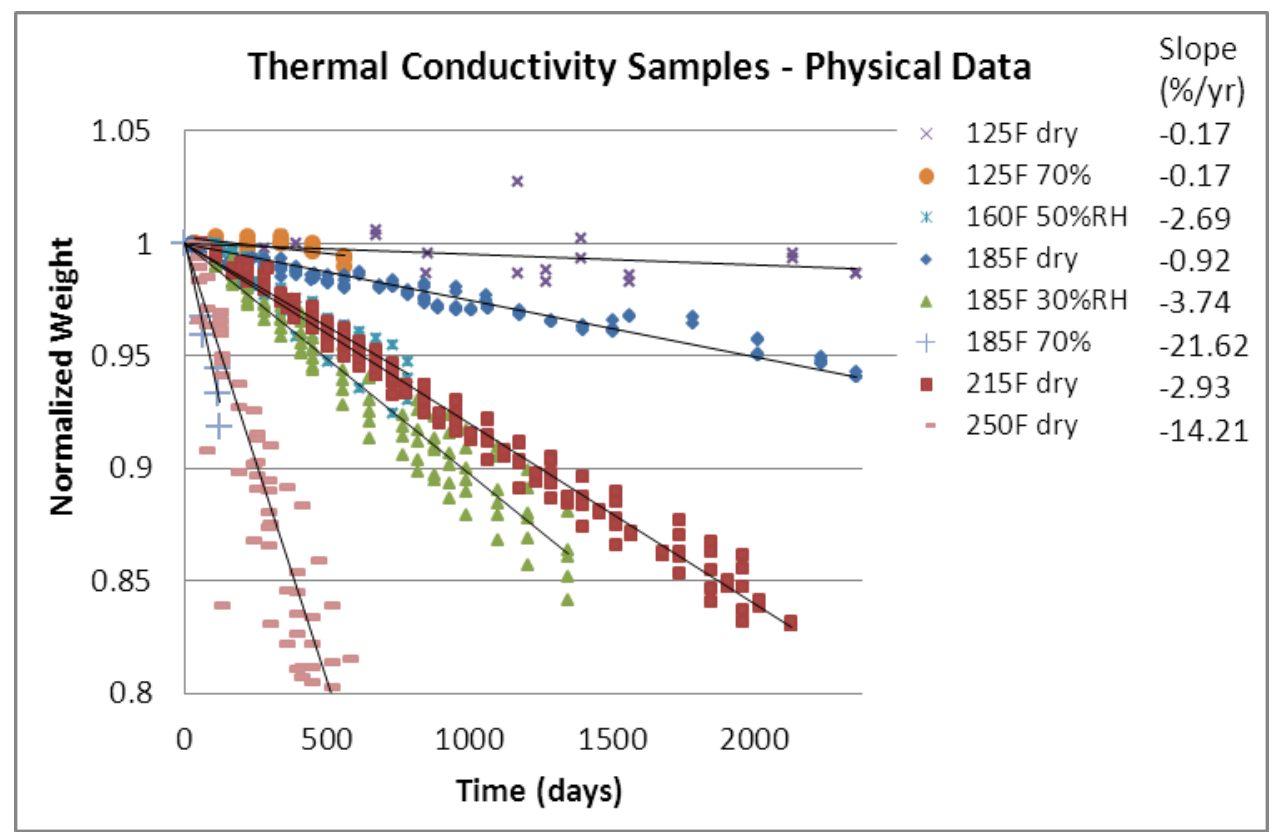

Figure 22. Physical data (weight change) trends from thermal conductivity samples 
Rev. 0

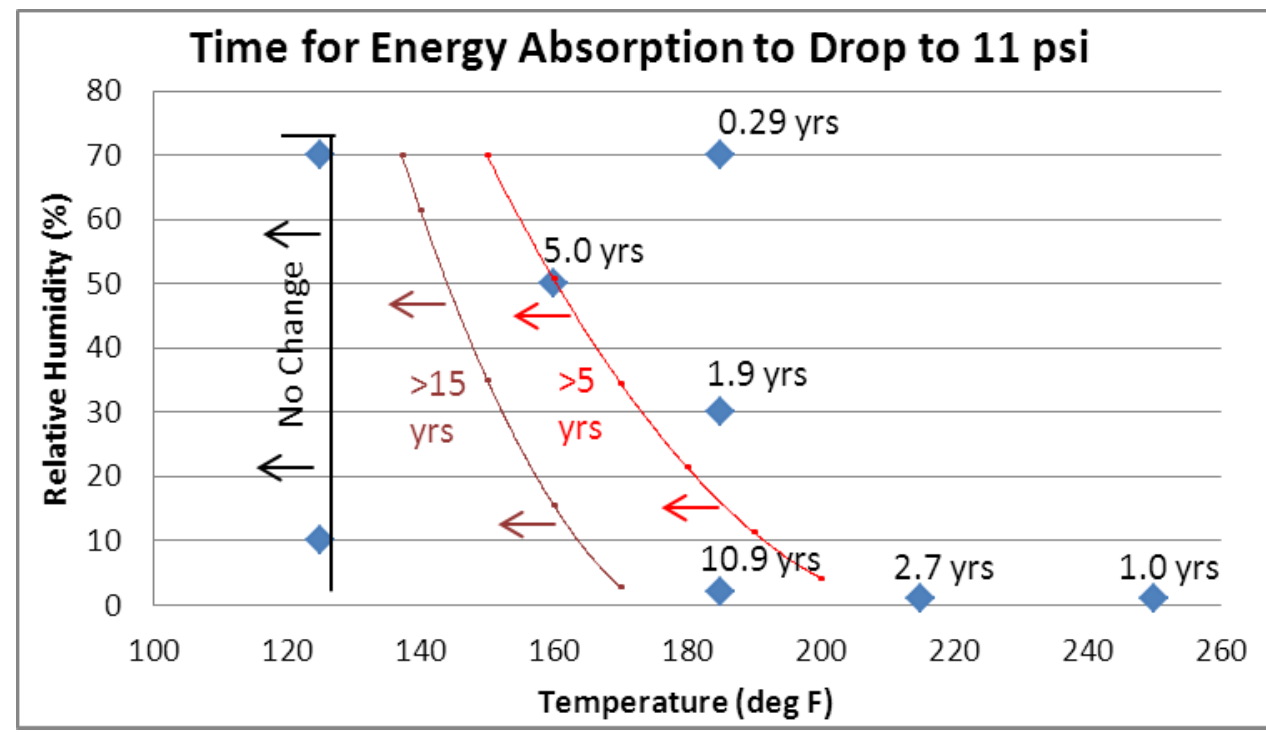

Figure 23. Model for energy absorption, based on compression test area under the stress-strain curve up to $40 \%$ strain. This graph shows contour lines describing environments for which energy absorption is predicted to drop to 11 psi over periods of 5 years and 15 years. 
Rev. 0

CC: J. S. Bellamy, 730-A

G. T. Chandler, 773-A

W. L. Daugherty, 773-A

K. A. Dunn, 773-41A

L. F. Gelder, 730-A

T. W. Griffin, 705-K

E. R. Hackney, 705-K

D. R. Leduc, 730-A

J. W. McEvoy, 707-C

D. L. Melvin, 705-K

T. E. Skidmore, 730-A

K. E. Zeigler, 773-41A

Document Control 